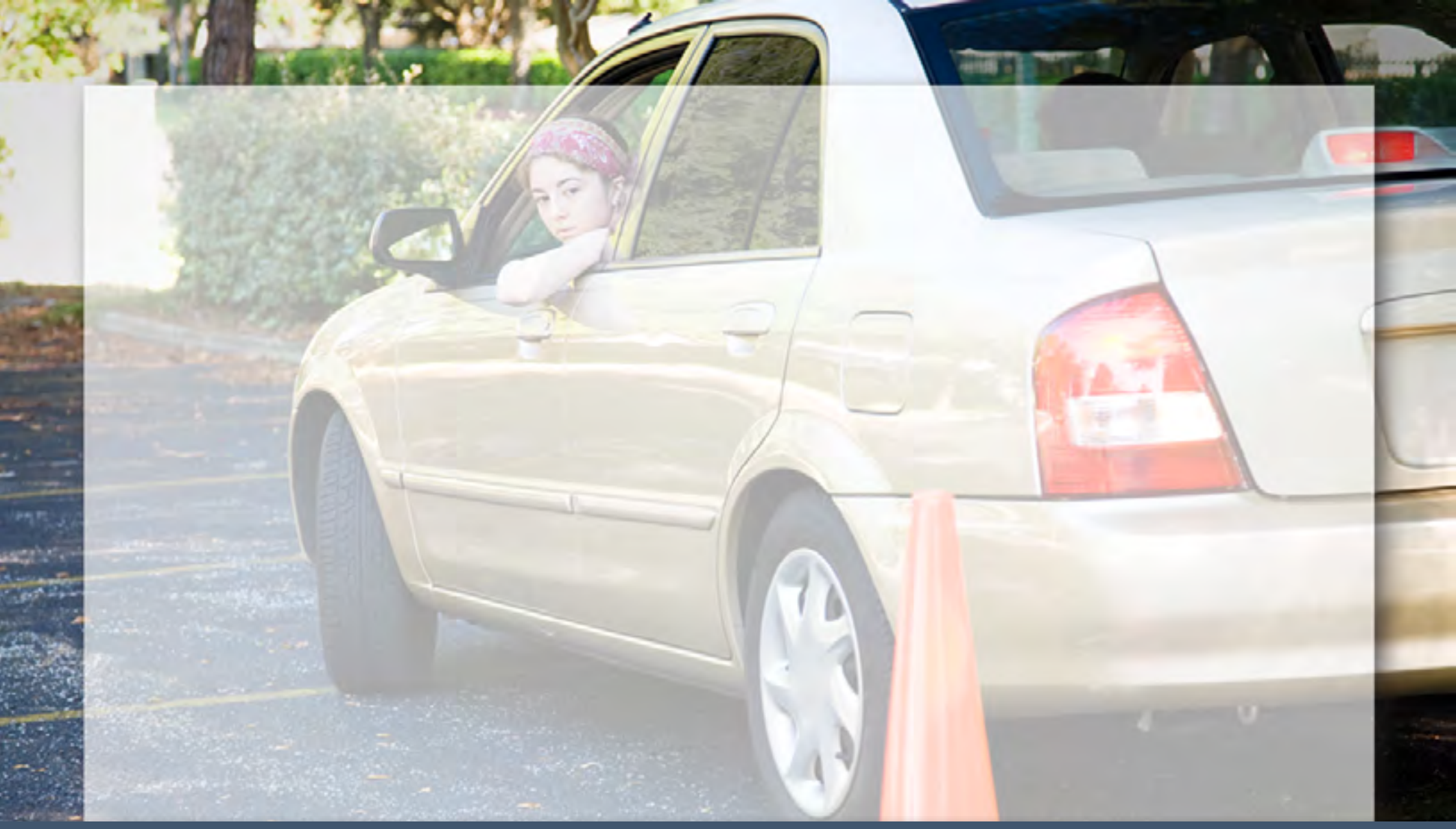

\title{
A Fresh Look at Driver Education in America
}

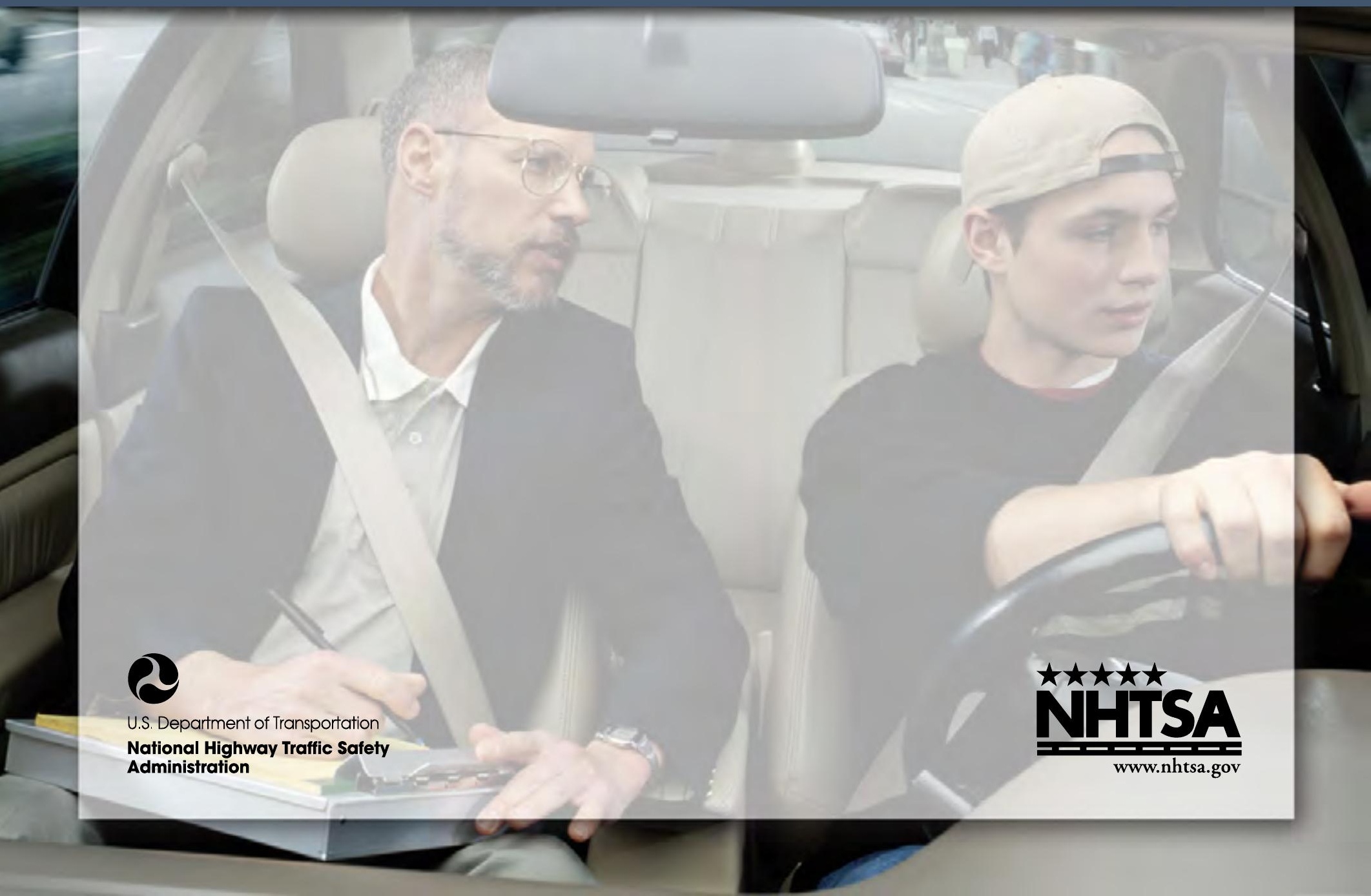


This publication is distributed by the U.S. Department of Transportation, National Highway Traffic Safety Administration, in the interest of information exchange. The opinions, findings, and conclusions expressed in this publication are those of the authors and not necessarily those of the Department of Transportation or the National Highway Traffic Safety Administration. The United States Government assumes no liability for its contents or use thereof. If trade or manufacturers' names or products are mentioned, it is because they are considered essential to the object of the publication and should not be construed as an endorsement. The United States Government does not endorse products or manufacturers.

APA Reference Format:

Thomas, F. D., III, Blomberg, R. D., \& Donald L. Fisher, D. L. (2012, April). A Fresh Look at Driver Education in America. (Report No. DOT HS 811 543). Washington, DC: National Highway Traffic Safety Administration. 


\section{Technical Report Documentation Page}

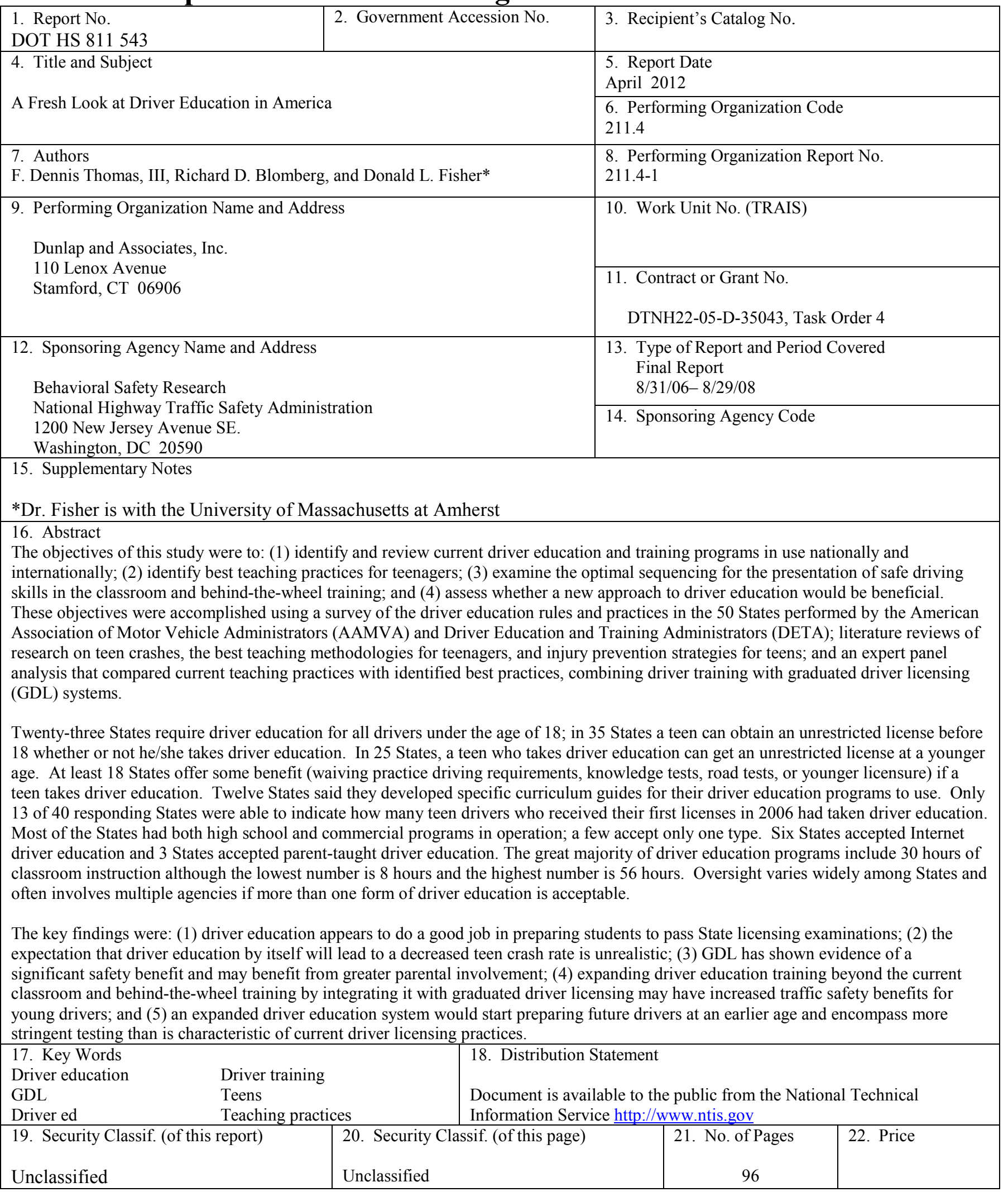

Form DOT F 1700.7 (8-72) 


\section{ACKNOWLEDGEMENTS}

The authors are grateful to the expert panel members identified in the body of the report for their time, effort, and insightful comments on the optimal sequencing of driver education and the merits of developing a new driver education curriculum.

The efforts of the American Association of Motor Vehicle Administrators (AAMVA) and Driver Education and Training Administrators (DETA) to distribute surveys and collect data were critical to determining the state of driver education in the United States. The authors also thank all of the State personnel who provided information to the project.

Although this study could not have been accomplished without the assistance of these individuals, the findings and conclusions cited here are those of the authors and are not intended to represent the positions of any of the cooperating agencies or individuals. 


\section{TABLE OF CONTENTS}

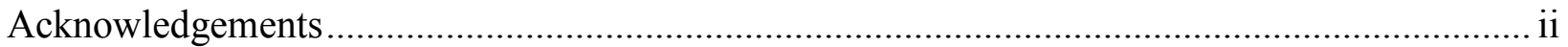

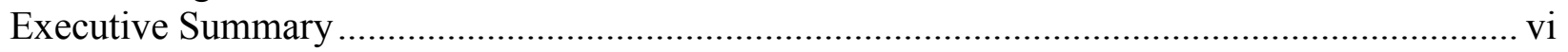

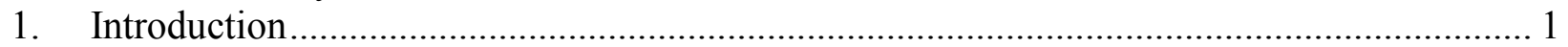

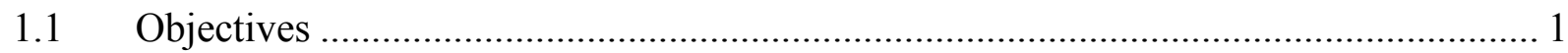

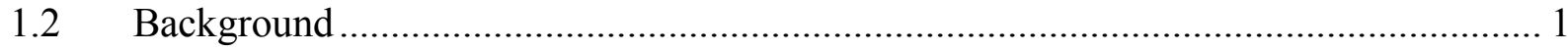

1.2.1 Education of the Novice Driver ....................................................................... 2

1.2.2 Reviews of Driver Education and Graduated Driver Licensing Programs ................. 2

1.2.3 Areas for Improvement of Driver Education ....................................................... 3

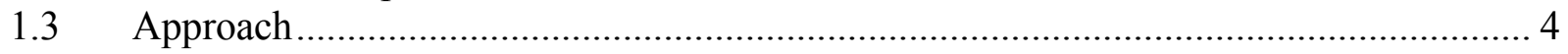

1.3.1 Collection of State Driver Education Data ........................................................... 4

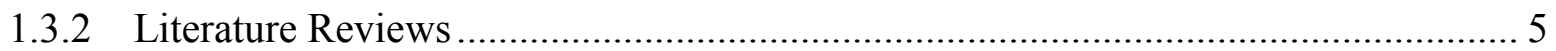

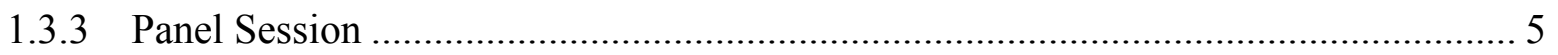

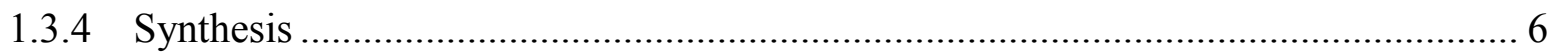

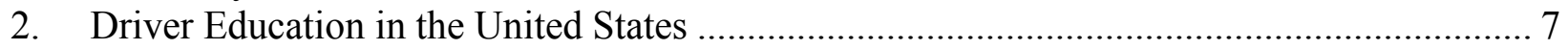

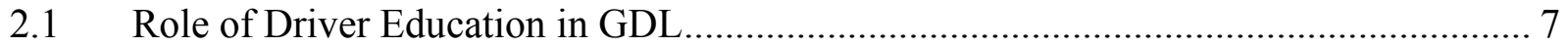

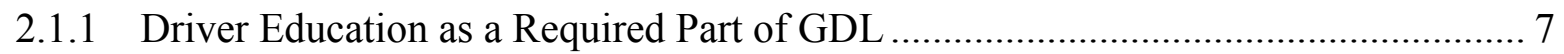

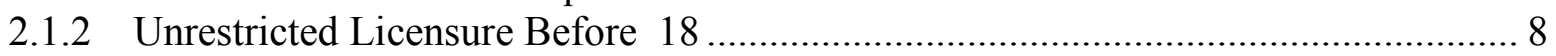

2.1.3 Other Benefit States Offer for Driver Education .................................................. 8

2.2 Driver Education Program Requirements and Operational Data..................................... 8

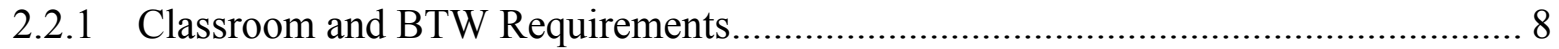

2.2.2 Required Use of Specific Curricula ...................................................................... 8

2.2.3 Oversight of Driver Education Programs ……....................................................... 9

2.2.4 Certification of Driver Education Instructors ....................................................... 9

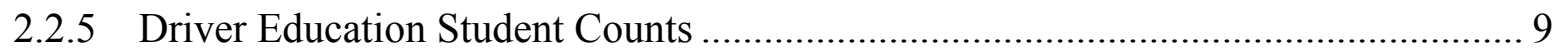

2.2.6 Number and Type of Driver Education Programs in Operation ................................ 9

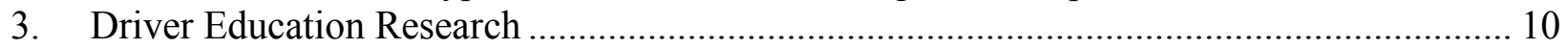

$3.1 \quad$ History of Driver Education..................................................................................... 10

3.2 Causes of Crashes Involving Newly licensed Drivers ............................................... 11

3.2.1 Scanning: Hazard Anticipation .......................................................................... 11

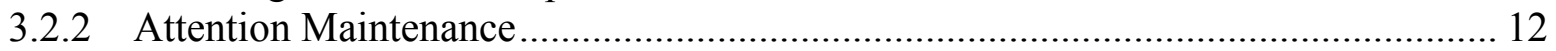

3.2.3 Vehicle Management: Hazard Anticipation...................................................... 12

3.2.4 Current Driver Education and Cognitive Skills Training ........................................ 12

3.3 New Driver Education/Training Programs ………............................................... 12

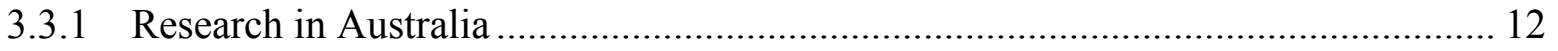

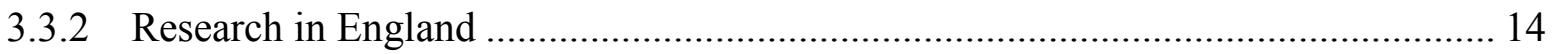

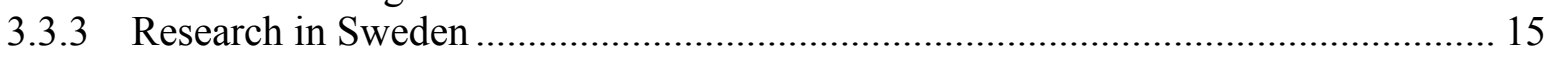

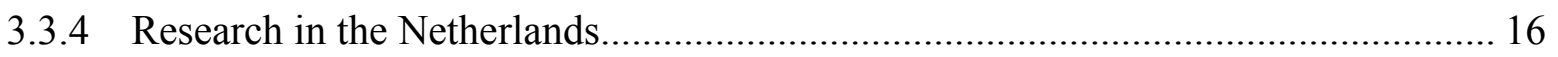

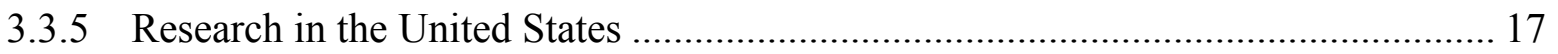

3.4 Summary of Driver Education/Training Research .................................................... 19

4. Driver Education's Use of Best Teaching Practices from General Education ....................... 21

4.1 Recommendation 1: Space Learning Over Time .................................................... 23

4.2 Recommendation 2: Interleave Worked Example Solutions and Problem-Solving Exercises ....................................................................................... 24

4.3 Recommendation 3: Combine Graphics with Verbal Descriptions ............................... 25 
4.4 Recommendation 4: Connect and Integrate Abstract and Concrete

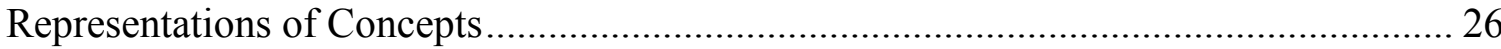

4.5 Recommendation 5: Use Quizzing to Promote Learning ......................................... 27

4.5.1 Recommendation 5a: Use Pre-questions to Introduce a New Topic ...................... 27

4.5.2 Recommendation 5b: Use Quizzes to Re-expose Students to Information ............. 28

4.6 Recommendation 6: Help Students Allocate Study Time Efficiently ........................ 28

4.6.1 Recommendation 6a: Teach Students How to Use Delayed Judgment of Learning Techniques to Identify Concepts that Need Further Study .................. 29

4.6.2 Recommendation 6b: Use Tests and Quizzes to Identify Content that

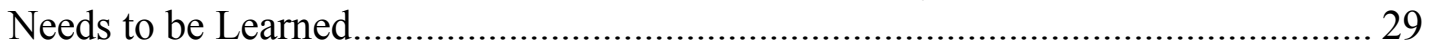

4.7 Recommendation 7: Help Students Build Explanations by Asking and

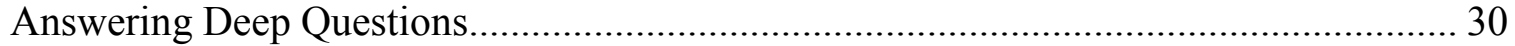

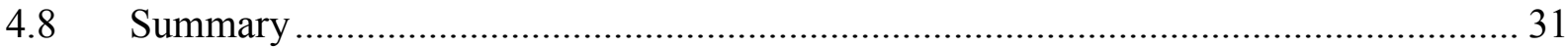

5. Injury Prevention Strategies for Teens: Health Domains .............................................. 32

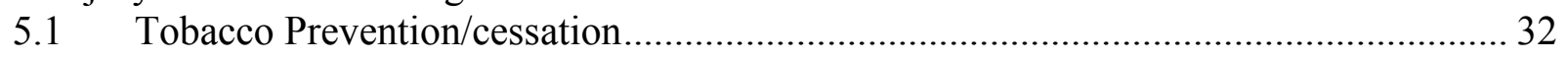

5.1.1 Community-based Programs......................................................................... 32

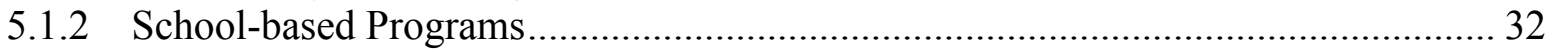

5.1.3 Healthcare Provider-based Programs................................................................. 34

5.1.4 Implications of Research on Tobacco Intervention Programs for Driver Education 34

$5.2 \quad$ Drugs and Alcohol Prevention/Cessation .......................................................... 34

5.2.1 Drug and Alcohol Intervention Research ...................................................... 35

5.2.2 Implications of Research on Drugs/Alcohol Intervention Programs for Driver

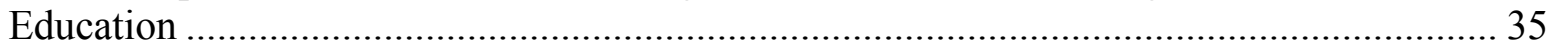

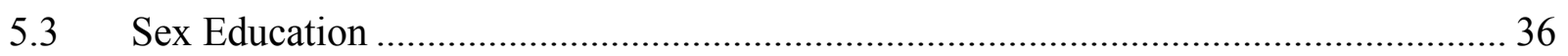

5.3.1 Sex Education Research............................................................................... 36

5.3.2 Implications of Research on Sex Education Programs for Driver Education........... 38

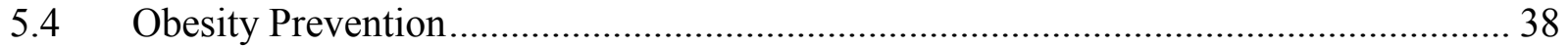

5.4.1 Obesity Prevention Research .................................................................... 38

5.4.2 Implications of Research on Obesity Prevention Programs for Driver Education ... 39

5.5 Summary of Implications of Prevention Strategies in

Other Teen Health Interventions for Driver Education ........................................... 40

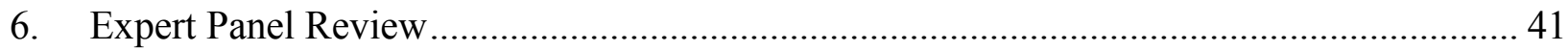

6.1 Panel Composition ........................................................................................... 41

6.2 Panel Procedures .......................................................................................... 42

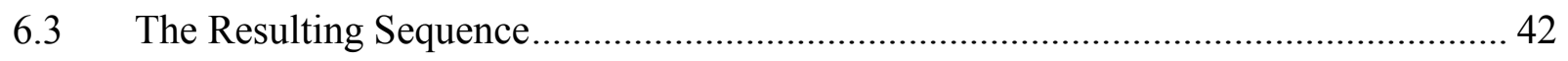

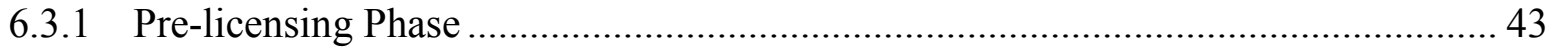

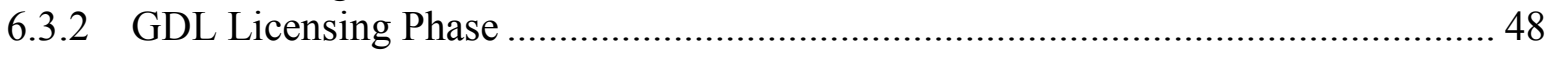

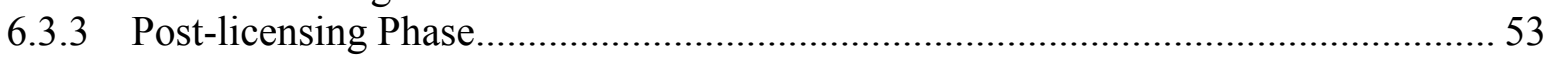

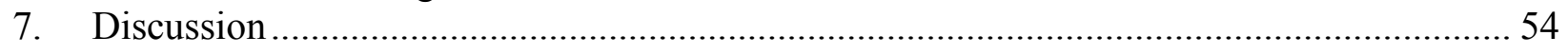

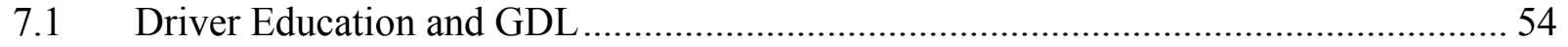

7.2 Is There a Need for a New Approach to Driver Education?...................................... 54

7.3 A Starting Point for an Optimal Sequencing for Driver Training ............................. 55

7.4 A Possible Expanded Driver Education System .................................................. 55

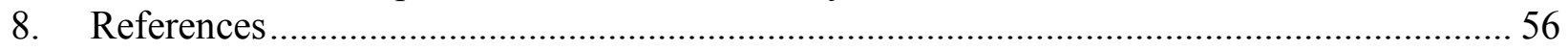

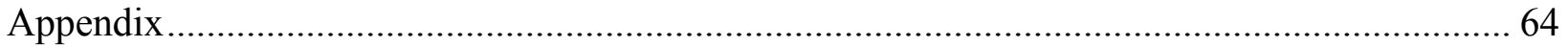




\section{LIST OF TABLES}

Table 1. Primary Education Stage: Component Readiness............................................. 45

Table 2. Preparatory Education Stage: Component Readiness ......................................... 48

Table 3. Learner's Permit Stage: Component Readiness.............................................. 51

Table 4. Restricted License Stage: Component Readiness ............................................ 52

\section{LIST OF FIGURES}

Figure 1. Institute of Education Sciences Levels of Evidence ........................................... 22

Figure 2. One Approach for Developing a Sequence for a Driver Education System

Encompassing Driver Education and GDL................................................................. 44

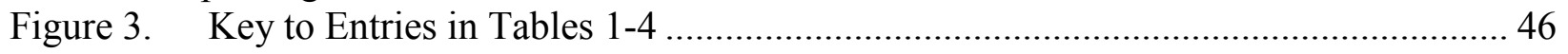




\section{EXECUTIVE SUMMARY}

\section{BACKGROUND AND OBJECTIVES}

The high rate of driver fatalities among 15- to 18-year-olds has raised the question of whether modifying current driver education practices could lead to safer novice drivers. In order to investigate this possibility, the objectives of this project were to:

- Identify and review current driver education and training programs in use nationally;

- Review the literature related to best teaching methodologies for teenagers;

- Compare current driver education teaching practices with identified best practices;

- Examine the optimal sequencing for the presentation of safe driving skills in the classroom and behind-the-wheel training; and

- Based on outcomes from previous tasks, assess whether a new approach to driver education would be beneficial.

\section{APPROACH}

The study approach consisted of the following main components:

- Collect State Driver Education Data. The following data sources were used to determine what current driver education programs across the nation were doing and how the driver education activities were integrated with graduated driver licensing (GDL) systems in each State:

- A survey conducted by the AAMVA of its members in each State;

- A survey conducted by DETA of its members and additional contacts in selected States;

- Contacts with State licensing officials to clarify their responses to the surveys; and

- State Web sites, driver manuals, and other licensing-related material.

- Literature Reviews. A series of literature reviews was conducted. One review examined research into the efficacy of driver education and driver training for teen drivers. This literature search included an update of Nichols' (2003) review of driver education, a closer look at the causes of teen driver crashes identified by research, and an examination of alternative driver education and training approaches that have been studied around the world. A second review identified best teaching practices for teens as described in the general education literature. A third literature review examined injury prevention strategies for teens in domains other than driving such as smoking, unsafe sex, or obesity.

- Panel session. The final data gathering step was a panel session in which experts from a variety of relevant domains including driver education, traffic safety research, general education, and injury prevention were brought together to discuss the information gathered in the first two tasks and to consider whether or not a new model of driver education integrated with GDL was warranted. The discussion was guided by a 
hypothetical sequencing of education, training, testing, and certification within GDL prepared by the project staff.

- Synthesis. All of the information obtained from the review of driver education in the United States, the literature reviews and the panel session were synthesized.

\section{CURRENT STATE OF DRIVER EDUCATION}

Representatives from 40 of the 51 jurisdictions (50 States and Washington, DC) responded to the AAMVA and/or DETA surveys. The depth of information provided in these responses varied across States, with some States providing very detailed information and others providing only minimal answers. Information was supplemented as required through calls with the contact listed on the survey and a review of State driver licensing Web sites and State driver manuals.

With respect to the key research questions of this study, it was determined that:

- A program would be categorized as "driver education" if the State termed the program driver education and if the program included at least 8 hours of classroom instruction and some behind-the-wheel (BTW) training with a licensed instructor.

- At the time of this survey, 23 States required driver education for all drivers under 18. An additional 6 States required some sort of short pre-licensing course or drug and alcohol awareness course for all drivers under 18.

- At the time of this survey, teens in 35 States could obtain an unrestricted license before 18 whether or not he/she took driver education. In 25 States, a teen who took driver education could get an unrestricted license at a younger age than someone who did not take driver education.

- At the time of this survey, at least 18 States offered some benefit (e.g., waiving practice driving requirements, knowledge or road tests; younger licensure) if teens took driver education.

- The great majority of driver education programs required by the States included 30 hours of classroom instruction, although the lowest number of required hours was 8 and the highest number mandated was 56. Most programs included 6 hours of BTW training, but some States required none while 1 required 20 hours BTW.

- At the time of this survey, 12 States indicated they developed specific curriculum guides for their driver education programs to use. The programs in most of these States, however, were not required to use the guides. A number of other States had core topics that had to be covered or some other standards, but no requirements as to how the topics should be covered or how the standards should be implemented. 
- Oversight varied widely among the States and often involved multiple agencies if multiple forms of driver education were acceptable. The State Department of Education oversaw high school driver education in most States.

- All but 1 of the States responding to the survey indicated that instructors had to be certified to teach driver education.

- Only 13 of the 40 responding States were able to provide any data in response to the question that asked how many teen drivers who received their first licenses in 2006 had taken driver education. Among these 13, only a few could provide exact data on the number of teens licensed who took each of the various types of driver education offered in their States.

- Most States had both high school and commercial programs in operation. A few States accept only commercial or high school driver education programs. Six States accepted Internet driver education at the time of the surveys. Three States explicitly stated that parent-taught driver education was accepted in addition to high school and commercial driver education.

\section{DRIVER EDUCATION RESEARCH}

If some of the goals of driver education programs are to provide the skills, knowledge, and attitudes necessary for safe driving, then one measure of success would be increased safety benefits for drivers who had been exposed to driver education programs. In 1976 a large-scale, controlled evaluation of driver education was undertaken in a suburb of Atlanta, Georgia. The results were somewhat disappointing, both in the short and long term, as no major crash reductions were found for the teens who had participated in the driver education programs (Stock, Weaver, Ray, Brink \& Sadof, 1983; Smith 1987). Twenty years later, Mayhew and Simpson (1996) reviewed 30 studies from several countries that evaluated the effect of driver education programs on teen driver crashes. There was very little support for the claim that formal driver education decreased crash involvement.

More recently, a number of literature reviews of the effectiveness of standard driver education programs have been conducted. The reviews cover Australia (Wooley, 2000), Great Britain (Roberts \& Kwan, 2002), Canada (Mayhew \& Simpson, 2002), Sweden (Engstrom, Gregersen, Hernetkoski, Keskinen \& Nyberg, 2003) and the United States (Vernick, Li, Ogaitis, MacKenzie, Baker \& Gielen, 1999; Nichols, 2003), and most recently a comprehensive, international review sponsored by the AAA Foundation for Traffic Safety (Clinton \& Lonero, 2006). These reviews were uniform in concluding that in the great majority of experimental evaluations of standard driver education programs, no reduction in the crash rates among newly licensed drivers was observed. This is not surprising given that the primary content and focus of most current driver education programs is on training drivers to pass the licensing exams.

Driver education does result in a high rate of passing the licensing exams and may provide other increased safety benefits (e.g., increased belt use or reduced speeding behaviors), and therefore may be a success against those objectives. 
A number of "new" driver education programs have been developed around the world to train some of the safety-critical skills identified as causal in novice driver crashes. Studies into the efficacy of these programs have shown them to be effective at improving performance in the simulator and on the road, but no large-scale assessment of these techniques using crashes as an outcome measure has been conducted. It is also unknown how long the training effects will last. Most of these newer programs do not address basic driving skills, something that traditional driver education appears to do quite well. The integration of these new programs into current driver education and GDL would appear to hold some promise. However, costs and the time needed for teens to complete the programs are barriers for some young drivers.

\section{BEST TEACHING PRACTICES FROM GENERAL EDUCATION}

An additional focus of the present study was to determine the extent to which current driver education programs are implementing best teaching practices as identified in the general education literature. The general education literature is massive, and research studies are oftenspecific to one educational topic such as reading, math, or science making it difficult to translate findings to other domains. The United States Department of Education published a practice guide titled Organizing Instruction and Study to Improve Student Learning (Pashler et al., 2007) that assembled the best practices from all areas of education. This guide provides seven recommendations that have relevance for driver education:

- Space learning over time. Classroom and laboratory research overwhelmingly support the tenet that students remember more information when they have been exposed to the information on at least two occasions.

- Interleave worked example solutions and problem-solving exercises. A worked example solution involves showing students a step-by-step example of how to solve a problem. After reviewing the worked example solution, the students are then given a similar problem to solve on their own.

- Combine graphics with verbal descriptions, which enhances learning.

- Connect and integrate abstract and concrete representations of concepts. Connecting different forms of representations helps a student master a concept and improves the likelihood that the concept will be used in a variety of contexts.

- Use quizzing to promote learning. Taking quizzes and tests promotes learning and reduces the rate of forgetting. This recommendation is actually composed of two subrecommendations. One part includes using pre-questions to activate prior knowledge and focus student attention on new material to be presented, while the second part uses quizzes to re-expose students to key content already covered.

- Help students allocate study time efficiently. Teachers should help students accurately assess what they know and do not know in order to promote efficient and effective study habits. This can help students break the "illusion of knowing" that can lead to students inaccurately assessing their knowledge. 
- Help students build explanations by asking and answering "deep" questions that require explanations that appeal to causal mechanisms, planning, well-reasoned arguments, and logic. The research evidence supporting this recommendation is very strong, with students at all grade levels benefiting from the use of deep questions.

The best practices from the general education literature, as identified by Pashler et al. (2007), suggested that the current driver training system as a whole (driver education and GDL combined), may not be operating at the most effective level with respect to a goal of teaching teens to become safer drivers. Many of the general education recommendations require more time than formal driver education classroom courses or professional instructors have available. It appears that much of the burden may fall upon parents of teen drivers to become "instructors." Many States are already increasing the number of required supervised practice hours for teen drivers, but the extent of support given to parent-supervisors to provide quality instruction is not clear. PC-based and e-learning alternatives may be partial solutions to the problem as they can educate both teens and parents. Including more and tougher testing as part of GDL may serve to increase teens' learning and possibly increase safety. In any case, it is still unclear if better educational approaches integrated within driver education and GDL will increase safety.

\section{INJURY PREVENTION STRATEGIES FOR TEENS: HEALTH DOMAINS}

In order to develop a complete picture of injury prevention strategies for teen drivers, it was of interest to examine approaches that have been used and studied in domains other than driver education. It is possible that a strategy that worked for teens in a health domain will transfer positively to driving. Therefore, strategies used to attempt to change behavior or alter attitudes of teenagers regarding tobacco use, drug/alcohol use, sex, and obesity/nutrition were examined as part of the present study.

Most of the successful adolescent health interventions start at much younger ages than traditional driver education programs. Many of the programs that have shown the best results start in elementary school and have age-appropriate lessons integrated into a variety of courses such as math, English, or physical education. Many programs have adopted the social influences model that addresses the need for knowledge about a topic and the need to understand what pressures teens may face from peers and how to resist these pressures. There is some evidence that having a specialized instructor will improve the success of a program, although in some domains specialized instructors were no better than normal teachers. Some research also indicates that a program developed with cultural norms in mind performs better than a more general program that is applied to all cultures. The development of any revised sequence for driver education together with GDL should give careful consideration to include these strategies.

\section{EXPERT PANEL REVIEW}

The study included the formation of an expert panel to apply the results of various literature reviews and data collection activities to driver education. The focus of the panel's activities were threefold. First, panel members were asked to discuss the findings from the literature and surveys of the driver education and licensing practices in the various States. Second, they were tasked with commenting on the best teaching practices applied to one hypothetical sequencing of 
education and training activities. Third, they were asked their opinions whether a new driver education curriculum was warranted.

The panel met in a one-day session to review presentations on the state of driver education in the United States, research on driver education and best teaching practices for teens, and a hypothetical model encompassing driver education, GDL, and additional functions.

\section{A POSSIBLE EXPANDED SEQUENCE}

There appeared to be general agreement among safety researchers that in order to achieve its full safety potential, driver education and training should focus on those aspects of the driving task that are linked to the risk of a crash. There are three phases related to driver licensing in which driver education could potentially play a role, pre-licensing, GDL licensing, and post-licensing (after receipt of an unrestricted license). Only the first two phases fall within the scope of current driver education and GDL provisions. Any post-licensing training would, by default, be focused on older teen drivers who have been driving unsupervised for some time under most current GDL laws.

\section{Pre-licensing Phase}

Pre-licensing refers to education and training that take place before teens enter the GDL process. Many States currently stipulate that a driver education course be taken before a teen can apply for a learner's permit. Pre-licensing activities fall into two stages that cover primary education and preparatory education.

Primary Education. Adopting injury prevention strategies learned from other public health domains, primary education should begin as early as possible (kindergarten) and continue through eighth grade. The goals of the primary period are to provide an improved foundation for learning safe driving skills and to impart specific information and skills as appropriate. The instruction should focus on the role of the passenger and on procedures, knowledge, and skills that enhance safe driving. Although children cannot drive at this age, they can learn and apply driving-related concepts as they watch the world from the passenger seat. Topics might include hazard identification, rules of the road (e.g., right of way), seat belt use, conspicuity, the impairing effects of alcohol and drugs, driver distraction, and the importance of keeping one's eyes on the road when driving.

Instruction would primarily be in the school classroom, but could be taught by other methods (e.g., parents) if needed. These topics could be taught in conjunction with bicycle and pedestrian safety, possibly as part of Safe Routes to School or other similar programs. The salient point is that there is ample bandwidth within the K-8 school curriculum to cover the important information and provide a solid underpinning for the specific driver training to follow.

Preparatory Education. This stage occurs immediately before a teen passes a test for a Learner's Permit. The important distinction between this stage and the Primary Education stage is that it specifically focuses on driving and the licensing requirements. 
The preparatory education stage would include on-road training so that students can apply concepts and practice specific skills. These training periods would train more than the vehicle handling skills needed to pass a road test. Specific emphasis could be placed on applying higher order cognitive skills such as hazard identification and attention maintenance in simulated and real-world environments.

Parental involvement and understanding also appear to be very important at this stage. Parents need to know and understand what their children are learning and need to be actively involved in at least some portion of the education process. The panel was adamant that parents cannot be expected to deduce the correct behaviors and skills to promote with their children. In order to fulfill their roles in the preparatory education stage, parents will likely require some specific training that may have to be mandated as part of the GDL laws. This training would be coupled with appropriate testing to verify achievements. Parents, as the primary regulators of teen activities, must also understand the GDL laws and their rationale so that they can adequately fulfill their oversight role.

\section{GDL Licensing Phase}

The next major phase in the licensing sequence involves GDL systems. The activities within this phase are dictated by the GDL laws and regulations in each State and include a learner's permit, a restricted license, and ultimately, an unrestricted license. In the hypothetical sequence developed with the assistance of the panel, almost all of the knowledge and skills training would be completed before the driver enters the GDL licensing process, that is, before the learner's permit stage. Education and training during the learner's permit and restricted license stages focuses on repeated driving practice of the information, procedures, and skills taught earlier.

Learner's Permit. The learner's permit stage is a time when teens apply skills to a variety of traffic situations. Entry into the learner's permit stage would be controlled by one or more tests on which the teen applicant would demonstrate relevant knowledge of topics such as GDL components and their rationale and key skills he or she must learn while holding a learner's permit. Just as is currently the case in most States, the primary instructor in this stage would be a parent, although private instruction is always a possibility. In order to prepare a parent for the instructional and supervisory responsibilities inherent in the proposed sequence, some form of instructor training for the parent must be included. Also, in order to be productive, the learner's permit stage would have to include a minimum number of practice hours with a parent, some of which would be required nighttime practice.

Restricted License. A teen who had successfully completed all of the precursor driver education requirements set forth above would likely be well-educated and well-practiced in a variety of driving situations by the time he or she reached the restricted license stage of GDL. The one thing missing, of course, would be any significant amount of driving alone without the oversight of a parent or instructor. Thus, the proposed sequence uses the restricted license stage as a period to gain additional driving experience and any necessary remedial education arising from the careful monitoring of the new driver. Although the teen would be allowed to drive alone as specified under current GDL restrictions, the hypothetical approach includes more requirements, limitations, and additional training than are typical of current GDL. In particular, 
the restricted license would include a requirement for a minimum number of practice hours day and night with a parent.

\section{Post-Licensing Phase}

The current study did not include consideration beyond the GDL licensing phase to the time when the young driver has an unrestricted license. Drivers at this stage of their driving lives typically have a much improved safety record compared to the GDL licensing phase. It is possible that additional appropriate restrictions and/or a probationary period that must be completed without excessive crashes or violations might have a safety benefit at this point. Sanctions such as zero-tolerance laws on driving after drinking for those under 21 have set a precedent for additional focus on the immediate post-licensing group of drivers. Additional research would be needed to determine if retaining some restrictions in this phase is warranted.

\section{DISCUSSION}

Driver education has been viewed as the "classic" pre-license training that has existed in the United States for decades, typically as the ubiquitous "30 and 6" program-30 hours of classroom study and 6 hours BTW. The research conducted by this study led to several important observations with respect to driver education and GDL:

- Driver education as currently delivered is focused primarily on providing students with the knowledge and skills they need to pass State driver examinations. It would be overly ambitious to assume that " 30 and 6" would be sufficient to prompt an inexperienced, immature adolescent to drive like a mature adult.

- Driver education at the time of this study appeared to be doing a good job in preparing students to pass the licensing examination. Thus, the driver education curriculum as currently constituted does not require revision as long as its purpose is to prepare for the license test.

- GDL has shown evidence of a significant safety benefit. GDL may benefit from greater parental involvement, but does little if anything to prepare parents for their important and potentially demanding roles as teachers/trainers and regulators/overseers. Thus, there would likely be a safety benefit from involving parents earlier and more deeply in the training process and preparing them more thoroughly for the significant tasks they must take on.

- One example of an expanded driver training and preparation system might integrate comprehensive training with an easy to understand GDL component that has appropriate severe sanctions for failure to comply. The system would encompass more stringent testing than is characteristic of current driver licensing practices. 


\section{Is a New Driver Education Curriculum Warranted?}

A new driver education curriculum does not appear to be warranted. The existing driver education approaches, as disparate as they may be across the States, seem to be adequately accomplishing their goal of preparing novice drivers to pass the current licensing examinations.

\section{Is There an Optimal Sequencing for Driver Training?}

An expanded and integrated driver education and graduated driver licensing system may be a reasonable starting point that can be supported by the literature. It is not, however, possible to characterize any one particular sequence as optimal, but improved content, delivery mechanisms, and legal/administrative framework can be identified.

\section{The Need for an Integrated Driver Education System}

A reasonable conclusion from the present analysis is that there may be a need for an expanded and integrated driver licensing education system that includes the existing driver education function and goes beyond it to better prepare drivers, parents, administrators, and others to facilitate the licensing process by gradually exposing a young teen driver to increased driving risks. This report provides one example of what an integrated system might entail. 


\section{INTRODUCTION}

This report documents a research project to assess whether a new approach to driver education would be beneficial based on findings from research related to driver education, general education of teenagers, successful injury prevention strategies, and the current state of driver education across the United States.

\subsection{Objectives}

The project's objectives were to:

- Identify and review current driver education and training programs in use nationally;

- Review the literature related to best teaching methodologies for teenagers;

- Compare current teaching practices with identified best practices;

- Examine the optimal sequencing for the presentation of safe driving skills in the classroom and behind-the-wheel training; and

- Based on outcomes from previous tasks, assess whether a new approach to driver education would be beneficial.

The current study examined programs in use across the United States and developed a status update on the present condition of driver education. It investigated the state-of-the-art of teaching and training for teenagers and the extent to which existing best practices from other injury prevention domains might enhance driver training. This study then used problem areas in current driver education approaches and recognized best practices to define a hypothetical driver training sequence that combines driver education and GDL. A panel of driver education, education and training experts met to discuss the information gathered in the first two tasks and to consider whether or not a new model of driver education integrated with GDL was warranted. The discussion centered on a hypothetical sequencing of education, training, testing and certification within GDL prepared by the project staff.

\subsection{Background}

The high rate of driver fatalities among 15- to 18-year-olds has raised the question of whether an overhaul of current driver education practices could lead to safer novice drivers. In order to understand which drivers in this group are most at risk, it is useful to distinguish among three groups of teen drivers: learner's permit, newly licensed, and experienced teen drivers. The fatality rate among drivers with learner permits is only marginally higher than the fatality rate among the much safer cohort of older drivers who act as their supervisors. However, the fatality rate among newly licensed drivers who have had their initial (often restricted) licenses 6 months or less is 5 times larger than the rate for more experienced teens who have held a restricted license for more than 6 months (Mayhew, Simpson \& Pak, 2003; Williams, 2003; Williams, Preusser, Ferguson, \& Ulmer, 1997). The fatality rate among experienced teen drivers is also unacceptably high, being some 2 to 3 times higher than the fatality rate among the safest cohort of drivers. The same pattern holds true in Europe, both for newly licensed and experienced teen drivers (Vlakveld \& Twisk, 2005). Given these high fatality rates, it is important to explore what driver education programs are doing across the United States and around the world and consider 
whether a revised approach to driver education is warranted based on the availability of enhanced techniques and/or content that is not currently included.

\subsubsection{Education of the Novice Driver}

Historically, driver education programs in the United States have consisted of 30 hours of classroom training and 6 hours of behind-the-wheel practice. These programs usually taught only basic rules of the road and elementary driving skills and were the sole education a novice driver would receive. However, two recent advances have complicated the driver education and licensing picture, and each has been implemented to varying degrees throughout the United States.

First, and most prominently, there are GDL systems consisting of three phases. In the learner's permit phase, a novice driver is only allowed to drive an automobile while supervised by an adult. There is great variability across States in the number of required hours of supervised driving, ranging from 0 (Arkansas, Hawaii) to 100 hours (Oregon). Minimal or no instruction is given to parents as part of the GDL process although several States, including Connecticut and New Jersey, were in the process of adding parental requirements to their GDL laws. Often, the learner's permit phase overlaps the time at which a student enrolls in a driver education program.

In the restricted license phase, the novice driver receives a solo license but can only drive under relatively "benign" conditions. Typically, these include not carrying passengers under age 21 and only driving during daylight hours. Finally, in the unrestricted phase, the teen is an unconditionally licensed driver with the previous restrictions under the provisional license lifted.

Second, there have been a number of potential advances in driver education beyond the standard curriculum. These include programs in the United States and abroad such as PC-based training (e.g., DriverZED produced by the AAA Foundation for Traffic Safety), and more advanced simulation programs such as those developed in Australia (DriveSmart), those developed by Simulation Technologies, Inc., here in the United States, and those now in widespread use in European countries such as the Netherlands (Vlakveld, 2006). Such programs typically focus on advanced skills such as hazard anticipation and risk assessment.

\subsubsection{Reviews of Driver Education and Graduated Driver Licensing Programs}

Recently, a number of literature reviews of the efficacy of standard driver education programs have been conducted. Four major reviews, which together provide a worldwide focus, were conducted by Mayhew and Simpson (2002), Vernick et al. (1999), Wooley (2000), and Roberts and Kwan (2002). These reviews are uniform in concluding that standard driver education does not reduce crash rates among newly licensed drivers.

Given the inability of evaluations to find a crash reduction benefit for driver education, and the generally positive reviews of the safety potential of GDL, one might tend to conclude that standard driver education is no longer relevant as a safety countermeasure. This might be correct if GDL programs alone were known to be producing drivers who exhibited improved safety behaviors. However, from a recent comprehensive review of research on GDL (Hedlund, Shults, \& Compton, 2006) it is clear that the majority of studies conclude that the observed effectiveness of GDL is not the result of safer driving behavior. Rather, the GDL safety benefit is a result of 
both a reduction in the number of licensed teenagers due to restricted license requirements and a decrease in teenagers' exposure to crash risks. Thus, it is still relevant to examine possible improvements to standard driver education and its coupling with GDL systems as a means to better inculcate safe driving behaviors in novice teenage drivers.

\subsubsection{Areas for Improvement of Driver Education}

The major questions at this point are: (1) Why don't driver education evaluations find reduced teen driver crashes? and (2) What, if anything, can be done to improve things?

There have been two recent national panel meetings in the United States designed to address just this problem - one convened by the National Transportation Safety Board in October 2003 (Bishop, Quinlan, Roeber, \& Van Etten, 2005) and one more recently jointly convened by the National Research Council and the Institute of Medicine in May 2006. In addition, there exist the previously mentioned general reviews and several recent reviews of the weaknesses of standard driver education programs (e.g., Mayhew \& Simpson, 2002) and the corresponding actions required to address these weaknesses. These reviews singled out five areas in which driver education could be improved as well as topics about which research from other fields should be reviewed in the context of driver education:

(1) Driver Education Could Expand Hazard Recognition and Risk Assessment Skills. The majority of standard driver education programs do give some attention to basic perceptual, motor, and cognitive skills but do not give enough attention to the higher level hazard recognition and risk assessment skills that have been shown to be at the core of collision involvement (McKnight \& McKnight, 2003). Recent research suggests that it may be possible to train these skills on a PC and successfully transfer them to the real-world driving, although research is needed to ascertain whether these promising, exploratory findings are applicable to the general population of young drivers (Fisher, Pollatsek, \& Pradhan, 2006). It is not yet known whether these programs actually reduce crash rates. More generally, although there is extensive literature from general education suggesting how one might best teach skills and behaviors to teens, this literature has not been reviewed with a specific focus on driving instruction. The potentially relevant information from injury prevention efforts in other domains such as antismoking has also not been specifically reviewed for possible relevance to an improved driver education approach.

(2) Driver Education Training Could Be Targeted for Teens. Evidence exists that teens learn differently than other students. It is known from the developmental psychology literature that adolescents differ from adults, especially with regard to their decision-making about risky behaviors, the role that peers play in their behavior, and perhaps even their sleep deprivation. More specifically, with respect to risky decision-making, it has been shown that teens estimate accurately their risks for a single event (e.g., a car crash), but not cumulative risks (Fischhoff et al., 2000). Yet, little of this knowledge has been widely reviewed and put to use in the development of driving instruction.

(3) Driver Education Could Make Safety Information More Relevant to Students. It is one thing to be able to teach teens to drive safely. It is quite another matter to ensure that teens actually put what they have learned into practice. Current driver education programs cannot affect this motivational factor since students currently attend such programs before obtaining their licenses. 
A number of different suggestions have been proffered. Perhaps the most radical is to offer instruction in safe driving practices after teens obtain their licenses (McKnight, 1985). The argument for doing this is that before obtaining their licenses teens have little motivation to attend to information about safe driving practices since their primary motivation is acquiring a license. However, once out on the road by themselves, coverage of safe driving practices would be much more meaningful. This suggests the need to review and supplement the literature relevant to the factors that motivate teens.

(4) Driver Education Could Require More Parental Involvement. Standard driver education programs do not involve parents in the instructional process. Nevertheless, the involvement of parents in the driver licensing process has been growing largely because of evolving State requirements that are part of GDL. In particular, GDL programs have mandated increased involvement of parents in supervised driving during the learner's permit phase. Unfortunately, little or no information is given to parents about how to maximize the effectiveness of their training and supervision time even though there is evidence that doing so might be useful during the learner's permit phase. Additionally, during the restricted license phase, there are opportunities for involving parents more fully in the enforcement of restrictions. Programs such as Checkpoints involve parents more heavily and have proven to be of modest benefit in this phase (Simons-Morton, Hartos, Leaf, \& Preusser, 2006). Standard driver education programs could include preparation of parents for their involvement in both the learner's permit and restricted license phases of their teen's driving.

(5) Driver Education Could Synthesize Information from Other Injury Prevention Programs. Reviews of educational and training programs designed to reduce teen risk-taking for other behaviors such as unprotected sex, smoking, drug abuse, and violence show that successful programs exist in these areas. These successes may provide insight into ways to reduce risky behavior behind the wheel. In reviewing research related to these other behaviors, it is important to keep in mind that they may not be totally analogous to driving for at least several reasons: teenage driving is a legal activity; getting licensed and driving is typically considered a natural "right of passage" by most teenagers; and parents are often relieved when their teenagers begin driving because they have grown weary of being the family chauffeurs.

\subsection{Approach}

Each of the following sections briefly describes the approach and process for this project's activities. The specific findings and implications from each of the efforts are described in further detail later in the report.

\subsubsection{Collection of State Driver Education Data}

This project was tasked with determining what current driver education programs across the nation were doing and how the driver education activities were integrated with GDL in each State. As described below, each State was contacted, and data were gathered from a variety of other sources in an attempt to describe the status of driver education in each State. Data were collected from May 2007 to May 2008 for the 50 States and the District of Columbia. Researchers gathered information from a variety of sources, including: 
- AAMVA conducted a survey of its members in each State;

- DETA conducted a survey of its members and additional contacts in selected States;

- Contacts with State licensing officials clarified their responses to the surveys; and

- Data gathered from State Web sites, driver manuals, and other licensing-related material.

The depth of information provided in response to the surveys and other contacts varied across States with some States providing very detailed information and others providing only minimal or no answers. That is why information from the State Web sites, driver manuals and other print/Internet sources was used to supplement any information provided by the States to AAMVA and DETA in the surveys.

A separate compendium of driver education practices in the 50 States and the District of Columbia was created as part of this project and delivered to NHTSA in print form. Tables 1 and 2 in the Appendix outline the information found in the compendium. Section 2 of this report summarizes some of the major findings of the State data collection efforts.

\subsubsection{Literature Reviews}

A series of literature reviews gathered information to help answer the basic research questions of the study. One review examined research into the efficacy of driver education and driver training for teen drivers. This literature search included an update of Nichols' (2003) review of driver education, a closer look at the causes of teen driver crashes identified by research, and an examination of alternative driver education and training approaches that have been studied around the world. Section 3 provides some highlights of the literature review of these areas and includes a discussion on the extent to which driver education/training has been shown to be successful at reducing crashes involving teen drivers.

A second review identified best teaching practices for teens as described in the general education literature. This review was included to determine if driver education is employing best practices that have been identified in other areas of education and whether these practices have been proved in domains analogous to driving. Section 4 outlines some of the best practices from the general education literature and discusses the extent to which driver education as documented appears to be using these best practices.

A third literature review examined injury prevention strategies for teens in domains other than driving. Efforts against risks such as smoking, unsafe sex, and obesity could possibly yield productive insights in the best ways to approach driver training with the same age group. The results of this examination are contained in Section 5.

\subsubsection{Panel Session}

The final data gathering step for this project was a panel session in which experts from a variety of relevant domains including driver education, traffic safety research, general education, and injury prevention were brought together to discuss whether or not a new model of driver education integrated with GDL was warranted. The panel considered the current state of driver education, research into the effectiveness of alternative driver training approaches and best teaching practices from general education. Panel members were asked to comment on a 
hypothetical sequencing of education, training, testing and certification within GDL prepared by the project staff. The results of the panel session are discussed in Section 6.

\subsubsection{Synthesis}

All of the information obtained from the review of driver education in the United States, the literature reviews and the panel session were synthesized regarding the need for the development, implementation, and evaluation of an expanded and integrated driver education and graduated driver licensing system. Full details of the conclusions are in the discussion in Section 7. 


\section{DRIVER EDUCATION IN THE UNITED STATES}

Researchers conducted a review of driver education programs and the role of driver education in the licensing process for first-time teen drivers in the United States. AAMVA and DETA distributed surveys to their members and other contacts within the States and District of Columbia to gather information about driver education practices. Representatives from 40 of the 51 jurisdictions responded to the surveys. The depth of information provided in these responses varied across States, with some States providing very detailed information and others providing only minimal answers. When more information was needed for a particular State, project staff called the contact listed on the survey for an unstructured discussion. Also, State driver licensing Web sites and State driver manuals were consulted to supplement the information provided in the survey responses or when there was no survey returned by a State.

The information included the GDL process for the State, how driver education plays a role in this process, data relating to the number of driver education programs operating in the State and the number of students taking those courses, and specifics about program curricula.

Table 1 in the Appendix provides information regarding the role of driver education in the GDL process for each State. Table 2 in the Appendix provides specific information about driver education program requirements and data concerning programs operating in the States and the number of students participating in driver education. The next sub-sections provide highlights from the review of driver education.

\subsection{Role of Driver Education in GDL}

Understanding the current role that driver education plays in the GDL process in the States was one area of interest for this study. In order to categorize the States for the summary below, a decision had to be made regarding what constitutes driver education. It was decided to call a program "driver education" if the State termed the program driver education and if the program was of sufficient duration and covered topics that would actually constitute the training of driving skills related to passing that State's driver license test. It was decided that a program must include at least 8 hours of classroom instruction and some behind-the-wheel training with a licensed instructor. Programs were not considered driver education if they were short duration (less than 8 hours) "pre-licensing" courses or other short programs such as drug and alcohol awareness classes. More information is available in Table 1 located in the Appendix.

\subsubsection{Driver Education as a Required Part of GDL}

As part of the licensing process for first-time teen drivers, 23 States required driver education (as defined above) for all drivers under 18. One additional State, Nevada, required driver education for all licensees under 18, but waived the requirement if there wass no course offered within 30 miles of an individual's home and if the person did not have Internet access to complete the online driver education course. An additional 6 States required some sort of short pre-licensing course or drug and alcohol awareness course for all drivers under 18. These courses were usually about 4 hours in duration and did not cover driving skills in any depth. 


\subsubsection{Unrestricted Licensure Before 18}

In 35 States, a teen could obtain an unrestricted license before 18 whether or not he/she took driver education. In 25 States, a teen could get an unrestricted license early if he or she took and passed driver education. "Early" refers to the fact that if driver education is taken, a teen could get an unrestricted license at a younger age than someone who does not take driver education. This number included 11 States that did not require driver education for all teens under 18 but rewarded teens who took a driver education course by allowing them to get unrestricted licenses early. Fourteen of the States that required driver education for all drivers under 18 allowed teens to obtain an unrestricted license early (i.e., before 18).

\subsubsection{Other Benefit States Offer for Driver Education}

At least 18 States offered some benefit beside, or in addition to, getting an unrestricted license early, if a teen took driver education. This included waiving practice driving requirements, knowledge tests, and road tests. For example, Oregon allowed teen drivers to forego 50 hours of supervised driving if they completed an approved driver education course (compared to 100 hours of supervised driving if they did not complete driver education).

\subsection{Driver Education Program Requirements and Operational Data}

Identifying what was being taught, who was doing the teaching and how many students were being taught is of great importance to understanding the potential impact of driver education on teen driver safety. For the 40 States that returned a survey, in-depth information was gathered on driver education program requirements, oversight of the programs, curricula used, the number of programs in operation, and the number of students taking driver education. When possible, information was gathered on the remaining 11 jurisdictions (who did not respond to the surveys) from driver licensing Web sites, driver manuals, and other Internet sources. The following subsections highlight some of the findings from this information gathering process. It is important to remember that not all States provided information. The information below is limited to those States for which apparently complete information could be obtained. Specific information for each State is presented in Table 2 in the Appendix.

\subsubsection{Classroom and BTW Requirements}

A State may have requirements for driver education courses even if driver education is not required for all teen drivers. The great majority of driver education programs were required by the States to include 30 hours of classroom instruction, although the lowest number of required hours was 8 and the highest number mandated was 56. Most programs required 6 hours of BTW training, but some States required none while one required 20 hours BTW. Also, some States had different requirements for high school, commercial, Internet, and parent-taught programs. Additionally, 18 States had some form of in-car observation requirement.

\subsubsection{Required Use of Specific Curricula}

Twelve States indicated that they had developed specific curriculum guides for their driver education programs to use. The programs in most of these States, however, were not required to use the guides. A number of other States had core topics or some other standards, but no 
requirements as to how the topics should be covered or how the standards should be implemented. A few States used the driver handbook/manuals as the curriculum guides or followed guidelines provided in selected textbooks.

\subsubsection{Oversight of Driver Education Programs}

Oversight varied widely among the States and often involved multiple agencies if more than one form of driver education was acceptable. In the majority of States, the State's department of education oversaw high school driver education. Other agencies involved often include the Division of Motor Vehicles, State Police, and public/transportation safety offices. In most instances, the programs must be certified by the supervising agency, although in some cases no real certification was required, especially for high school programs. This was usually the case when a State was a local control State (i.e., local school boards are responsible for program oversight). Commercial programs were often subject to greater scrutiny and had to recertify/relicense more often than other types of programs.

In 2009 NHTSA published the Novice Teen Driver Education and Training Administrative Standards, a guide for States to provide consistent driver education and training. The guide addressed administrative issues such as program administration, education/training standards, instructor qualifications, parent involvement and coordination with driving licensing areas (www.nhtsa.gov/DOT/NHTSA/Traffic\%20Injury\%20Control/Teen\%20Driver/files/TeenDriverE TAS-1.pdf).

\subsubsection{Certification of Driver Education Instructors}

All but one of the States responding to the survey indicated that instructors had to be certified to teach driver education. Many States required that a certain number of hours of college coursework be completed and/or some other type of training be completed to teach in the classroom and BTW.

\subsubsection{Driver Education Student Counts}

Only 13 of the 40 responding States provided any data in response to the question that asked how many teen drivers who received their first license in 2006 had taken driver education. Among these 13, only a few provided detailed data on the number of teens licensed who took each of the various types of driver education offered in the State. Some of the 13 States were able to provide the number of students who took driver education but not necessarily how many had been licensed. Most States simply did not have the mechanisms in place to extract this information. A few States said that they had the information in their databases but that it would take extensive programming to pull the data and therefore did not provide information.

\subsubsection{Number and Type of Driver Education Programs in Operation}

Of the 40 States that responded to the AAMVA and DETA surveys, 38 provided counts of operating programs. Most of the States had both high school and commercial programs in operation. A few States accepted only one type of driver education program, either commercial or high school. Six States indicated that they accepted Internet driver education. Three States (Indiana, Arkansas, and North Carolina) explicitly stated that parent-taught driver education was 
accepted in addition to high school and commercial driver education. A few other States defined parent-taught driver education as the practice-driving portion of GDL, although no guidelines or instructional materials were usually provided to the parents. Several States also identified "other" types of driver education programs (e.g., community college, motorcycle) as being acceptable.

\section{DRIVER EDUCATION RESEARCH}

A review of driver education research examined the effectiveness of traditional driver education programs and the potential impact of newer programs on the safety of teen drivers. First, a review of the history of driver education is presented followed by a review of current research into "new" driver education programs.

\subsection{History of Driver Education}

The first known driver training program in the United States was established in 1916 (NHTSA, 1994). The earliest programs simply attempted to teach the most basic skills of maneuvering a vehicle (Butler, 1982). These driver training programs have evolved considerably and are now referred to more broadly as "driver education" programs. In the first National Conference on Driver Education, held in 1949, safety was not mentioned directly in the objectives. At the Fifth National Conference on Driver Education, held in 1973, the stated purpose of driver education was: "To develop safer and more efficient highway users who understand the essential components of the highway transportation system in a manner that will enhance the effectiveness of such components" (Aaron \& Strasser, 1977). Most recently, in a 1994 report to Congress, NHTSA defined driver education as follows: "Driver education is a training program of organized learning and practice designed to provide the basic knowledge, attitudes and skills needed to drive safely, and to provide the advanced knowledge and skills needed for safe driving performance under special circumstances." A thorough history of driver education has recently been completed in October 2003 by James Nichols for the National Transportation Safety Board (Nichols, 2003). Some of the highlights from Nichols (2003) will be presented here, along with works completed since his review was published.

If one of the goals of driver education programs is to provide the skills, knowledge and attitudes necessary for safe driving, then one measure of the success of such programs would be a reduction in the crashes of drivers who had been exposed to driver education programs. A number of the early evaluations of high school driver education, beginning in 1941 and continuing through the 1950s and 1960s, reported a reduction in the number of crashes and/or violations among younger drivers (Nichols, 2003). However, it was not until 1976 that a largescale, controlled evaluation of driver education was undertaken in a suburb of Atlanta, Georgia. The results were somewhat disappointing, both in the short- and long term, as no major crash reductions were found for the teens who had participated in the driver education programs (Stock, Weaver, Ray, Brink, \& Sadof, 1983; Smith, 1987). Twenty years later, Mayhew and Simpson (1996) reviewed 30 studies from several different countries that evaluated the effect of driver education programs on crashes. There was very little support for the claim that formal driver education decreased crash involvement. More recently, a number of literature reviews of the effectiveness of standard driver education programs have been conducted. The reviews have spanned the globe, including Australia (Wooley, 2000), Britain (Roberts \& Kwan, 2002), Canada (Mayhew \& Simpson, 2002), Sweden (Engstrom, Gregersen, Hernetkoski, Keskinen, \& Nyberg, 
2003) and the United States (Vernick, Li, Ogaitis, MacKenzie, Baker, \& Gielen, 1999; Nichols, 2003), and most recently a comprehensive, international review sponsored by the AAA

Foundation for Traffic Safety (Clinton \& Lonero, 2006). These reviews are uniform in failing to identify a crash reduction benefit for standard driver education programs.

\subsection{Causes of Crashes Involving Newly licensed Drivers}

The fact that driver education program evaluations appear in the aggregate not to find crash reductions raises three important questions. (1) What are the behaviors of novice drivers that are causing them to crash? (2) Can current driver education programs address those behaviors? (3) If not, does there exist any reason to believe that alternative driver education programs (i.e., programs using a different approach) might actually succeed in changing the causal behaviors?

To the general public, alcohol and high speeds are perhaps the two reasons that immediately come to mind as causing the crashes of newly licensed drivers. However, during the first 6 months of driving, the percentage of newly licensed drivers who crash while under the influence of alcohol (IIHS, 2008) or while traveling at very high speeds (McKnight \& McKnight, 2003) is relatively small. Rather, analyses of police crash reports indicate that failures of visual scanning (ahead, to the sides and to the rear), attention maintenance, and speed management are responsible, respectively, for $43.6 \%, 23.0 \%$ and $20.8 \%$ of the crashes (the causes overlap) among drivers between 16 and 19 years old (McKnight \& McKnight 2003). Somewhat surprisingly, the percentage of crashes caused by the inferred failure of a given behavior did not change as a function of the experience of the young driver. Thus, if overall crashes per licensed driver are decreasing rapidly during the first 6 months, it must be because newly licensed drivers are improving in all three areas. In addition to the data that are available from police crash reports, there is evidence from laboratory studies and from naturalistic and experimental studies in the field that young drivers differ considerably from much more experienced drivers in all three areas identified by McKnight and McKnight (2003).

\subsubsection{Scanning: Hazard Anticipation}

When driving in simulators, young drivers are much less likely than experienced drivers to scan for potential hazards when these hazards are difficult to detect, such as a pedestrian that might emerge suddenly from behind a vehicle stopped in front of a midblock crosswalk (Pollatsek, Narayanaan, Pradhan, \& Fisher, 2006); although such is not the case when the hazard is more easily detected (Sagberg \& Bjørnskau, 2006). These differences in tactical hazard anticipation scanning (the scanning pattern observed when a feature in the environment suggests that a hidden threat is especially likely to materialize at a particular location and time in a scenario) coexist with differences in strategic hazard anticipation scanning (the scanning pattern observed when there is no such key feature). Specifically, as evidenced by studies on the open road, young drivers: (1) scan less broadly from side to side, especially when changing lanes (Mourant \& Rockwell, 1972); (2) have, on average, less widely spaced eye movements as measured along the horizontal axis (Crundall \& Underwood, 1998); and (3) are less likely to make consecutive fixations on objects in the periphery (Underwood, Chapman, Brocklehurst, Underwood, \& Crundall, 2003). 


\subsubsection{Attention Maintenance}

Studies on the open road - controlled (Wikman, Nieminen, \& Summala, 1998), naturalistic (Klauer et al., 2006), and in the laboratory (Chan et al., 2008) -- indicate that young drivers are much more likely to gaze for longer than 2 seconds at secondary tasks inside the vehicle. For example, in a controlled study on the open road (Wikman et al., 1998), it was found that only $13 \%$ of the experienced drivers had glance durations of at least 2.5 seconds inside the vehicle, whereas fully $46 \%$ of inexperienced drivers had glance durations of at least this length. These findings imply that distracted driving (e.g., use of portable entertainment devices) may be particularly hazardous to young, novice drivers because they pay excessive attention to tasks inside the vehicle at the expense of critical tasks outside the vehicle.

\subsubsection{Vehicle Management: Hazard Anticipation}

Speed management was identified by McKnight and McKnight (2003) as the third most prevalent cause of crashes among young drivers. This included adjusting the speed of the vehicle to traffic/road conditions, curves in general, and slick curves and surfaces. It is clear that these are examples of a more general category of vehicle management, which could also include vehicle behaviors such as maintaining the proper space between vehicles and adjusting the vehicle lane position in response to traffic and road conditions. Tactical vehicle management is particularly important when potential hazards might materialize. A recent study of the differences in the tactical hazard anticipation vehicle management skills of young and experienced drivers indicated that the differences are pronounced in situations where hazards are difficult to detect (Fisher et al., 2002).

\subsubsection{Current Driver Education and Cognitive Skills Training}

Current driver education programs did not appear to be addressing, in any depth, the advanced cognitive skills needed for crash reduction. This is partly because until recently there has been little empirical evidence to support the development of a particular content for the training of crash reduction behaviors. Although the recommendation has been made that driver education programs should focus on hazard perception and risk assessment (Mayhew \& Simpson, 1995, 1996), this recommendation was too broad to be of much assistance to driver education instructors. Thus, coverage of key tactical or strategic behaviors that would decrease novice drivers' crash risk has been minimal (Mayhew \& Simpson, 2002). It is also unrealistic to expect programs at the level of scope of current driver education to produce a meaningful reduction in crashes.

\subsection{New Driver Education/Training Programs}

A number of driver education programs have been developed around the world to train some of the safety-critical skills discussed above. Some examples of these programs and the research supporting them are discussed below.

\subsubsection{Research in Australia}

Researchers at the Monash University Accident Research Center have engaged in an extensive development (Regan, Triggs, \& Wallace, 1999) and evaluation (Regan, Triggs, \& Godley, 2000) 
of a novice driver-training program. The program that was eventually developed, DriveSmart, combined CD-ROM and simulator training. A total of 14 different content areas in driving were identified as requiring emphasis (e.g., hazard anticipation, attention maintenance). These content areas were then taught in one of three different driving contexts (rural, freeway, or urban) using either digitized real-world videos or a 3-dimensional virtual world. The combination of content, context and instructional modes led to a product with six training modules. In the Scanning module, video clips were used to provide the background for the training of hazard anticipation skills. Each of the 67 clips lasted between 20 and 30 seconds. The video was stopped at a given point and the driver was asked to say and to click on likely risks. In the Keeping Ahead and Playing Safe module, the video was paused and the driver was asked to indicate and to say what the driver should do next. In the Concentration module, 3-dimensional virtual words were used to train attention prioritization. As a drive-through simulated world unfolded, either the participants were asked to keep a constant distance between their car and a car ahead whose velocity varied, or they were asked to monitor areas of the periphery in which numbers would suddenly appear, and then to perform operations on those numbers. In the fifth and sixth modules, On the Road - Urban Driving and On the Road - Country Driving, participants were again asked to both scan the roadway and plan ahead. The drives that were presented in these modules exposed the participants a number of times to near transfer scenarios (i.e., scenarios similar to ones upon which they would be evaluated after training) and a limited number of times to far transfer scenarios.

In order to evaluate DriveSmart, 103 learner drivers between 16 years and 11 months and 17 years and 10 months were randomly assigned to the treatment (training with DriveSmart) or control (training with a Microsoft flight simulator, no obvious relevance) groups. Training was undertaken for both the experimental and control groups in four separate sessions. Immediately after training and then four weeks later, participants were evaluated on a driving simulator in each of four 5-minute risk perception drives and three 5-minute attentional control drives. There were a total of four scenarios in each risk-perception drive in which it was possible to score vehicle behaviors indicative of hazard perception (and thus a total of 16 scenarios across all 4 drives). One or more dependent variables were used to index the participant's safe driving performance in each scenario. Two of the scenarios in each drive mirrored what had been trained in DriveSmart (near transfer); two were different (far transfer). In four of the neartransfer and four of the far-transfer scenarios immediately after training, the treatment group was significantly more likely than the control group (at the $10 \%$ level) to detect a hazard, as indicated by at least one of the measures. In the remaining eight scenarios there was no statistically significant difference. Much the same results were observed 4 weeks later, with the treatment group performing better in 3 of the 8 near transfer and 4 of the 8 far transfer scenarios. In each of the three attention drives, the speed limit changed in six different places. During each attention drive, the participants had to listen to a series of 2-digit numbers, e.g., "83," and then say aloud the absolute value of the difference between the first and last digit, "5." In the evaluation immediately after training, the treatment group reached the speed limit more quickly and drove closer to the posted limit than did the control group, all while performing the arithmetic task with equal accuracy. In the evaluation undertaken 4 weeks after training, the treatment group still reached the speed limit more quickly. Unfortunately, the dependent measures were not reported for each scenario so it is difficult to know exactly how large a practical effect the training had. Additionally, one cannot know what effect the changes might have on on-the-road driving experiences or on actual crashes. In part due to this work, passing a hazard perception test is now part of the licensing requirement in Victoria, Australia. 


\subsubsection{Research in England}

Researchers in England focused on strategic hazard anticipation that has been identified as critical to reducing novice driver crashes (Chapman, Underwood, \& Roberts, 2002). Specifically, hazards were presented in video clips to novice drivers. The training took approximately 1 hour. No clip that appeared in the training phase appeared later in the evaluation phase. There were five phases. In the first phase, drivers saw 4 clips, commented on what they saw, and pressed a button whenever they saw a hazard. In the second phase, drivers twice viewed the same 5 clips run at half speed, commenting first both on the areas circled in blue (general areas of interest) and on the areas circled in red (specific hazards) and listening next to the comments of experts on why the different areas were circled. In the third phase, 5 different clips were played and paused at critical points. The participant had to anticipate the hazard. The clip was then restarted and an expert explained why the hazard looms. In the fourth phase, the 10 clips from the two previous phases were played at full speed with the red and blue circles overlaid appropriately. The driver commented on the clip and was asked to anticipate the hazards. In the final, fifth, phase the driver watched 4 clips and provided commentary as well as pressing a button at each potential hazard.

Three months before training, immediately after training, and then 3 to 6 months later still, the eye movements of the participants were evaluated in the field on a predetermined course on the open road at 18 selected points. The full drive included three different road types (urban, rural, and dual carriageway) and four different speed limits (30, 40,60 and $70 \mathrm{mph})$. Additionally, at each of the three phases of the experiment, the eye movements of the participants were monitored while watching 13 video clips (the 13 clips in each phase were different). Several different indices of the effects of training were used, including time headways and eye movements. There were no differences in the time headways of the trained and untrained novice drivers either immediately after training or 3 months post training in situations where a vehicle was directly in front of the driver. There were, however, large differences in the variance of the search along the horizontal axis immediately after training (the trained newly licensed drivers having a larger variance) with the trained drivers increasing from an average of $38.2^{\circ}$ to $53.7^{\circ}$, and the untrained drivers actually decreasing from $40.4^{\circ}$ to $37.9^{\circ}$. No differences were found between groups 3 to 6 months after training.

Similar differences were found when video clips were used to test scanning. Also, in another experiment it was possible to compare the eye movement behavior of the trained drivers viewing video clips with experienced drivers seeing the same clips (Chapman \& Underwood, 1998). In the clips identified as hazardous, the experienced drivers, like the newly licensed drivers, had a larger search variance. However, in the scenarios identified as nonhazardous, the variance of the newly licensed drivers' scan continued to be large, unlike the experienced drivers, suggesting that the training is not helping the newly licensed driver discriminate hazardous from nonhazardous situations. Note that Chapman et al. (2002) did not determine whether the trained drivers were actually looking at areas of the roadway which might reduce their likelihood of a crash; they used only global measures of amount of eye scanning behavior.

Chapman et al. (2002) understand that it is not simply enough to bring novice drivers to the point where their eye movement patterns resemble those of more experienced drivers, which is why the training program focused on knowledge, scanning and anticipation, rather than simply modifying the observable patterns of eye movements. Nevertheless, without more specific 
information than the horizontal variance of the search it is difficult to know whether the training changed much other than the observable scanning patterns.

\subsubsection{Research in Sweden}

The European research project TRAINER took place between 2000 and 2004. The aim of this project, funded by the European Commission and in which various research institutes participated, was the development of new methods for driver training in which computer-based training (CBT) and simulator training were key elements (TRAINER, 2002). The objectives for the simulator training and CBT were derived from the Goals of Driver Education framework, which was the result of a literature review of the causes of the high crash rate of young novice drivers in an earlier European research project called GADGET (Hatakka et al., 2003).

The CBT that was developed in the TRAINER program differed from DriveSmart, the Australian CBT, and Driver ZED (the CBT that was developed in the United States, discussed below). In contrast with DriveSmart and Driver ZED, only a small proportion of the material in TRAINER was concerned with hazard anticipation. This part contains video clips that freeze after about 15 seconds. The learner driver has to click on the spot in the frozen picture where a potential risk is visible (e.g., a pedestrian in the distance on the sidewalk). All potential risks are explicit, and there are no hidden risks. The rest of the CD-ROM contains questions and answers about participant behavior such as drunk driving, peer group pressure, and fatigue.

The simulator training that was developed had a total of 31 scenarios divided into five training blocks. The blocks were: (1) basic knowledge (application of rules of the road and vehicle control), (2) maneuvering and safety, divided attention (car following and overtaking), (3) maneuvering and safety, hazard perception (search strategies, gap acceptance, and hazard anticipation), (4) particular situations with higher risk (road and weather conditions, darkness) and (5) particular situations: new technology and personality aspects (driving with ABS, ecological driving, distraction and attention, motives for driving).

Falkmer and Gregersen (2003) tested whether the hazard perception skills of learner drivers improved when the CBT and the simulator training of the TRAINER project was part of the regular initial driver training in Sweden. As training simulators, a so-called low cost simulator (LCS) and a so-called mean cost simulator (MCS) were used. The LCS consisted of a driver chair, pedals, a gear lever, a steering wheel, a dashboard, only one monitor (40 degrees field of view horizontally) right in front of the driver, and a sound generator. The pedals and steering wheel had force feedback, but there was no motion system. The MCS had the same configuration but with three monitors (a field of view of about 120 degrees horizontally) and had a simple motion and vibration system. All the participants were learner drivers from a driving school. They had professional driver training (on the road with an instructor), but had not yet taken the driving test. The participants were divided into three groups. The first group initially completed CBT and after that received the simulator training on an MCS, the second also completed CBT first but received the simulator training on an LCS, and the third (control) group completed neither CBT nor simulator training.

To test the acquired hazard perception skills, a high-end research simulator with a moving base was used to present six scenarios to the participants. In the first scenario the participants drove in an urban environment. At a junction, a bus approached from the right hand side, and 
according to the rules of the road, the bus must yield the right-of-way, however, it did not stop in this scenario. This situation demands early detection and immediate reaction in order to avoid a crash. In the second scenario, the participants drove on a rural road with forest all around. A moose suddenly crossed the road and, after a few seconds, two calves followed. In this condition, situation awareness is required for early detection. In the third scenario, the participant received a short message service communication on his/her mobile phone when driving on a rural road, and directly after the phone signal, the participant passed a traffic sign indicating a lower speed limit (it was $90 \mathrm{~km} / \mathrm{h}$ and the sign says $50 \mathrm{~km} / \mathrm{h}$ ). Of key interest is whether participants were distracted by the phone signal and did not recognize the change in speed limit. Scenarios 4 to 6 were actually one long scenario divided into three parts. In the first part, fog gradually reduced the visibility to 100 metres. In the second, the fog disappeared and then the driver entered a second fog bank in which a van appears that is driving in the same direction. If the participant was driving too fast, a rear-end collision would occur. In the third, the fog disappeared, but then the van (which was directly in front of the participant driver) started to accelerate (over the speed limit).

For each scenario, Falkmer and Gregersen (2003) used a different set of dependent variables. All of the measures dealt with car performance such as speed, onset of braking, following distance, time to collision, lateral position, etc., so that the drivers' eye behavior was not measured directly (e.g., the scanning behavior was not measured with an eye tracker). There were few significant differences on all dependent variables among the three groups across all scenarios.

In summary, the simulator training and the CBT had some positive effects on the driving performance of learner drivers, and the group that was trained on the MCS did slightly better than the group that was trained on the LCS. However, there was no improvement when the testing scenarios were considerably different in their appearance from the training scenarios even though there was the same underlying principle in both. That is to say, there was some near transfer but there was no far transfer.

\subsubsection{Research in the Netherlands}

In the Netherlands, driving simulators were used both for initial and advanced driver training, with more than 100 systems in use at the time of this study. Using driving simulators for driver training requires that cost and effectiveness are carefully balanced. Even though driver training in the Netherlands was relatively expensive (taking about 35 to 40 hours at a cost of 35 to 40 Euros an hour to pass the practical driving test), driving schools operate a business with small margins.

In 2002 Algemene Nederlandse Wielrijders Bond (ANWB), the Dutch automobile association, started using simulators in driver training that were developed using ELSTAR and MASTER principles. With a PC-based simulator using a car mock-up, a wide $180^{\circ} 3$-channel projection system, and a sophisticated, scripted, traffic system with virtual instructor, they provided 18 lessons of 20 minutes each, in which students learned to master basic vehicle operation and traffic participation. The simulators are located in regional centers, with clusters of 2 to 4 simulators operated by a single instructor. Each simulator lesson is focused on a specific topic (e.g., highway driving, negotiating complex intersections, negotiating roundabouts). These specific topics were also treated in the theory book (the homework for that day), in CBT prior to 
the simulator lessons, and as the focus of the practical driving lessons that day. An evaluation of the effectiveness of the system showed that practical driving instructors rated the performance of simulator students above average when compared to students that did not receive simulator training. Being freed from explaining and training the relatively boring basic principles of traffic participation, practical driving instructors commented that they had more time to teach students the more cognitive "higher order" aspects of driving. One ANWB simulator instructor estimated that students learned three times faster in the simulator than in a practical driving course. Based on this evaluation, the ANWB driving school decided to proceed with the introduction of the simulator in its curriculum. It now uses 30 simulators in its schools, each with a supervising simulator instructor. In 2003, other Dutch driving schools started using driving simulators, but they tended to use simpler driving simulators that were operated in clusters or as stand-alone machines (depending on the size of the school). These simulators did not present specific scenarios to the student, but instead manipulated more general traffic parameters (traffic density, percentage of "aggressive" drivers, etc.) to deliver lessons of different difficulty levels. These schools generally offer the simulator lessons at a reduced cost as an "extra," prior to the start of the regular practical driver training. Apart from the evaluation that was conducted at ANWB driving schools, the Dutch driving simulators have not been subjected to a classical validation study.

\subsubsection{Research in the United States}

There have been several attempts to introduce more targeted hazard anticipation, attention maintenance and vehicle management training in the United States over the past 10 years. Most evaluations have been conducted only on a driving simulator.

Driver ZED. The American Automobile Association (AAA) developed a risk awareness training program called Driver ZED (Zero Errors Driving). Participants sit in front of PCs and watch a total of 80 different scenarios filmed in city, town, and rural settings (Willis, 1998). The scenarios contain views filmed from the cabin in a moving vehicle both of the roadway ahead and the roadway as seen in the side and rear view mirrors. The participant needs to take one of several actions sometime during or after each scenario, the exact action depending on the mode of presentation. There are four modes: scan, spot, act, and drive. In the scan mode, the driver needs to answer questions at the end of a scenario to assess how well the driver has been paying attention to everything in the scenario (e.g., the driver might be asked whether there was a vehicle approaching in the rear view mirror). In the spot mode, the scenario is stopped at the last frame. The driver is asked to use the mouse to click the cursor on each risky element in the scenario (e.g., a child playing with a ball on the sidewalk). In the act mode, the driver is asked what action he or she would take midway through a scenario (e.g., the driver might be asked whether he or she should speed up or slow down at an intersection where the traffic signal was displaying a yellow globe). Finally, in the drive mode, the driver needs to click on the mouse at the point in a scenario when they would take an action that could potentially avoid a crash (e.g., the participant might need to brake suddenly when approaching a driveway out of which a car was backing).

The risky scenarios in Driver ZED were selected specifically because they were ones in which younger drivers frequently crashed (Lonero, Clinton, Black, Brock, \& Wilde, 1995). Fisher et al. (2002) evaluated the effect of training on a subset of these scenarios, including examples from categories of crashes in which younger adults are frequently involved, such as proceeding 
straight ahead through an intersection, as well as examples from categories in which younger adults are only infrequently involved, but which are often fatal such as passing other vehicles (Aizenberg \& McKenzie, 1997). The vehicle behaviors of three groups of drivers on the driving simulator were recorded: novice drivers (high school students with a learner's permit) who were trained to recognize risks using Driver ZED, novice drivers who were trained only through standard drivers' education programs, and more experienced drivers (qualified college students who were driving buses for the university in which they were enrolled). Each group drove through a number of potentially risky scenarios on the driving simulator, and vehicle behavior was recorded throughout each drive. The behavior of the trained novice drivers closely resembled that of the experienced drivers. For example, in response to the "Truck Left Turn" scenario the experienced drivers braked opposite the truck more frequently than the novice drivers, indicating that they recognized the risk that an obscured vehicle in the opposing lane could be in the process of turning across their path; the more frequent braking was also characteristic of the trained novice drivers. Similar differences in driving behavior between the trained and untrained novice drivers were reported in other scenarios. However, from these data it could not be determined how much of the differences between the untrained novice drivers on the one hand and the trained novice and experienced drivers on the other were due to differences in hazard anticipation skills (predicting that a car might intrude) and a combination of hazard and speed control skills (actually braking). Perhaps all drivers predicted the presence of a potential hazard, but only the trained and experienced drivers were able to act on this information.

Driver Assessment and Training System. In a recent study, over 500 novice drivers in California participated in a study of how effective driving simulators were at reducing crash rates among this population of drivers (Allen et al., 2007). The drivers were assigned to one of three simulator-training modes: a single monitor desktop simulator, a 3-monitor desktop simulator, or a wide-screen vehicle cab simulator. One group of drivers came from the Department of Motor Vehicles and were assigned either to the 3-monitor desktop or wide-screen vehicle cab simulators. Training occurred in a laboratory setting. A second group of drivers came from high school driver education courses. Training occurred in the high schools on the single monitor desktop simulator. Crash data were obtained from the California DMV for up to two years posttraining.

The crash rates per licensed driver were then computed for each of the three simulator groups over a 2-year period. At the end of two years, approximately $17 \%$ of the one monitor desktop simulator participants had a crash, approximately $14 \%$ of the 3-monitor desktop simulator participants had a crash, and approximately $7 \%$ of the 3 -screen vehicle cab simulator participants had a crash ${ }^{1}$. As a control group, the authors compared the cumulative crash rates of drivers in California and Canada the first two years after obtaining their license. Crash rates were regressed on time. The linear increase in cumulative crash rates of drivers in California and Canada were indistinguishable from each other and clearly higher than the increase in the cumulative crash rates of the participants in the 3-screen vehicle cab simulator. Unfortunately, assignment of the participants to the experimental groups was not random nor was assignment of the participants to experimental and control groups random. Thus, it is difficult to determine if the lower crash rates of the 3 -screen vehicle cab participants is representative.

\footnotetext{
${ }^{1}$ These values are estimates because they are taken from a figure in the text.
} 
Risk Awareness and Perception Training Program. A program to train novice drivers to anticipate hazards was motivated by the finding that younger drivers are less likely to anticipate hazards than more experienced drivers (Pradhan et al., 2005). In the simplest version of the Risk Awareness and Perception Training (RAPT) program, participants are presented a plan view of a hazardous situation. For example, a driver is approaching a marked mid-block crosswalk. There are two travel lanes in each direction and a parking lane. A truck or other large vehicle is stopped in front of the crosswalk in the parking lane, potentially obscuring from the driver a pedestrian who might be crossing in front of the truck. Six markers (3 yellow ovals and 3 red circles) are positioned off to the side. Trainees must drag the yellow ovals to areas on the plan view where a potential threat might be located (in front of the truck) and the red circles to locations on the plan view where they would expect the threat to materialize (to the left and front of the truck). Between 1 and 3 markers are needed in each plan view. Trainees are then told the correct locations of the two markers (Pollatsek et al., 2006). In other versions of RAPT, sequences of photographs of hazardous situations are used. These versions use sequences generated by taking a picture every second or two as a hazardous situation is approached and passed. The trainee must use the mouse to move the cursor to locations in each photograph where a risk might appear or was latent. Again, feedback about correctness is provided.

In a series of studies, it was found that RAPT increased the likelihood that newly licensed drivers anticipated hazards to the point that their performance was not much different than much more experienced drivers. The effects of training existed both immediately after exposure to the training program and for up to one week later. The effects were present both on a driving simulator and in the field, and they were evident both in scenarios which are similar to ones that were trained and ones that were quite dissimilar (Pollatsek, Fisher, \& Pradhan, 2006). One study found an extremely large effect in the driving simulator and on the road (Fisher et al., 2007). The trained group fixated on the critical region $77.4 \%$ of the time, whereas the control group fixated the critical region only $40.0 \%$. The overall training effects found in the simulator were somewhat larger than the overall averages observed in the field study. In the field study the training effect was 27.1 percentage points $(64.4 \%$ correct for trained versus $37.3 \%$ correct for untrained).

An interesting variation of the training program was recently evaluated. In that variation, a head-mounted driving simulator was used to train hazard anticipation scanning skills (SIMRAPT) in addition to the training they received with RAPT (Diete, 2007). The driver sat in a real car in which inputs from the wheels, brake and accelerator were sent to a computer which then displayed movements through the virtual world on the head mounted display consistent with these inputs. Participants who did not make a head movement indicating that they recognized a potential hazard had to repeat the drive. At the end of the combined RAPT and SIMRAPT training, both the trained participants and a group of participants who had not been trained were evaluated on an advanced driving simulator. The training effect here was no different than the training effect with just RAPT alone. It is not entirely clear why the additional simulator training did not provide a larger benefit.

\subsection{Summary of Driver Education/Training Research}

Based on published research, driver education evaluations have failed to demonstrate decreases in crash rates for teen drivers. Based on the content and focus of most current driver education programs, as identified in the literature review and through the review of practices in the States 
conducted for this study, this is not surprising. Because classic driver education is primarily focused on training drivers to pass the licensing exams, it is not surprising that safety-related information, including hazard and risk perception, may get "lost" in the mix. Driver education does result in a high rate of passing the licensing exams and therefore is a success against that objective.

Newer driver education/training programs focus on using technology to teach higher-level knowledge and skills that appear to be related to teen crashes. Many of these programs assume that the trainee has already mastered basic vehicle handling skills. The programs generally use computer simulation on either a personal computer or in the simulator. The key is that the programs provide feedback to the user and generally require that the user achieve a certain level of performance before advancing to the next training session.

A major unknown with the newer programs relates to how long the training effects will last. It also remains unclear whether drivers will be motivated to apply what they have learned in training when they are out on the open road by themselves, and it is not certain that there will be a reduction in crashes. Most of these programs do not address basic driving skills, something that traditional driver education appears to do quite well. The integration of these new programs into current driver education and GDL would appear to hold some promise. However, the costs and time needed for a teen to complete the programs present further barriers for widespread adoption. 


\section{DRIVER EDUCATION'S USE OF BEST TEACHING PRACTICES FROM GENERAL EDUCATION}

An additional focus of the present study was to determine the extent to which current driver education programs implement best teaching practices as identified in the general education literature. The general education literature is massive, and research studies are often very specific to one educational topic (e.g., reading, math, science) making it difficult to translate findings to other domains. The United States Department of Education recently published a practice guide entitled Organizing Instruction and Study to Improve Student Learning (Pashler et al., 2007) that assembles the best practices from all areas of education. This guide provides recommendations created by an expert panel, is based largely on research reviewed by the What Works Clearinghouse (WWC), and includes corresponding grades as to the level of evidence available to support the recommendations. The WWC examines a large volume of research related to education and provides summaries of the research as well as recommendations for best practices based on the outcomes of the research.

The practice guide states that the "recommendations in this practice guide are intended to provide teachers with specific strategies for organizing both instruction and students' studying of material to facilitate learning and remembering information, and to enable students to use what they have learned in new situations." The recommendations themselves can be considered best practices, although some of the recommendations have stronger research support than others. The authors assert that the guide, as with any good practice guide, contains recommendations intended to be actionable and coherent and are connected with the level of evidence supporting the recommendation through a grading system. It is noted that the recommendations might be different if another group of experts were to be convened, but that the panel was composed of nationally recognized experts in education, and the guide itself was subject to extensive review by the Institute of Education Sciences (IES) at the Department of Education (Pashler et al., 2007).

The grading system found in the practice guide focused on determining the value of research studies on a particular topic and for drawing causal conclusions as to what works for instructing students. Figure 1 below contains the actual grading criteria used in the guide (Pashler et al., 2007). 


\section{Figure 1. Institute of Education Sciences Levels of Evidence}

\section{Strong}

In general, characterization of the evidence for a recommendation as strong requires both studies with high internal validity (i.e., studies whose designs can support causal conclusions), as well as studies with high external validity (i.e., studies that in total include enough of the range of participants and settings on which the recommendation is focused to support the conclusion that the results can be generalized to those participants and settings). Strong evidence for this practice guide is operationalized as:

- A systematic review of research that generally meets the standards of the What Works Clearinghouse (see http://ies.ed.gov/ncee/wwc/) and supports the effectiveness of a program, practice, or approach, with no contradictory evidence of similar quality; OR

- Several well-designed, randomized, controlled trials or well-designed quasi-experiments that generally meet the standards of the What Works Clearinghouse and support the effectiveness of a program, practice, or approach, with no contradictory evidence of similar quality; OR

- One large, well-designed, randomized, controlled, multisite trial that meets the standards of the What Works Clearinghouse and supports the effectiveness of a program, practice, or approach, with no contradictory evidence of similar quality; OR

- For assessments, evidence of reliability and validity that meets The Standards for Educational and Psychological Testing.

\section{Moderate}

In general, characterization of the evidence for a recommendation as moderate requires studies with high internal validity but moderate external validity, or studies with high external validity but moderate internal validity. In other words, moderate evidence is derived from studies that support strong causal conclusions but where generalization is uncertain, or studies that support the generality of a relationship but where the causality is uncertain. Moderate evidence for this practice guide is operationalized as:

- Experiments or quasi-experiments generally meeting the standards of the What Works Clearinghouse and supporting the effectiveness of a program, practice, or approach with small sample sizes and/or other conditions of implementation or analysis that limit generalizability, and no contrary evidence; OR

-Comparison group studies that do not demonstrate equivalence of groups at pretest and therefore do not meet the standards of the What Works Clearinghouse but that (a) consistently show enhanced outcomes for participants experiencing a particular program, practice, or approach and (b) have no major flaws related to internal validity other than lack of demonstrated equivalence at pretest (e.g., only one teacher or one class per condition, unequal amounts of instructional time, highly biased outcome measures); OR

- Correlational research with strong statistical controls for selection bias and for discerning influence of endogenous factors and no contrary evidence; OR

- For assessments, evidence of reliability that meets The Standards for Educational and Psychological Testing, but with evidence of validity from samples not adequately representative of the population on which the recommendation is focused.

\section{Low}

In general, characterization of the evidence for a recommendation as low means that the recommendation is based on expert opinion derived from strong findings or theories in related areas and/or expert opinion buttressed by direct evidence that does not rise to the moderate or strong levels. Low evidence is operationalized as evidence not meeting the standards for the moderate or high levels.

As can be seen in Figure 1, a recommendation that receives a Strong grade is a recommendation that is supported by research that has the highest levels of internal and external validity and has passed the rigorous standards defined by the WWC. A recommendation graded as Moderate 
means that the research supporting a recommendation is limited in its generalizability, usually because the research on the topic involved small samples or the samples were limited in diversity. A recommendation with a Low grade is largely based on the opinion of the expert panel members, but has strong research support in related areas and is likely to be an effective recommendation for instructing students in the classroom.

The guide outlines seven recommendations. Highlights from each of the seven recommendations are described below. ${ }^{2}$ Each recommendation is discussed in relationship to current driver education practices and how it may be better applied/implemented to improve overall driver training.

\subsection{Recommendation 1: Space Learning Over Time (Level of Evidence $=$ Moderate)}

Classroom and laboratory research overwhelmingly support the tenet that students remember more information when they have been exposed to the information on at least two occasions (Pashler et al. 2007). This even holds true when the total amount of time that is spent across the two sessions (e.g., two 10-minute sessions) is the same as that would have occurred for a single learning session (e.g., one 20-minute session). Students typically remember much more information in the delayed learning situation. The time between the two learning sessions and testing of recall, however, is a key factor in determining the amount of information that is recalled. Research indicates that remembering is generally best when the amount of time between two learning sessions is no less than $5 \%$ of the interval during which the information has to be retained. This means that if the two learning sessions are close together and the testing is in the relatively distant future, recall will not be as good as a condition in which two learning sessions were more evenly spaced relative to the testing of recall. Also, it is important to note that spacing the learning sessions further apart does not affect recall as much as spacing them too closely. Thus, Pashler et al. (2007) assert that it makes sense to have enough spacing, but not to worry about having too much.

Specific to learning in the classroom, Pashler et al. (2007) recommend that students be exposed to key course concepts on at least two occasions and that the exposures should be several weeks to several months apart. They suggest that the exposure could be through homework assignments, quizzes, in-class reviews, quizzes, or other exercises. The authors note that some content is automatically reviewed as a part of the course since students must build upon prior knowledge to progress. This recommendation is most relevant to those courses where important knowledge and information are not automatically reviewed.

One important limitation of the research in this area is that most of the research has focused on learning relatively small amounts of information such as vocabulary, historical facts, or simple mathematics (Pashler et al., 2007). The authors note that very few studies have examined the acquisition of complex bodies of structured information. They argue, however, that there is no evidence that would suggest that delayed review would not work for these more complex learning conditions.

\footnotetext{
${ }^{2}$ See the Organizing Instruction and Study to Improve Student Learning (Pashler et al., 2007) guide for the full description of each of the recommendations and for the references of the supporting research studies.
} 
Driver education/training would fall into the category of complex learning since the amount of information needed to operate a vehicle safely is rather large, and this information must be appropriately applied in a dynamic environment. Traditional driver education in the classroom appears to be doing a relatively good job at spacing the learning of the basic knowledge/skills over time. The issue for any comprehensive driver training, however, is the shear amount of time that would be needed to repeat the key topics in a timely manner in order to improve driving safety. While traditional driver education may be doing a good job at teaching the basic skills and knowledge needed to pass the licensing exams, it alone cannot be expected to provide the repetition of higher order skills training that is needed to actually improve teen driver safety. This would likely require a more comprehensive driver training or qualification system commencing well before the driving age.

\subsection{Recommendation 2: Interleave Worked Example Solutions and Problem-Solving Exercises (Level of Evidence $=$ Moderate)}

It is recommended that instructors interleave worked example solutions and problem-solving exercises (Pashler et al., 2007). The laboratory research supporting the benefits of alternating between worked example solutions and problem-solving exercises is extensive. Studies in the classroom have also shown that the strategy can be effective for all grade levels. A worked example solution involves showing students a step-by-step example of how to solve a problem. After reviewing the worked example solution, the students are then given a similar problem to solve on their own. Interleaving the worked example solutions and problem-solving exercises has proven to be far more effective than simply having students solve problems on their own or when students are given all of the example solutions first and are then asked to solve all of the problems at once. This type of instruction has most often been employed in the sciences, mathematics, and technology.

The exact amount of guidance and annotation needed for the worked example solutions varies depending on the situation and student. Pashler et al. (2007) note that some research suggests that worked examples without instructional explanations for each step were most effective, but other research has found that labeling steps within a problem solution according to the goal they seek to achieve can be effective. Also, as students gain greater expertise, it appears that decreasing example use and increasing problem-solving can improve learning. Pashler et al. (2007) also refer to other research that demonstrates using worked examples and problems that have greater variability and put greater demands on the student initially but can lead to better learning and test performance.

Pashler et al. (2007) assert that interleaving worked example solutions with problem solving helps students recognize what they do not understand; something that the authors suggest students are generally not very good at doing.

It is not clear to what extent traditional classroom and BTW driver education is implementing this recommendation, but the likelihood that a traditional 30 hour classroom and 6 hour BTW driver education course is implementing this recommendation is remote. There is likely wide variation depending on the instructor, whether in the classroom, on the road with a professional driving instructor, or with a parent. Some newer driver training programs (e.g., DriverZed) already employ worked examples, but these programs are not widely used, and these programs may not cover all of the essential topics. 
Within the current GDL process in most States, the only real place to apply this recommendation is during the supervised practice driving. An issue, however, is that most parents would themselves need to be trained on how to properly teach their teen drivers. Expecting parents to be able to provide good worked examples without specific training and guidance may be stretching the limits of what a parent can reasonably do.

Implementing this recommendation as part of all driver education/training courses would likely require a workbook of exercises that addresses at least a representative subset of the wide variety of circumstances a new driver may encounter. This workbook, however, would need to be very large to provide step-by-step examples of the variety of situations that can occur on the roadway. Simulators or increased on-road training might be needed to walk new teen drivers through the examples. Simulators have the advantage that the teen driver can be exposed to the situations over and over again until the correct behavior is learned. The amount of classroom and on-road time for driver education would need to be greatly increased to implement this recommendation. Other solutions would involve the use of e-learning completed at home to supplement the classroom and simulator instruction.

\subsection{Recommendation 3: Combine Graphics with Verbal Descriptions (Level of Evidence $=$ Moderate)}

Pashler et al. (2007) identify the central findings from research on using graphics and verbal descriptions and suggest that combining graphics and verbal descriptions can enhance learning. It is first noted that adding relevant graphical presentations to text enhances learning when compared to text alone. It is also stated that research has shown that students learn more when a verbal description is presented in audio form instead of with written text. Pashler et al. (2007) suggest that audio is better because it allows the student to examine the graphic while hearing the description instead of having to try to read the text and look at the graphic at the same time. The authors note several studies that have shown large improvements in student learning at all grade levels using this approach, especially in mathematics.

The guide specifically addresses the use of graphics and verbal descriptions when teaching students about processes and procedures that can be represented through pictures, figures, charts, and video clips (Pashler et al., 2007). It is stated that teachers should combine verbal descriptions of the key steps in the process with the graphics to illustrate these steps. When using handouts or other text materials, the guide asserts that brief text or labels should be placed as close as possible to the aspect of the graphic that is being described to help students identify specifically what they are looking at. Verbal descriptions should also specifically identify for students what they should be looking at.

Another point is that the graphics do not always have to be realistic. It is suggested that a photorealistic graphic can actually be distracting and may include aspects that are irrelevant to the point that is being made. Pashler et al. (2007) state that more abstract visualizations can sometimes be better than realistic illustrations, and that a well-chosen sequence of still pictures is as good, or sometimes better, than animations for enhancing learning. In any case, the graphics should be chosen for their relevance to the topic. Often times, graphics can be used to help students understand abstract concepts by depicting the concept in a variety of ways, so long as 
the teacher helps students understand the core concept being expressed in the differing representations.

Most current driver education programs make use of some form of graphics and videos. Whether or not the videos and graphics are up to date is an open question. Also, the explanations given by instructors may vary greatly, which could affect the impact of the graphics. This recommendation supports the use of PC-based learning or e-learning as a viable means to teach teens. Still photos, videos and abstract visualizations can be employed with relative ease in electronic media format to cover a wide range of topics. An advantage of PC-based learning is that the explanation of the graphics is consistent for all teens completing the training and can be delivered via audio or with text inserted over the graphics.

\subsection{Recommendation 4: Connect and Integrate Abstract and Concrete Representations of Concepts (Level of Evidence $=$ Moderate)}

It is recommended that teachers connect and integrate abstract representations of a concept with concrete representations of the same concept. Pashler et al. (2007) state that connecting different forms of representations helps students master a concept and improves the likelihood that the concept will be used in a variety of contexts. Again, this approach has been applied primarily in the teaching of mathematics, science, and technology.

The research in this area has found that using only abstract or concrete representations of concepts leads to less flexible knowledge acquisition than teaching students to recognize and use key principles across a number of situations. Using both abstract and concrete representations allows students to apply the concept to multiple contexts, even if the exact context has not been encountered before. It must be noted that students often have an easier time initially understanding a concept when presented in a concrete form, but transfer to other contexts is limited. At first, learning abstract concepts may be difficult, but the learned knowledge can usually be applied to very different situations if needed. One approach identified by Pashler et al. (2007) uses concrete representations for initial learning, but gradually replaces the concrete components with abstract representations. This method appears to allow learners to quickly grasp the concepts and then further develop the abstract understanding of the concept such that it can be applied in new situations.

Research also suggests that it may be important for a teacher to explicitly mark the relationships between different representations. It is suggested that the instructor must draw the students' attention to both the relevant and shared aspects of the various representations. Otherwise, the students may not be able to identify which components are in fact important and should be transferred to new problems or situations. It is also noted that lower-achieving students may improve learning with hands-on problems that involve the application of underlying principles so long as the instructor can guide the student in understanding the important concepts to be applied in the hands-on situation.

Along the same line, Pashler et al. (2007) note that instruction often uses new terms or symbols before the students understand the meanings of the terms and symbols by drawing connections to familiar objects or situations. That is to say, the students may memorize new terms or learn how to manipulate math problems without ever understanding the underlying meaning or concept by drawing connections. In these situations the student's learning does not generally transfer to 
other situations. This can often be overcome by "anchoring" new ideas in stories or problems familiar to the students. The students can draw on their prior knowledge and by using successively more abstract representations of the idea the students can gain a better understanding of the core concept.

This recommendation is especially relevant to driver education/training since teens must quickly learn and apply new and skills across a variety of situations. How well current driver education programs link abstract concepts to concrete concepts is not well-defined. Most driver education programs do not appear to give a great deal of importance to abstract concepts such as hazard anticipation and attention maintenance, or at least they are unable to provide sufficient practice time to link these abstract concepts to real world experiences.

Another concern is that teens enter current driver education programs under-prepared to link abstract and concrete concepts because they lack the vocabulary and prior knowledge to do so. Often, the only experience a teen has with driving is through video games or by watching parents drive. This argues for increased teaching of driving related concepts at an early age to introduce potential young drivers to the relevant vocabulary in order to help them learn quickly and to link abstract concepts to the concrete actions needed when driving.

\subsection{Recommendation 5: Use Quizzing to Promote Learning}

Pashler et al. (2007) contend that the process of taking quizzes (or tests) can promote learning and reduce the rate of forgetting. This recommendation is actually composed of two subrecommendations. One part includes using pre-questions to activate prior knowledge and focus student attention on new materials to be presented, while the second part is to use quizzes to reexpose students to key content already covered.

\subsubsection{Recommendation 5a: Use Pre-questions to Introduce a New Topic (Level of Evidence $=$ Low)}

Pre-questions are questions that are posed to students before they have been exposed to the material covered in the questions. The idea is to help students identify what material they do not yet know and therefore need to study. It is suggested that these pre-questions also serve to activate any relevant prior knowledge. Essentially, the pre-questions serve as a preview of the topic(s) to be covered. Most of the evidence for this recommendation stems from laboratory studies concerned with learning from written text. Some experimental studies have shown that students can remember more from a text if they first answered questions about the text than if they did not answer questions first. The only issue with such pre-questioning is whether or not students will selectively read the texts to learn only the information that was asked in the prequestions. Research suggests that this potential issue can be overcome if students are explicitly required or encouraged to read all of the material. It is important to note, however, that prequestions are generally used to direct a student's attention to the key concepts to be covered and should not focus on extraneous information.

Pre-questions might prove effective for all phases of driver training. Such questions might prove especially helpful during BTW training. Pre-questions would help teens to think about the driving situations they are about to encounter and to apply what they learned in the classroom. Such questions would work well when the driving situation is predictable. As the teen shows 
improvement, the pre-questions may become more complicated to account for a more dynamic traffic environment where many scenarios could develop.

\subsubsection{Recommendation 5b: Use Quizzes to Re-expose Students to Information (Level of Evidence $=$ Strong)}

Using quizzes to re-expose students to key course content and enhance learning is widely supported in experimental studies. Use of quizzes overlaps Recommendation 1 that suggested delayed re-exposure to information to help students remember the information. Pashler et al. (2007) suggest closed-book quizzes/tests and the use of items that require students to actively recall the information (e.g., fill-in-the-blank, short answer) instead of multiple-choice items. It is also important to provide correct-answer feedback to promote learning.

Quizzing leads to what is often termed the "testing effect" in which testing on a topic leads to better performance in subsequent testing. This effect is very robust, and has been shown to be true for people of all ages (Pashler et al., 2007). Interestingly, the testing effect occurs even when the intervening test is different from the later test. That is to say, a fill-in-the-blank test can improve subsequent performance for a multiple-choice test that covers the same topic.

Additionally, research has shown that having students take tests is almost always more effective than making the students spend more time studying the materials. This has even proved true for Web-based courses. Quizzing also reduces forgetting.

Pashler et al. (2007) note that quizzing does not always have to be formal. Games or any other method that requires students to actively recall information can be considered quizzing and are likely to prove effective at enhancing learning and reducing forgetting. In any case, the authors reiterate the point that corrective feedback should be given when incorrect answers are provided.

Traditional driver education generally incorporates some formal quizzing into the classroom and BTW practice in preparation for the licensing exams. After the licensing exams, however, no more testing usually takes place. Thus, students may forget much of the information they had learned in preparation for the licensing tests, not to mention that most driver licensing tests do not include anything related to higher order cognitive skills such as hazard anticipation. This recommendation suggests that knowledge may be increased if the GDL process included more testing. Additional testing would require teen drivers to learn and re-learn information important to safe driving. New tests relevant to safety would have to be developed.

\subsection{Recommendation 6: Help Students Allocate Study Time Efficiently}

This recommendation suggests that teachers help students accurately assess what they know and do not know in order to promote efficient and effective study habits. Pashler et al. (2007) assert that this can help students break the "illusion of knowing" that can lead to students inaccurately assessing their knowledge. This recommendation is broken down into two parts. The first part is focused on teaching students how to create accurate judgments. The second part is concerned with using tests and quizzes to help students identify content that needs further study. 


\subsubsection{Recommendation 6a: Teach Students How to Use Delayed Judgment of Learning Techniques to Identify Concepts that Need Further Study (Level of Evidence $=$ Low)}

This recommendation stems from research that has shown most people, without training, cannot accurately judge what they do and do not know. People also tend to overestimate how well they have mastered material after studying. This is often referred to as the "illusion of knowing." Pashler et al. (2007) remark that research has led to the development of a number of techniques teachers can use to help students accurately judge whether or not they have learned something and subsequently what they need to spend their time studying.

One technique that appears to be valuable is called the "cue-only delayed judgment of learning" procedure. This procedure involves:

- The student testing their mastery only after a meaningful delay

- Only having access to the cue, not the answer

- Students should judge how likely they are to get the correct answer on a quiz instead of just generating the answer.

It has been shown that students using this technique are highly accurate at judging whether or not they know the answer. If a student is able to identify that he/she does not know something, he/she should be more likely to study that particular topic and improve test performance. Research has supported just this idea, finding that older students ( 9 years and older) are more likely to allocate study time to information they know they do not know or failed to answer correctly.

With driving, it is imperative that the student know the correct behavior before actually entering the roadway on his/her own. Not surprisingly, most teens tend to think that they are better drivers than the average person and know the correct behaviors, whether they do or not. Helping a teen to understand what he or she does not know about driving might prove helpful. This recommendation might be most beneficial during the supervised practice period when students are attempting to apply what they have learned. The supervising adult must provide the student with feedback or direction to ensure that the teen driver performs correctly. Therefore, the supervising adult would also need to be educated on how to help a teen understand what he or she does not know.

\subsubsection{Recommendation 6b: Use Tests and Quizzes to Identify Content that Needs to be Learned (Level of Evidence $=$ Low)}

Here, it is recommended that quizzing be used after the presentation of new materials in order to help students identify information that they do not know. Feedback should be given to help students remedy incorrect responses. This method will help students identify the content they have yet to master. This technique, however, has primarily been tested in the laboratory, and no studies have been completed in the context of classroom instruction to date. Once again, it is recommended that closed-book quizzes be used, and the quizzing can be either formal or informal. Quizzing can also be conducted at the beginning of class in order to test information covered in a homework assignment. In any case, the teacher should explicitly tell students if they did not get answers correct and should encourage students to study specific topics. If there 
is not enough time in the classroom for quizzing, online self-checking quizzes can be used. Selfchecking quizzes can direct students to where answers can be found in the text. Pashler et al. (2007) note that quizzing of this kind should not be viewed as testing by students; rather they should begin to understand that the quizzes are a tool that they can use to evaluate their own performance and enhance their learning.

Online quizzing would likely be an effective tool for teen drivers and parents alike as teens attempt to learn how to drive in a variety of situations. The quizzes might involve computer simulations that are similar to situations the teen just encountered or will encounter on a planned drive. Providing the teen with the correct answer will reinforce what the parent or instructor says.

\subsection{Recommendation 7: Help Students Build Explanations by Asking and Answering Deep Questions (Level of Evidence $=$ Strong)}

The research evidence supporting this recommendation is very strong, with students at all grade levels benefiting from the use of deep questions. This recommendation can only be enacted after students have acquired a basic set of knowledge about a topic. Deep questions require deep explanations that appeal to causal mechanisms, planning, well-reasoned arguments, and logic (Pashler et al., 2007). These questions can be used during normal class time or during independent study. Questions often start with why, why not, how, and what if. The benefits are realized across a wide range of topics. Deep questions go beyond recall of basic factual or skill knowledge (shallow knowledge) and require learners to describe causal relationships between facts and/or concepts.

Teachers must identify deep-level questions that can be used to prompt students to reason about underlying principles. Answering deep questions, however, requires more time and effort for students, and often students may need the teacher to model the process of how to answer a question. The more a student can see examples of high-quality explanations, the more he/she will be able to develop a good answer. Thinking aloud in the classroom or when studying alone can help students develop a better understanding of what constitutes a quality answer to a deep question. Computers can also be used to model high-quality answers to deep questions both in and out of the classroom.

Pashler et al. (2007) caution that some students may not have the requisite knowledge to answer or ask deep questions. In such cases, deep questions may actually hinder learning as students become disappointed and/or lose motivation to learn. Also, when a student provides a "shallow" answer to a deep question, the teacher must prompt the student with feedback or provide examples that model what a better answer would look like. Some students may also lack the motivation to invest the cognitive effort to answer a deep question. In these situations, it can help to make the deep question relevant to the student's life and experiences.

Although this recommendation has the strongest support from education research, it is probably underused in most current driver education programs. Many States reported that their driver education programs teach students to pass the driver licensing exams and not to be safer drivers. There is usually not a requirement that the student have a deeper understanding of why certain things should be done; rather only that they should be done and that the licensing exam will ask a question, and a particular answer should be given. 
To a certain extent, the development of a deeper understanding of "safe driving" may be beyond the reach of many teen drivers simply because they lack the requisite knowledge or mental capabilities to develop such an understanding. If this is the case, an argument can be made to delay licensure until an individual has the mental capabilities to develop a deeper understanding of what constitutes safe driving. As such, GDL would be based on advancement through the driver training process instead of age-related milestones as most GDL processes are currently.

\subsection{Summary}

The best practices from the general education literature, as identified by Pashler et al. (2007), suggest that the current driver training system as a whole (driver education and GDL combined), may not be operating at the most effective level with respect to a goal of producing safer drivers. Many of the recommendations require more time than formal driver education classroom courses or professional instructors have available. It appears that much of the burden may fall upon parents of teen drivers to become "instructors." Many States are already increasing the number of required supervised practice hours for teen drivers, but the extent of support given to the parent-supervisors to provide quality instruction is not clear. PC-based and e-learning alternatives may be partial solutions to the problem as they can educate both teens and parents. Including more and tougher testing as part of GDL may serve to increase learning by teens and possibly increase safety. In any case, it is still unclear if better educational approaches integrated within driver education and GDL will increase safety. 


\section{INJURY PREVENTION STRATEGIES FOR TEENS: HEALTH DOMAINS}

In order to develop a complete picture of injury prevention strategies for teen drivers, it is of interest to examine approaches that domains other than driver education have studied and used. A strategy that worked for teens in a health domain may transfer positively to driving. The next section presents strategies used to attempt to change behavior or alter attitudes of teenagers in regards to tobacco, drug, or alcohol use; sex; obesity; and nutrition.

\subsection{Tobacco Prevention/cessation}

Smoking is a high-risk behavior. In a survey of high school students from across the country, the Centers for Disease Control and Prevention (CDC) found that $54.3 \%$ of students admit to having tried cigarettes or other tobacco products (CDC, 2006). It is not clear if America's youth are receiving the message that tobacco use is bad for their health, or if teens are simply ignoring the message.

Krowchuk (2005) provides a good summary of research into the effectiveness of the various types of tobacco prevention programs. Krowchuk (2005) classifies programs as communitybased, school-based, and healthcare-provider-based. According to Krowchuk (2005), a community-based program targets a large group of individuals in a particular geographic region. It involves people from all levels of the community and uses media to raise the level of awareness regarding the ill effects of tobacco use. School-based programs specifically target school-aged children and integrate the programs into the school curriculum. Healthcareprovider-based programs use doctors, nurses and other healthcare experts to counsel adolescents about the issues associated with smoking. The review discusses the effectiveness of each class of programs and the implications for future programs. Some examples of the outcomes of research covered in Krowchuk's (2005) review and other studies are discussed below.

\subsubsection{Community-based Programs}

Snowden and Snead (2003) reviewed 17 community-based programs in the United States, United Kingdom, Australia, and Finland. Many of the programs included a school-based intervention that was part of the larger project. In all 17 studies teens' knowledge about the effects of smoking increased in the intervention groups, but only two of the studies revealed significant differences in smoking behavior between the intervention and comparison groups. The two programs that found behavioral differences aimed to improve decision-making among teens using social learning theory as the foundation for the intervention (e.g., at boys' and girls' clubs). Similarly, Friend and Levy (2002) found evidence that community-based programs that used social influences models worked best.

\subsubsection{School-based Programs}

Schools are trying a variety of methods to help prevent tobacco use by America's youth. Various school policies have been put in place in districts around the country to help control the use of tobacco. These policies range in scope and include the banning of tobacco on school campuses by both students and staff, not allowing students to bring tobacco products onto school campuses, enforcing school bans on tobacco use on off-campus school sponsored events, and prohibiting students from wearing or brining to school any tobacco merchandise (e.g., T-shirts, 
caps). Violation of these school policies have a variety of consequences; oral or written reprimand, specific punishments from a school administrator or even referral to a program to help students discontinue the use of tobacco products (Gingiss, Boerm, \& Roberts-Gray, 2006). In Texas, researchers found that school policies were enforced $90 \%$ of the time (Boerm, Gingiss, $\&$ Roberts-Gray, 2007). Schools have also tried to offer tobacco cessation support, to help those who would like to discontinue their use of tobacco products. It has been shown that a school program can lower teen tobacco use by $25 \%$ to $60 \%$ (Gingiss et al., 2006).

There is currently no standard curriculum in place to support tobacco use prevention, although some states, such as Texas and Washington, have tried to implement statewide programs. Most educators still use traditional instructional methods such as lectures, group discussions and videos to educate students on the health hazards of tobacco. Some school districts are starting to incorporate more student-centered delivery models and instructional methods such as roleplaying, simulations, and peer education (Gingiss et al., 2006). Krowchuk (2005) refers to the following potentially effective models:

- Direct instruction (inform and instruct) model. Krowchuk (2005) indicates that this is the most common method. It is based on the idea that increased knowledge about the health risks associated with tobacco will reduce usage. Thomas and Perera (2002) found that these types of programs were highly effective at increasing teens' knowledge of smoking risks, but did not change behaviors.

- Social competence model. This model assumes that the use of tobacco products is entirely influenced by a teen's environment and attempts to build a teen's skills in problem solving and decision making to help them be better prepared to deal with stresses in life that may lead to tobacco use. There has been some evidence that these types of programs work (Thomas \& Perera, 2002).

- Social influence model. In programs using social influence models, teens learn how to resist media, family and peer influences to smoke. These programs use role playing, peer-education, resistance skills training along with discussions and demonstrations to help teens be prepared to resist influences that promote tobacco use. These programs demonstrated effects, but the benefits appear to be short-lived (Thomas \& Perera, 2002). There is some evidence that booster sessions can revive the benefits and even lead to longer-lasting effects (Skara \& Sussman, 2003). Programs aimed at preventing teen tobacco use that employ social influence models appear to be the most effective (Krowchuk, 2005).

- Mathematical reasoning model. These types of programs use basic math skills in an attempt to inform students of the costs associated with a particular behavior. For example, the Short Story of Life Smoking Education and Prevention Program, a multigrade program, has students at various grade levels use mathematical skills to determine the costs (e.g., shortened life span, monetary) of smoking over a lifetime (Burd et al., 2006). Over $70 \%$ of students surveyed after taking this program preferred it to other programs they had been through in the past. Notably, the program was designed to be brief enough for schools to use in the time available for non-academic activities, or to be easily incorporated into a variety of classes (e.g., math, health, science). Additionally, this particular program cost less than $\$ 3$ per student (Burd et al., 2006). 


\subsubsection{Healthcare Provider-based Programs}

Krowchuk (2005) identified six non-blinded random control trials that examined the effectiveness of healthcare-provider-based adolescent smoking interventions (Fidler \& Lambert, 2001; Hovell, Adams, \& Adams, 2001; M. F. Hovell et al., 1996; Kentala, Utriainen, Pahkala, \& Mattila, 1999; Sims, Meurer, Sims, \& Layde, 2004; Stevens et al., 2002). Of these six studies, only one (Fidler \& Lambert, 2001) demonstrated a significant effect for the intervention group. The program instituted here involved the teen's primary provider mailing age-appropriate antismoking material to the teen every three months for a year, in addition to counseling teens on the risks associated with smoking. The lack of effectiveness for the other programs, however, suggests that the inform and instruct method used by most healthcare-provider-based programs is largely ineffective at changing a teen's behavior.

\subsubsection{Implications of Research on Tobacco Intervention Programs for Driver Education}

Research on tobacco intervention programs outlined above suggests that increasing knowledge is not enough. According to Krowchuk (2005) the most effective programs are:

- Based on social influence models;

- Begun in early adolescence;

- Comprehensive multi-setting interventions that deliver age-appropriate messages in clinical, school and community settings;

- Culturally sensitive; and

- Periodically repeated.

If applied to driver education, the social influences model potentially could be effective at helping teens resist temptations that come with unsupervised driving (e.g., speeding, showing off for friends). It is a logical conclusion that if such activities are started as early as middle or even elementary school, the likelihood that they will influence a teen driver increases. Coherent messages coming from multiple sources (e.g., parents, media) would likely reinforce any message learned in a driver education classroom. It also makes sense that a teen might be more influenced by messages that are culturally sensitive. Repeating the message over many months and years through booster sessions would likely serve to reinforce the message and possibly lead to safer drivers. Overall, it appears that driver education could apply a number of the lessons learned from the tobacco prevention/cessation programs and research.

\subsection{Drugs and Alcohol Prevention/Cessation}

Alcohol and drug use are other major health and safety risks for teens. In a survey conducted by the CDC (CDC, 2006), over $80 \%$ of high school seniors reported that they have had at least one drink in their lifetime, and nearly $74 \%$ of students in all grades of high school admitted to having at least one drink. In the same CDC survey, students were also asked about their marijuana use; $38 \%$ said they had tried marijuana in the past and $20 \%$ of high school students admitted to using marijuana in the 30 days prior to the survey. Students were also asked about other drug use; $7 \%$ admitted to using some form of cocaine; $12 \%$ an illegal inhalant; $8 \%$ a hallucinogenic drug; $6 \%$ methamphetamine; $6 \%$ ecstasy; and $2 \%$ heroine (CDC, 2006). It is clear from these numbers that American teens are experimenting with and using drugs at an alarming rate. 


\subsubsection{Drug and Alcohol Intervention Research}

Several programs have been developed around the country to help better educate American teens on the dangers of alcohol and drug use. Ringwalt et al. (1994) notes that most drug and alcohol prevention programs are school-based and fall into one of three categories:

- Knowledge/information programs which often use a direct instruction approach and are founded on the basis that teens use drugs because they lack information about the negative consequences of using drugs. Ringwalt et al. (1994), notes that knowledge/information programs, although capable of increasing knowledge, generally have not been effective in preventing drug use among youth.

- Affective programs that emphasize increasing self-esteem, enhancing self-awareness, clarifying values, making responsible decisions and improving interpersonal skills (Ringwalt et al., 1994). Affective programs also typically use direction instruction methods but often include group activities as well. Affective strategies have not fared any better than knowledge/information programs when it comes to changing behaviors related to drug and alcohol use (Tobler, 1986). In fact, one study found students who received an affective education program reported significantly more drug use than students in a comparison group and that these differences increased over time (Hansen, Johnson, Flay, Graham, \& Sobel, 1988).

- Social influences programs, as already discussed above in the tobacco prevention section, are based on the assumption that teens use drugs because they are not prepared to resist social pressures (Ringwalt et al., 1994). Social influences programs focus on better decision-making, improved communication, reducing anxiety and enhancing drugspecific social skills. Social influences programs generally use participatory learning experiences and peer-to-peer teaching. Ringwalt et al. (1994) cite a number of program evaluations that found positive effects when the social influences model was implemented as the central instructional method. The Drug Abuse Resistance Education (DARE) program is a well-known anti-drug campaign that generally follows the social influences model. The Refuse, Explain, Avoid and Leave (REAL) curriculum developed by the National Institute of Drug Abuse through Pennsylvania State University and Arizona State University is another example of a social influences approach. (Harthun, Drapeau, Dustman, \& Marsiglia, 2002). The “Keepin' it REAL" implementation of the REAL curriculum had 3 distinct programs, one for each of the different ethnic communities the programs were to be used in. Students who participated in the "Keepin' it REAL" program reported a $16 \%$ decrease in alcohol use, while students in control groups indicated an increase of over $20 \%$ in alcohol use. Students at the intervention sites also indicated that they had less positive views of drugs and alcohol after completing the program (Harthun et al., 2002).

\subsubsection{Implications of Research on Drugs/Alcohol Intervention Programs for Driver Education}

Based on Tobler (1986) and Ringwalt et al.'s (1994) research, it appears that interactive programs are more effective at changing behaviors that are heavily influenced by peers. It is highly likely that teen driving behaviors are influenced by their peers even when there are no 
other teens in the car. If a teen thinks all of his or her friends speed, do not wear seat belts, or perform any variety of other poor driving behaviors, the teen is probably more likely to engage in the same bad behaviors. By restricting the numbers of same-age peers in a vehicle, GDL programs are acknowledging that driving is a peer influenced behavior. Driver education may benefit by using interactive programs that attempt to counter peer pressure by improving refusal skills, promoting improvement of general social competencies, and correcting beliefs about what other peer drivers are doing.

The study of "Keepin' it REAL" (Harthun et al., 2002) indicates that creating a program for specific cultures can have an impact on acceptance of the program and can ultimately improve the target behavior. Developing a driver education program that targets specific populations by addressing the social norms for specific populations could prove effective at improving teen driver behavior in schools where the population is relatively homogenous. However, implementing such programs in schools where there are diverse populations could prove problematic.

\subsection{Sex Education}

According to the CDC (2006), approximately $47 \%$ of high school students are sexually active, with over $60 \%$ of high school seniors having had sexual intercourse. Just over $6 \%$ of high school students surveyed by the CDC (2006) admitted to having sex before the age of 13 , and $14 \%$ of students admitted to having four or more sexual partners. Of the students surveyed, roughly $34 \%$ admitted to having had sex in the three months preceding the survey; of those students only $62 \%$ noted that they or their partner had used a condom during intercourse, and only about $17 \%$ said that they or their partner were taking birth control pills. Almost $88 \%$ of students indicated that they had been taught about HIV/AIDS, but only about $12 \%$ have ever been tested for HIV/AIDS (CDC, 2006).

\subsubsection{Sex Education Research}

In recent years, a large portion of Federal funding for sex education has been awarded to programs that teach abstinence from sex until an individual is married. Denny and Young (2006) point out, however, that very few evaluations of the long-term (more than 1 year after the program) effectiveness of abstinence programs have been conducted. Evaluations of the shortterm effectiveness of abstinence have had mixed results, with a number of the evaluations showing no or very small behavioral changes due to the programs (Denny \& Young, 2006).

A great majority of the recent research on the effectiveness of various types of sex education programs, other than abstinence programs, has been conducted overseas. The sections below discuss some specific sex education programs, the programs' effectiveness, and how the strategies used in the programs may benefit driver education.

United States Abstinence Program: Sex Can Wait. Denny and Young (2006) evaluated the effectiveness of the "Sex Can Wait" program. This program has components in upper elementary, middle school and high school classrooms. The 18-month study was conducted using a survey that was given to students before they were enrolled in the program, immediately following completion of the program (in their grade level), and 18 months after they completed the program. A control group, composed of students who were enrolled in a standard 
health and sex educated curriculum, also took the surveys at the same intervals. The study demonstrated that the Sex Can Wait program positively affected students at all ages, but that long-term behavioral effects varied by age (Denny \& Young, 2006). The program appeared to have the greatest behavioral effects on upper elementary and middle school students. For the 18month follow-up, students in these age groups who had participated in the program were less likely to report participation in sexual intercourse than students who were not enrolled in the course. High school students who participated in the program showed short-term reductions in sexual intercourse, but the reductions were not present at the 18-month follow-up (Denny \& Young, 2006).

Safe, Happy, REsponsible (SHARE). While the current focus in the American education system is on abstinence programs, many European countries are looking at sex education in a different light. In the United Kingdom the Safe Happy and REsponsbile (SHARE) program was developed. The program was aimed at students 13 to 15 years old, and was developed by NHS Health Scotland and the Medical Research Council in the mid 1990s. The SHARE program was originally designed as a pilot research project, and was adopted nationally in Scotland (Wight \& Dixon, 2004). It consists of 20 lessons delivered by classroom teachers. The rationale for using "normal" classroom teachers is that the cost of hiring and training a specialized teacher is too high for most schools. The program is designed to encourage students to make planned decisions. The lessons vary throughout the curriculum and cover relationships, physiology, contraception, sexually transmitted infections (STIs), experience of first intercourse, planning and negotiating safer sex, and accessing sexual health care services. Each lesson involves a variety of instructional methods including small-group work, games, and role-plays. Teachers who deliver the SHARE program receive some professional development to aid in the delivery of the program (Wight \& Dixon, 2004).

Henderson et al. (2007) examined the impact of SHARE on registered conceptions and terminations for 16- to 20-year-olds who had been through the SHARE program compared to a group that had been through a standard sex education program. The results of the study showed no significant differences between the groups for conceptions and terminations. Henderson et al. (2007) go as far to say that enhancing teacher-led sex education beyond the standard program in Scotland is unlikely to reduce terminations in teenagers.

Scandinavian Approach to Sex Education. Scandinavian countries have similar rates of teen sexual activity as the United States, but lower rates of teenage pregnancy, abortion, and STIs. Norway has been able to implement a national sex education curriculum with little controversy (Bartz, 2007). Bartz's (2007) review of sex education in Norway examines the differences between sex education in Norway and programs in the United States.

Rather than having a group educational approach such as that used in classrooms in the United States, schools in Norway use a one-on-one approach to sex education. For example, the largest high school in Oslo has four full-time counselors devoted solely to sex education and counseling. The goal of Norwegian sex education, similar to American sex education, is to reduce harm associated with sex, namely unwanted pregnancies, sexually transmitted diseases, and AIDS (Bartz, 2007). Norway stresses individual choice, contraception, and intimacy.

In Norway, all students nationwide are mandated to receive sex education, and sex education is integrated into many subjects, ranging from social science to religion (Bartz, 2007). In Norway 
the aim of sex education is to give students the appropriate information to make choices for themselves, not to tell them what choices to make (Bartz, 2007).

\subsubsection{Implications of Research on Sex Education Programs for Driver Education}

Many successful sex education programs, both abstinence-based and other types of programs, start at an early age. Some of the European programs start as early as age 7 in an effort to increase student knowledge of risks associated with certain sexual behaviors. These early start programs are often integrated into many school subjects and the content is tailored to the age of the students. It would likely not be too difficult to incorporate at least some aspects of driver education into elementary school and middle school curricula. For example, students could work on math problems that relate to speed and chance of injury, or students could do research projects on the dangers of not wearing seat belts. If students can understand some of these safety concepts earlier in their lives, perhaps they would be more likely to practice safer behaviors later when they start to drive.

When it comes to a more intensive driver education course for older teens, however, the disappointing results of the SHARE sex education study in Scotland suggest that it may be better to have specialized instructors teach a course. Using "normal" teachers for teaching sex education did not appear to affect the behaviors of teens, at least as relating to conceptions and terminations. The success of Norway's use of specialized counselors for one-on-one sex education could make an argument for a similar approach to driver education. Specially trained driving instructors using one-on-one training may prove better at teaching driver education than "normal" teachers who have received minimal additional training. This also argues against parents teaching teens how to drive, unless the parent has received training on how to teach driving skills. The costs of one-on-one instruction could be prohibitively expensive, however, and the logistics might be difficult in a public school setting.

\subsection{Obesity Prevention}

Data from the National Health and Nutrition Examination Survey show an alarming increase in obesity, not just for adults, but also for children. The prevalence of overweight 12- to 19-yearolds increased from 5.0\% in 1980 to 17.4\% in 2004 (CDC, 2007). Magarey, Daniels, Boulton and Cockington (2003) found that obesity persisted into adulthood for $70 \%$ of obese adolescents. Stice, Shaw, and Marti (2006) note that research has shown that treating obesity through weight loss programs has been largely ineffective, often resulting only in about a $10 \%$ loss of weight, which is usually regained within a few years. Because of the lack of success in treating obesity, much effort has been devoted to prevention programs.

\subsubsection{Obesity Prevention Research}

Stice et al. (2006) conducted a meta-analytic review of 64 obesity prevention programs for children and adolescents. Stice et al. (2006) state that studies have evaluated four major types of interventions related to obesity/weight-gain prevention:

1. Multi-focus cardiovascular disease prevention programs that targeted obesity along with other risk factors for cardiovascular disease (e.g., hypertension and smoking);

2. Prevention programs that focused solely on the prevention of obesity or weight gain; 
3. Interventions designed to solely increase physical activity; and

4. Eating disorder prevention programs that promoted use of healthy weight-management skills.

Of the 64 intervention programs in the meta-analysis, only 13 showed significant positive intervention effects. All four types of programs were represented among the 13 with positive effects. Three of the programs showed prevention effects that persisted for a prolonged period. Only one prevention program had effects that were replicated in multiple trials. Unexpectedly, interventions that were of shorter duration produced significantly larger effects than longer programs. Also, those programs that focused solely on obesity produced larger effects than programs that had multiple areas of focus. These last two findings are related because programs that had multiple focus areas tended to be longer in duration. Those programs focusing solely on obesity tended to be shorter in duration (Stice et al., 2006).

The meta-analysis also revealed that self-selected recruitment was a significant predictor of program success. Those interventions that had self-selected participation showed greater effects than those that had mandated participation (Stice et al., 2006). Programs that included greater parent involvement and delivery by trained professionals did not show any larger effects (Stice et al., 2006).

In another review of childhood obesity prevention studies, Budd and Volpe (2006) identified 12 research studies that used randomized controlled trials. Four of the studies listed obesity prevention as the primary aim of the intervention. Two of these studies found significant reductions in body mass index (BMI) after the intervention. One program, the Planet Health intervention, consisted of lessons incorporated into math, science, English, social studies, and physical education classes (Budd \& Volpe, 2006). The lessons were taught by the regular teachers for the respective classes. After two years, girls showed a significant reduction in BMI, but boys did not when compared to the control group. Also, boys and girls showed reductions in time watching television, and girls also showed improved dietary patterns (Gortmaker et al., 1999). Budd and Volpe (2006) also note another program conducted by Robinson (1999) in which 3rd and 4th graders were encouraged to reduce their television watching and video-gameplaying times. The intervention lasted 6 months and included 18 class sessions taught by the regular school teachers. The intervention included a family monitoring component and selfreporting of television and video game usage (Budd \& Volpe, 2006). Also, the program culminated with a "10-day no television" challenge for the students. Boys and girls in the intervention group showed significant reductions in BMI compared to the control group. Also, students and parents demonstrated large drops for hours of television viewing and video game use, as well as a drop in the number of meals consumed while watching television (Robinson, 1999). From their review, Budd and Volpe (2006) conclude that older students benefit more from classroom instruction and physical education, especially females. They state that behavior change programs that reduce sedentary behavior are more beneficial for younger children (Budd \& Volpe, 2006).

\subsubsection{Implications of Research on Obesity Prevention Programs for Driver Education}

The obesity prevention research discussed above has several implications for driver education. The improved response of self-selected program participants suggests a possible benefit to including in the driver education sequence a component for young children that increases their 
desire to take extensive driver training when they reach driving age. The relative ineffectiveness of multi-focus programs might suggest that a driver education program that tries to cover too many topics will not be as effective as a program that focuses on fewer topics at one time. The findings in the Robinson (1999) study suggest that parents and self-monitoring can also improve behavior. Most States already require parents to monitor a teen's driving for a certain period of time, but the extent to which parents actually monitor the driving is unclear.

\subsection{Summary of Implications of Prevention Strategies in Other Teen Health Interventions for Driver Education}

Most of the successful interventions related to adolescent health start at much younger ages than traditional driver education programs. Many of the programs that have shown the best results start in elementary school and have age appropriate lessons that are integrated into a variety of courses (e.g., math, English, physical education). Many of these programs have adopted the social influences model that addresses not only the need for knowledge about a topic, but also the need to understand what pressures a teen may face from peers and how to resist these pressures. There is some evidence that having a specialized instructor will improve the success of a program, although in some domains specialized instructors were no better than normal teachers. Some research also indicates that a program that is developed with cultural norms in mind will perform better than a more general program that is applied to all cultures. The development of any revised sequence for driver education together with GDL should give careful consideration to including these strategies. 


\section{EXPERT PANEL REVIEW}

This study included the formation of an expert panel to apply the results of the various literature reviews and data collection activities to driver education. The focus of the panel's activities was threefold. First, panel members were asked to discuss the findings from the literature and the surveys of the driver education and licensing practices in the various States. Second, they were tasked with commenting on what the sequencing of educational and training activities should be to enhance safety. Third, they were asked their opinions concerning the issue of whether a new driver education curriculum was warranted. This section discusses the operation of the panel session and its results. The implications of these results for the answer to the study's basic research questions are contained in Section 7.

\subsection{Panel Composition}

The panel membership was selected to include experts on: driver education, driver licensing, young driver research, emerging driver training technologies, and the development and evaluation of behavior modification programs for teenagers. Panel members:

- $\quad$ R. Wade Allen

President and Technical Director

Systems Technology, Inc.

- $\quad$ Steve Blackistone

State and Local Affairs Representative

National Transportation Safety Board

- John Brock

Program Manager

Windwalker Corporation

- Bud Chauncy

President

Driving School Association of the Americas

- Pamela S. Fischer

Director

New Jersey Division of Highway Traffic Safety \& Governor's Representative

- John L. Harvey

Program Manager-Driver Education

Oregon Department of Transportation

- Bruce Simons-Morton

Chief, Prevention Research Branch

National Institute of Child Health and Human Development 
- Allan F. Williams

Researcher and former Vice President of Research

Insurance Institute for Highway Safety

Discussants and observers included the authors and research and program personnel from NHTSA.

\subsection{Panel Procedures}

The panel session was conducted on May 14, 2008, at NHTSA headquarters in Washington, DC. After a description of the study and the objectives/ground rules for the session, there were brief presentations on the state of driver education in the United States (the material in Section 2 of this report), research on driver education (Section 3 of this report), and teaching practices for teens (Section 4 of this report). Next the panel discussed and critically reviewed a hypothetical sequence for an integrated education and training system encompassing driver education and GDL.

The hypothetical sequence served both as stimulus material for the panel session and as a starting point for discussion. The sequence was prepared by the project staff as one reasonable approach that could be supported by the literature reviews and other data collection conducted during this study. It was not altered much by the panel to reach their recommended approach to a new, integrated system encompassing driver education and GDL. The hypothetical sequence was presented on a series of wall charts, the components of which were contained on "sticky notes." This permitted the participants to reorder things quickly as the discussion proceeded and to add functions or comments easily. A video camera was kept running and aimed at the wall charts to capture any changes made. The audio track of the video was used to record the conversation for later review if necessary.

\subsection{The Resulting Sequence}

There appears to be general agreement among safety researchers that in order to achieve its full safety potential, the education and training of new drivers should focus on those aspects of the driving task that are linked to the risk of a crash. In essence, what is needed is a comprehensive driver education system that encompasses driver education and the GDL process and expands it meaningfully in both scope and breadth.

The hypothetical sequence consists of 3 phases related to driver licensing in which driver education could potentially play a role-Pre-licensing, GDL licensing and post-licensing (after receipt of unrestricted license). Only the first 2 phases fall within the scope of the current project since it is focused on younger, first-time teen drivers and reducing crashes in the first 6 months of unsupervised driving for these young drivers. Any post-licensing training would focus on older teen drivers who have been driving unsupervised for some time under most current GDL laws.

As shown in Figure 2, the hypothetical sequence enumerates components in the pre-licensing and GDL licensing phases. The purpose of the sequence is to define which components might be beneficial in each phase of the driver licensing process to improve teen driver safety based on an interpretation of the relevant literature and the expert inputs of the panel. It was not the task of the present study to provide design details for each component (e.g., hours required, specific 
technologies), nor to determine how components that require a change in laws or regulations might be enacted. The discussion below includes an initial assessment of the readiness of each component in the pre-licensing and GDL licensing phases.

\subsubsection{Pre-licensing Phase}

Within the developed sequence, pre-licensing refers to education and training activities that take place before a teen enters the GDL process. Many States that require driver education currently stipulate that a driver education course be taken before the teen can apply for a learner's permit. These standard driver education courses are usually taken in the 9th or 10th grade when the teen is 14 to 16 years old. The hypothetical sequence assumes that pre-licensing education should be more encompassing and divides the pre-licensing activities into two stages that cover primary education and preparatory education.

Primary Education. The primary education stage of the pre-licensing phase should start much earlier in a driver's learning career than does traditional driver education. The panel considered it best to begin the primary education stage as early as possible (kindergarten) and to continue it through 8th grade. Children in this age range can pay attention to instruction and can apply concepts learned but have yet to be unduly influenced by the driving habits of their parents or peers.

The goals during the primary period would be to provide an improved foundation for learning safe driving skills and to impart specific information and skills as appropriate. Instruction should focus on the role of the passenger and on procedures, knowledge, and skills that enhance safe driving. Although children cannot drive at this age, they can learn and apply driving-related concepts as they watch the world from the passenger seat. Topics might include hazard identification, rules of the road (e.g., right of way), seat belt use, driver distraction, the importance of keeping one's eyes on the road when driving, conspicuity, and the impairing effects of alcohol and drug use. All these topics, and possibly many more, can be combined from the point of view of how the passenger can help or hinder the driver.

Instruction primarily would be in the school classroom, but could be taught by other methods (e.g., parents) if needed. Topics could be taught in conjunction with bicycle and pedestrian safety, possibly as part of Safe Routes to School or similar programs. The salient point is that there is ample bandwidth within the K-8 school curriculum to cover the important information and provide a solid underpinning for the specific driver training to follow.

Table 1 describes the readiness of the components of the primary education stage in order to provide an initial rough estimate of the development effort that would be required to implement the outlined approach. The categories in Table 1 and the similar tables that follow for the other stages are adapted from the approach used in Countermeasures That Work (NHTSA, 2009) and are explained in Figure 3 
Figure 2. One Approach for Developing a Sequence for a Driver Education System Encompassing Driver Education and GDL

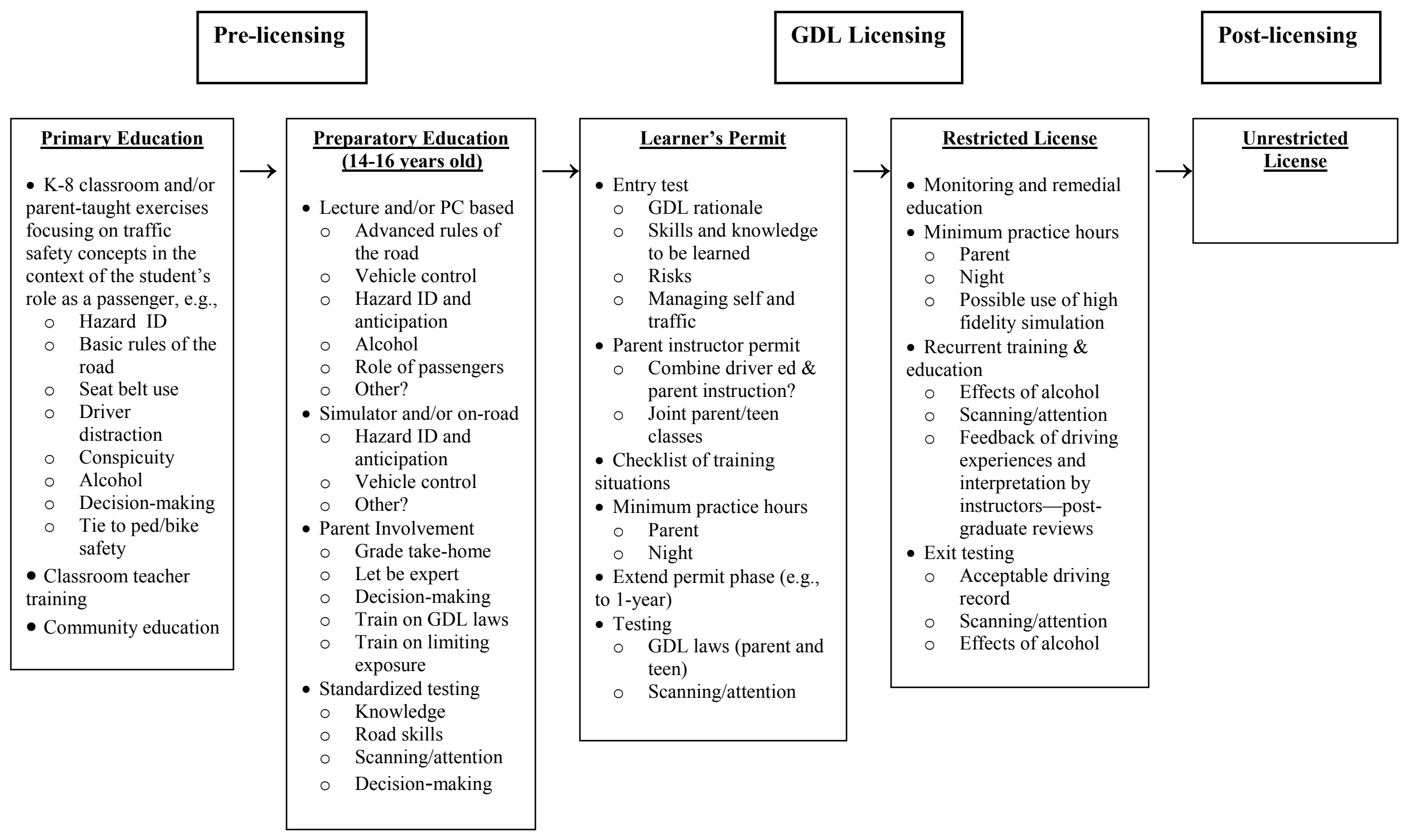




\begin{tabular}{|c|c|c|c|c|c|}
\hline Component & $\frac{\text { Evidence of }}{\underline{\text { Effectiveness }}}$ & $\underline{\text { Current Use }}$ & $\frac{\text { Cost to }}{\text { Develop and }}$ & $\begin{array}{l}\frac{\text { Time to }}{\text { Develop and }} \\
\text { Implement }\end{array}$ & $\underline{\text { Role }}$ \\
\hline $\begin{array}{l}\text { K-8 classroom and/or } \\
\text { parent-taught exercises } \\
\text { focusing on traffic safety } \\
\text { concepts in the context of } \\
\text { the student's role as a } \\
\text { passenger, e.g., } \\
\text { - Hazard ID } \\
\text { - Basic rules of the } \\
\text { road } \\
\text { - Seat belt use } \\
\text { - Driver } \\
\quad \text { Distraction } \\
\text { - Conspicuity } \\
\text { - Alcohol } \\
\text { - Decision-making }\end{array}$ & $\star \star \star$ & Low & Medium & Long & $\begin{array}{l}\text { Provides } \\
\text { improved } \\
\text { foundation for } \\
\text { later stages to } \\
\text { enhance their } \\
\text { effectiveness }\end{array}$ \\
\hline $\begin{array}{l}\text { Highway safety training } \\
\text { for classroom teachers }\end{array}$ & $\star$ & Low & Medium & Long & $\begin{array}{l}\text { Supports } \\
\text { effectiveness } \\
\text { of classroom } \\
\text { curricula }\end{array}$ \\
\hline $\begin{array}{l}\text { Community-based } \\
\text { education }\end{array}$ & $\star \star$ & High & High & Long & $\begin{array}{l}\text { Sensitize } \\
\text { populations } \\
\text { not directly } \\
\text { involved }\end{array}$ \\
\hline
\end{tabular}

Table 1. Primary Education Stage: Component Readiness 


\section{Figure 3. Key to Entries in Tables 1-4}

$\begin{array}{ll}\text { Evidence of Effectiveness (in terms of crash reduction) } \\ \star \star \star \star \star & \text { Demonstrated to be effective by several high-quality evaluations with consistent results } \\ \star \star \star \star & \text { Demonstrated to be effective in certain situations } \\ \star \star \star & \text { Likely to be effective based on balance of evidence from high quality evaluations or other sources } \\ \star \star & \text { Effectiveness still undetermined; different implementation methods produce different results } \\ \star & \text { Limited or no high-quality evaluation evidence }\end{array}$

Current Use in the United States

\begin{tabular}{ll}
\hline High & More than two-thirds of the States, or a substantial majority of communities \\
Medium & Between one-third and two-thirds of States or communities \\
Low & Fewer than one-third of the States or communities
\end{tabular}

\section{Cost to Develop and Implement}

High Requires extensive new facilities, staff, equipment, or publicity, or makes heavy demands on current resources

Medium Requires some additional staff time, equipment, facilities, and/or publicity

Low Can be accomplished with current resources and staff, perhaps with training; limited costs for new equipment or facilities

Time to Develop and Implement

\begin{tabular}{ll}
\hline Long & More than one year \\
Medium & More than three months but less than one year \\
Short & Three months or less
\end{tabular}

(Adapted from the classification categories used in Countermeasures That Work: A Highway Safety Countermeasure Guide for State Highway Safety Offices, Fourth Edition, NHTSA, 2009)

Preparatory Education. This stage of the proposed DES flow is equivalent to current driver education practices, although the hypothetical sequence adds several components that may

Preparatory Education. This stage of the proposed flow is equivalent to current driver education practices, although the hypothetical sequence adds several components that may require more time on and off the road. Some of the components might be integrated into GDL licensing requirements through law changes whether or not they remain in this phase. The important distinction between this stage and the primary education stage is that it specifically focuses on driving and the licensing requirements.

Classroom lectures might cover more advanced concepts included in the vehicle and traffic laws, vehicle control and handling skills, hazard identification or anticipation, including scanning techniques, attention maintenance, alcohol effects, and the role (both positive and negative) of passengers. These lectures could be accompanied by PC or Web-based training.

On-road and simulator training could be included in this stage so that students can apply concepts and improve specific skills. These training periods would train more than the vehicle handling skills needed to pass a road test. Specific emphasis can profitably be placed on applying higher order cognitive skills such as hazard identification and attention maintenance in simulated and real-world environments. Eye-tracking equipment that provides feedback on students' performance might be beneficial for on-road and simulator training. 
Parental involvement and understanding also appear to be important at this stage. Parents need to know and understand what their children are learning and need to be actively involved in at least some portion of the education process. The panel was adamant that parents cannot be expected to deduce the correct behaviors and skills to promote with their children. Parents are unlikely to be knowledgeable of the details of GDL laws and the best techniques for teaching and practicing decision-making and attention maintenance.

Some specific ways in which parents might get involved include "grading" take-home exercises that the student must then return to school (parents would need the answers so they are the "experts") or the use of joint Internet courses for parents and teens that require verification of completion.

In order to fulfill their roles in the preparatory education stage, parents will require some specific training that may have to be mandated as part of the GDL laws. In addition to the specifics of the licensing laws, candidate topics include alcohol and drugs, vehicle control, attention maintenance, and hazard recognition. One specific topic that the panel believed to be important for parents was the need for and the techniques to limit and control driving exposure, particularly under hazardous conditions.

The consensus of the panel was that an effective education and licensing sequence must include mandatory activities and/or testing of students and parents if it is to be successful. Some level of knowledge testing would be included in primary education as part of normal school procedures. The first standardized written and road tests would not take place until the end of the preparatory education stage. These tests might be more in-depth than the current tests administered by State licensing authorities. For example, students might have to demonstrate both knowledge and skill (e.g., vehicle control, higher order cognitive skills) to pass the tests. The tests could be administered by driving instructors, "roving" examiners, or a State testing facility. Scanning, attention, and decision-making testing might be performed via a PC-based test or on a simulator with eye tracking equipment.

Another step that the panel strongly believed was necessary involved a test of knowledge of the GDL laws for both the novice driver and his/her parents. Existing GDL laws, as discussed earlier, tend to be somewhat complex and unintuitive. Novice drivers must understand them in order to comply with their provisions. Parents, as the primary regulators of teen activities, must also understand the GDL laws and their rationale so that they can adequately fulfill their oversight role.

The readiness of the components in the preparatory education stage is presented in Table 2 . 


\begin{tabular}{|c|c|c|c|c|c|}
\hline Component & $\frac{\text { Evidence of }}{\underline{\text { Effectiveness }}}$ & $\underline{\text { Current Use }}$ & $\begin{array}{c}\text { Cost to } \\
\text { Develop and } \\
\text { Implement }\end{array}$ & $\begin{array}{c}\text { Time to } \\
\text { Develop and } \\
\text { Implement }\end{array}$ & Role \\
\hline $\begin{array}{cl}\text { Expanded lecture and/or } \\
\text { PC-based education, e.g., } \\
\text { - } & \text { Advanced rules of } \\
& \text { the road } \\
\text { - } & \text { Vehicle control } \\
\text { - } & \text { Hazard ID and } \\
& \text { anticipation } \\
\text { - } & \text { Alcohol } \\
\text { - } & \text { Role of passengers }\end{array}$ & $\overline{t \star \star}$ & Low & Medium & Long & $\begin{array}{l}\text { Adds topics } \\
\text { that research } \\
\text { has linked to } \\
\text { crash } \\
\text { occurrence }\end{array}$ \\
\hline $\begin{array}{c}\text { Additional on-road and } \\
\text { simulator training e.g., } \\
\qquad \quad \text { Hazard ID and } \\
\\
\quad \text { anticipation } \\
\bullet \quad \text { Vehicle control }\end{array}$ & $\star \star$ & Low & High & Long & $\begin{array}{l}\text { Broadens } \\
\text { existing on- } \\
\text { road } \\
\text { experience to } \\
\text { encompass } \\
\text { additional } \\
\text { topics }\end{array}$ \\
\hline 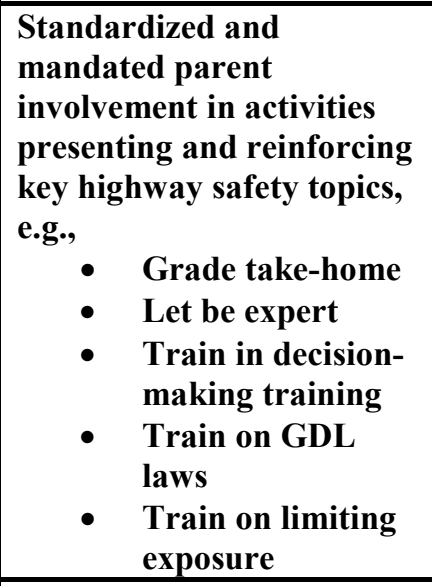 & $\star \star \star \star$ & $\overline{\text { Low }}$ & High & Long & $\begin{array}{l}\text { Creates a } \\
\text { qualified } \\
\text { "parent- } \\
\text { trainer" so that } \\
\text { parental } \\
\text { guidance is } \\
\text { more effective } \\
\text { and } \\
\text { standardized }\end{array}$ \\
\hline $\begin{array}{l}\text { Development and } \\
\text { integration of expanded } \\
\text { standardized testing in } \\
\text { relevant areas, e.g., } \\
\text { - Knowledge } \\
\text { - Road skills } \\
\text { - Scanning/attention } \\
\text { - Decision-making }\end{array}$ & $\star \star \star$ & Low & High & Long & $\begin{array}{l}\text { Improves } \\
\text { screening of } \\
\text { drivers before } \\
\text { they are } \\
\text { licensed }\end{array}$ \\
\hline
\end{tabular}

Table 2. Preparatory Education Stage: Component Readiness

\subsubsection{GDL Licensing Phase}

The next major phase in the licensing sequence involves GDL licensing. The GDL laws and regulations dictate the activities within this phase in each State. GDL systems generally use a 3step licensing process. With the issuance of a learner's permit, the teen driver cannot drive unless accompanied by a supervising adult with a specified amount of driving experience. After completing a required number of practice hours and after a specified duration, often 6 months, a teen can then apply for a restricted license. This license usually has passenger, nighttime driving, and electronic device use restrictions. Other restrictions related to seat belt use and 
alcohol use may also apply. After holding a restricted license for a specified amount of time or upon attaining a specified age, the teen can apply for an unrestricted license that is subject to the normal vehicle and traffic laws. In the sequence developed with the assistance of the panel, drivers complete almost all of the knowledge and skills training before entering the GDL licensing process. Education and training during the licensing stages would focus on applying the information, procedures and skills taught earlier on the open road.

Learner's Permit. In the hypothetical sequence, the learner's permit stage is a time of application of skills to a variety of traffic situations. Entry into the learner's permit stage would be controlled by one or more tests on which the teen applicant would have to demonstrate knowledge of:

- The GDL components and their rationale;

- The key skills he or she must learn while holding a learner's permit;

- The primary knowledge needed to drive safely including rules of the road as learned in the pre-licensing phase;

- The major risks facing a driver, particularly a novice driver;

- How to manage oneself (e.g., setting priorities, controlling emotions); and

- How to cope with or manage traffic.

Other testing included at this point might focus on higher order skills related to scanning and attention. Both parents and teens would be tested, and there could be a requirement that both must pass the GDL law test before the teen would be allowed a restricted license. Such testing would verify that both parents and teens are fully aware of the restrictions associated with a restricted license. The scanning/attention test could be performed via a PC-based test or on a simulator with eye tracking equipment. The test could be administered by either the driving school or the licensing authority. This would likely be the same or similar test battery under the same conditions as the tests conducted at the end of the pre-licensing phase. Scoring criteria might however, be different as skills should have improved. This testing could be accomplished by the licensing agency or by licensed private driving schools. The important point is that the entry test for a learner's permit should verify that the applicant has successfully learned the knowledge and skills intended to be instilled by the pre-licensing phase before permitting entry into the GDL licensing process.

Just as is currently the case in most States, the primary instructor in this stage would be a parent, although private instruction is always a possibility. In the proposed sequence, however, supervised driving would be distributed across both the learner's permit and restricted license stages whereas most current GDL programs only require supervised driving in the learner's permit stage. It is difficult for law enforcement to monitor GDL restrictions effectively. Enforcing an age-based restriction on carrying passengers or driving at night requires a police officer to make an accurate judgment of the age of an observed driver. Although use of new technology (e.g., an electronic restricted license that permits a police officer to know if a learner 
is driving) may simplify the law enforcement task, the reality is that the parents or guardians of novice drivers must shoulder much of the responsibility for enforcement of the GDL restrictions.

In order to prepare a parent for the instructional and supervisory responsibilities, some form of instructor training for the parent must be included. This training would cover, for example, the rationale for GDL and the basics of how to instruct a teen driver. One suggestion includes the notion of a "parent instructor permit" that a parent would be required to obtain in order for their child to drive with a learner's permit. This might require the parent to attend classes (with or without their child) and could include testing the parent's knowledge.

One of the potential issues with the learner's permit stage relates to the type of driving the novice driver gets to experience. The basic idea is to expose the new driver to a variety of situations (e.g., day, night, freeway) while under the supervision of the parent/instructor. Simply amassing hours on the road under relatively benign circumstances is not likely to bring the student to a sufficient level of competence to maximize safety. To prescribe the best mix of supervised driving practice, parents might be provided with a checklist of situations that the teen driver must complete. As part of the qualification process, the checklist would have to be signed and returned to the driver licensing authority to certify all of the situations and any time practice requirements were completed.

To be productive, the learner's permit stage would have to include a minimum number of practice hours with a parent. Nighttime practice with a parent should also be prescribed. This will build experience at night since most restricted licenses limit night driving. More experience, both day and night, might be amassed if the learner's permit stage were extended. This could be done by expanding the time a permit must be held before a restricted license can be issued (e.g., from 6 months to 9 months or a year) or by adding additional permit-like restrictions to the restricted license as discussed below. Table 3 shows the assessment of readiness of the components in the learner's permit stage.

Restricted License. A teen who successfully completed all of the precursor requirements set forth above would likely be well-educated and well-practiced in a variety of driving situations by the time he or she reached the restricted license stage of GDL. The one thing missing would be experience driving alone without the oversight of a parent or instructor. The restricted license stage is the period to gain additional driving experience and remedial education arising from the careful monitoring of the new driver.

Although the teen is allowed to drive alone as specified under current GDL restrictions, the proposed approach includes more requirements, limitations, and additional training than are typical of current GDL systems. In particular, the restricted license would include a requirement for a minimum number of practice hours day and night with a parent. This permits the parent to continue to supervise, instruct, and enforce the license restrictions. One suggestion was to transfer some of the practice hours to a high fidelity simulator if cost were not an issue.

Monitoring equipment may be effective in allowing parents or the licensing authority to monitor teens and provide feedback on how to improve driving skills. The feasibility of using such monitoring equipment on a large scale, however, is not known although several small trials have been conducted and are documented in the literature (compare to McGehee et al., 2007). Given 
the state-of-the-art, the panel was most comfortable with allocating the monitoring, feedback, and remedial education functions to parents.

\begin{tabular}{|c|c|c|c|c|c|}
\hline$\underline{\text { Component }}$ & $\frac{\text { Evidence of }}{\underline{\text { Effectiveness }}}$ & $\frac{\text { Current }}{\underline{\text { Use }}}$ & $\begin{array}{c}\frac{\text { Cost to }}{\text { Develop and }} \\
\text { Implement }\end{array}$ & 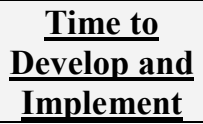 & Role \\
\hline $\begin{array}{l}\text { Expanded entry test to } \\
\text { determine if Primary and } \\
\text { Preparatory lessons were } \\
\text { learned, e.g., } \\
\begin{array}{l}\text { - } \\
\text { - }\end{array} \\
\quad \text { SkLills and knowledge } \\
\text { to be learned } \\
\text { - } \quad \text { Risks } \\
\quad \text { Managing self and } \\
\quad \text { traffic }\end{array}$ & $\star \star \star \star$ & Low & High & Long & $\begin{array}{l}\text { Ensures that } \\
\text { the candidate } \\
\text { has the } \\
\text { requisite } \\
\text { knowledge to } \\
\text { proceed to } \\
\text { through the } \\
\text { GDL process }\end{array}$ \\
\hline 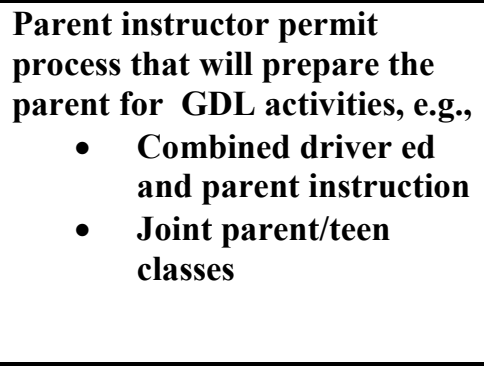 & $\star \star$ & Low & Medium & Medium & $\begin{array}{l}\text { Creates a } \\
\text { process to } \\
\text { verify that } \\
\text { the parent is a } \\
\text { qualified } \\
\text { member of } \\
\text { the } \\
\text { instructional } \\
\text { team }\end{array}$ \\
\hline $\begin{array}{l}\text { Checklist of training situations } \\
\text { to standardize application and } \\
\text { ensure sufficient breadth of } \\
\text { driving experiences }\end{array}$ & $\star$ & Low & Low & Short & $\begin{array}{l}\text { Standardizes } \\
\text { the practice } \\
\text { situations to } \\
\text { which } \\
\text { learners are } \\
\text { exposed }\end{array}$ \\
\hline $\begin{array}{l}\text { Minimum practice hours or } \\
\text { months specification for } \\
\text { driving with: } \\
\text { - Parent } \\
\text { - At night }\end{array}$ & $\star \star$ & Medium & Low & Long & $\begin{array}{l}\text { Prescribes an } \\
\text { adequate } \\
\text { amount of } \\
\text { supervised } \\
\text { driving } \\
\text { experience } \\
\text { under the } \\
\text { most } \\
\text { hazardous } \\
\text { conditions }\end{array}$ \\
\hline $\begin{array}{l}\text { Extend Permit Phase (e.g., one } \\
\text { year) }\end{array}$ & $\star \star \star \star$ & Low & Low & Long & $\begin{array}{l}\text { Extends the } \\
\text { restricted } \\
\text { driving } \\
\text { period to } \\
\text { build } \\
\text { experience }\end{array}$ \\
\hline $\begin{array}{l}\text { Additional testing, e.g., } \\
\text { • } \\
\text { GDL laws (parent and } \\
\text { teen) } \\
\text { • } \\
\text { Scanning/attention }\end{array}$ & $\star$ & Low & Medium & Long & $\begin{array}{l}\text { Ensures teen } \\
\text { and parent } \\
\text { are } \\
\text { adequately } \\
\text { prepared }\end{array}$ \\
\hline
\end{tabular}

Table 3. Learner's Permit Stage: Component Readiness 
The panel recommended providing parents with a checklist of driving skills and requiring them to assess their teen's ability to properly perform the skills. The panel also recommended examining ways to involve school professionals, such as health and physical education instructors, in the assessment process. The approach could involve both peer and expert feedback to teen drivers in a non-threatening, roundtable type of setting.

Recurrent training in the form of more class time, professional driving instruction, or Internet education regarding scanning techniques and alcohol education could be included. Adherence to and enforcement of GDL laws may be the best way to increase safety at this point.

Testing and performance criteria will determine if the novice driver is ready for an unrestricted license. First, as currently done in most States, the holder of a restricted license must have an acceptable driving record in terms of crashes and violations before receiving an unrestricted license. Some States require the teen to remain crash and citation free during this period before advancing to the next level. Second, it is believed beneficial to administer the scanning and attention test again at the end of the restricted license stage to ensure that teens are mastering and retaining these important skills. Testing about the effects of alcohol should be beneficial at this stage because the combination of teenage driving and alcohol use has been shown to be deadly. These tests could be administered by a driving school or the licensing authority. The component readiness for the Restricted License stage is shown in Table 4 below.

\begin{tabular}{|c|c|c|c|c|c|}
\hline Component & $\begin{array}{c}\text { Evidence of } \\
\text { Effectiveness } \\
\end{array}$ & Current Use & $\begin{array}{c}\frac{\text { Cost to }}{\text { Develop and }} \\
\text { Implement }\end{array}$ & $\begin{array}{c}\text { Time to } \\
\text { Develop and } \\
\text { Implement }\end{array}$ & $\underline{\text { Role }}$ \\
\hline $\begin{array}{l}\text { Increased monitoring, } \\
\text { e.g., of minimum practice } \\
\text { hours, and remedial } \\
\text { education: } \\
\text { - } \quad \text { Parent } \\
\text { - Night } \\
\text { - } \quad \text { Possible use of high } \\
\quad \text { fidelity simulation }\end{array}$ & $\overline{\star \star \star \star}$ & Low & Medium & Long & $\begin{array}{l}\text { Permits parent } \\
\text { to continue } \\
\text { supervision/ } \\
\text { Instruction and } \\
\text { to enforce } \\
\text { restrictions }\end{array}$ \\
\hline $\begin{array}{l}\text { Recurrent training and } \\
\text { education on key topics, } \\
\text { e.g., } \\
\text { - } \quad \text { Effects of alcohol } \\
\text { - Scanning/attention } \\
\text { - Feedback of driving } \\
\text { experiences and } \\
\text { interpretation by } \\
\text { instructors-post- } \\
\text { graduate reviews } \\
\end{array}$ & $\bar{\star}$ & Low & High & Long & $\begin{array}{l}\text { Reinforces the } \\
\text { entire process } \\
\text { before } \\
\text { restrictions are } \\
\text { removed }\end{array}$ \\
\hline $\begin{array}{l}\text { Comprehensive exit } \\
\text { testing to determine if } \\
\text { student is ready for an } \\
\text { unrestricted license, e.g., } \\
\text { - Acceptable driving } \\
\quad \text { record } \\
\text { - Scanning/attention } \\
\text { - Effects of alcohol }\end{array}$ & $\star \star$ & Low & High & Long & $\begin{array}{l}\text { Provides } \\
\text { additional } \\
\text { assurance that } \\
\text { the learner is } \\
\text { qualified to } \\
\text { have } \\
\text { restrictions } \\
\text { removed }\end{array}$ \\
\hline
\end{tabular}

Table 4. $\quad$ Restricted License Stage: Component Readiness 


\subsubsection{Post-licensing Phase}

Drivers at this stage of their driving lives, when they have full unrestricted licenses, typically have an improved safety record compared to those in the GDL licensing phase. Nevertheless, it is possible that additional restrictions at this point or a probationary period that must be completed without crashes or violations might have a safety benefit. Other sanctions such as alcohol zero tolerance laws for those under 21 have set a precedent for an extra focus on the immediate post-licensing group of drivers. Additional research would be needed to determine if retaining some restrictions in this phase is warranted. 


\section{DISCUSSION}

The primary goal of the present project was to assess the current state of driver's education in America, review the literature in driver training and education, examine the best educational practices for teaching adolescents, consider how well current driver education programs are integrated with graduated driver licensing system, and consider whether a new approach to driver education would be beneficial. The foregoing material provides extensive background upon which to base a decision with respect to this question.

\subsection{Driver Education and GDL}

Driver education has been the classic pre-license training in the United States for decades, most often as the ubiquitous "30 and 6" program-30 hours of classroom study and 6 hours BTW. GDL systems are more recent and have been shown to reduce crashes among young drivers by gradually introducing them to the risks of driving. States have enacted a variety of GDL requirements to guide new drivers through learning and restricted license periods leading up to a full unrestricted license.

Driver education as currently delivered focuses primarily on providing students with the knowledge and skills they need to pass State driver examinations, and is very successful in fulfilling that objective. Driver education was not initially intended as a comprehensive safe driving program. It promotes some level of safe driving by imparting the rules of the road and basic vehicle handling skills. It would be overly ambitious to assume that " 30 and 6" hours of instruction would be sufficient to prompt an inexperienced, immature adolescent to drive like a mature adult. Thus, the driver education curriculum as currently constituted does not require revision.

GDL has shown evidence of a significant safety benefit. The many variants of GDL, however, give rise to a question about which is the most effective way to proceed. GDL may benefit from greater parental involvement, but there is little or no information available to prepare parents for their demanding role as teacher, trainer, and enforcer and few requirements for parents to obtain or demonstrate the necessary capabilities. The opinion of the panel and a clear suggestion to be derived from the literature is that there is a likely safety benefit from involving parents earlier in the training process and better preparing them for the tasks they must take on.

Injury prevention work and the traffic safety literature suggest that an expanded driver training system that fully integrates driver education with GDL is the most promising approach to address young drivers. GDL systems should emphasize severe sanctions for non-compliance and encompass more stringent testing than is characteristic of current driver licensing practices.

\subsection{There a Need for a New Approach to Driver Education?}

A new standalone driver education curriculum does not appear to be warranted. The existing driver education programs, as disparate as they may be across the States, seem to be adequately accomplishing their goal of preparing novice drivers to pass the current licensing examinations. This conclusion, however, does not mean that there could not be a better approach to instilling safe driving practices in new teenage drivers or in administering the programs. The crash statistics point to a strong need for an improved approach and, particularly, one that can deal 
with the large overrepresentation in crashes and fatalities of drivers in their first 6 months of driving. There is significant research available, as shown earlier in this report, to assist current driver education practitioners in updating and improving current approaches. This type of continuous improvement can be accomplished cost-effectively as part of the normal update cycle of material and through various professional groups associated with driver training.

\subsection{A Starting Point for an Optimal Sequencing for Driver Training}

One objective was to examine the optimal sequencing for the presentation of safe driving skills in the classroom and behind-the-wheel training. The hypothetical sequence examined in the expert panel session represents only one example of what a comprehensive integrated driver education and graduated driver licensing system might entail. Even if there were widespread agreement that all of the elements in the proposed sequence were necessary and sufficient for the task, determining the most effective order has yet to be made, and many combinations are possible. The consensus of a panel of experts was that this approach is an excellent starting point for beginning the development of the content, delivery mechanisms, and legal/administrative framework that would be required.

\subsection{A Possible Expanded Driver Education System}

A reasonable conclusion from the present analysis is that an expanded driver education system may be beneficial. It would encompass existing driver education and go beyond it to better prepare drivers, parents, administrators, and others involved in the licensing process to deal with the root causes of crashes to newly licensed teenagers. Current research has shown that these causes stem not only from deficient skills and knowledge but also from attitudinal, social and societal issues that are best resolved together through a systematic process.

The components of an expanded driver education program coupled with GDL that came from the panel session are a good starting point for future development efforts. The sequence identifies reasonable elements and an overall concept supported by current literature and the analyses conducted as part of the present study. It is suggested that those components of the sequence with the highest uncertainty and longest development times be examined first and in the greatest depth. The extent and nature of these uncertainties should dictate which technical specialties (e.g., traffic safety, motor vehicle administration, education, sociology) should take the lead in examining a particular component.

Developing an effective and expanded driver education and licensing program will be a task that involves multiple disciplines and diverse political factions. The first step in the process might involve a feasibility assessment of the sequence in which the readiness levels - technical, administrative, and political — of each element are completely assessed. It would be beneficial to derive specific research questions for each element as part of this feasibility assessment. These could be used to focus research on the most salient issues needed to either qualify an element for inclusion or to determine what additional enabling research and development was necessary to make the element viable. Another benefit to this approach is that it is incremental and does not require the commitment of a large quantity of resources at once.

In summary, an expanded driver education and training approach, integrated with comprehensive GDL systems, may be a promising approach to address the problems of young novice drivers. 


\section{REFERENCES}

Aaron, J. E., \& Strasser, M. K. (1977). Driver and traffic safety education (2nd ed.): New York: MacMillan Publishing, Inc.

Aizenberg, R., \& McKenzie, D. M. (1997). Teen and senior drivers. (CAL-DMV-RSS-97-168). Sacramento: California Department of Motor Vehicles.

Allen, R. W., Park, G. D., Cook, M. L., \& Fiorentino, D. (2007). The effect of driving simulator fidelity on training effectiveness. Proceedings of DSC 2007 North America. Iowa City: University of Iowa.

Allen, R. W., Park, G. D., Cook, M. L., Fiorentino, D., \& Viirre, E. (2003b, November). Experience with a low-cost, PC-based system for young driver training. Proceedings of the First International Conference on Driver Behaviour and Training. Stratford-uponAvon, U.K.

Allen, R. W., Park, G. D., Cook, M. L., \& Viirre, E. (2003a). Novice driver training results and experience with a PC-based simulator. Proceedings of the 2nd International Driving Symposium on Human Factors in Driver Assessment, Training and Vehicle Design. Park City, Utah.

Bartz, T. (2007). Sex education in multicultural Norway. Sex Education, 7(1), 17-33.

Bishop, J., Quinlan, K., Roeber, D., \& Van Etten, G. (2005). Driver education and training forum. Journal of Accident Investigation, 1(1), 36-43.

Boerm, M., Gingiss, P., \& Roberts-Gray, C. (2007). Association of the presence of state and district health education policies with school tobacco prevention program practices. Journal of School Health, 77(4), 207-217.

Budd, G. M., \& Volpe, S. L. (2006). School-based obesity prevention: research, challenges, and recommendations. Journal of School Health, 76(10), 485-495.

Burd, L., Deal, E., Burd, C., Klug, M. G., Dickerson, J., York, B. E., et al. (2006). Results of a feasibility evaluation of the Short Story of Life Smoking Education and Prevention Program in public schools. Journal of Developmental and Physical Disabilities, 18(4), 401-417.

Butler, G. T. (1982). Effectiveness and efficiency in driver education programs. Washington, DC: National Highway Traffic Safety Administration.

Centers for Disease Control and Prevention. (2007). Overweight and Obesity. www.cdc.gov/nccdphp/dnpa/obesity/index.htm. Retrieved November 2, 2007. 
Chan, E., Pradhan, A. K., Knodeler, M. A., Pollatsek, A., \& Fisher, D. L. (2008). Empiricial evaluation on a driving simulator of the effect of distractions inside and outside the vehicle on drivers' eye behaviors. Proceedings of the 87th Transportation Research Board Annual Meeting.( CD-ROM.) Washington, DC: Transportation Research Board.

Chapman, P., Underwood, G., \& Roberts, K. (2002). Visual search patterns in trained and untrained novice drivers. Transportation Research Part F: Traffic Psychology and Behaviour, 5(2), 157-167.

Chapman, P. R., \& Underwood, G. (1998). Visual search of driving situations: Danger and experience. Perception, 27(8), 951-964.

Clinton, K., \& Lonero, L. (2006). Evaluation of Driver Education: Comprehensive Guidelines. Washington, DC: AAA Foundation for Traffic Safety.

Crundall, D., \& Underwood, G. (1998). Effects of experience and processing demand on visual information acquisition in drivers. Ergonomics, 41, 448-458.

Denny, G., \& Young, M. (2006). An Evaluation of an Abstinence-Only Sex Education Curriculum: An 18-Month Follow-up. Journal of School Health, 76(8), 414-422.

Diete, F. (2007). Evaluation of a simulator based, novice driver risk awareness training program. A master's thesis submitted to the Graduate School of the University of Massachusetts at Amherst. Amherst, MA: Department of Mechanical and Industrial Engineering.

Eaton, D. K., Kann, L., Kinchen, S., Ross, J., Hawkins, J., Harris, W. A.,...Wechsler, H.. (2006). Youth Risk Behavior Surveillance: United States, 2005. (Surveillance Summaries, June 9, 2006, Vol. 55, No. SS-5.) Atlanta: Centers for Disease Control and Prevention. Available at http://www.cdc.gov/mmwr/pdf/ss/ss5505.pdf.

Engstrom, I., Gregersen, N. P., Hernetkoski, K., Keskinen, E., \& Nyberg, A. (2003). Young novice drivers, driver education and training. (Literature review, VTI-rapport 491A). Linköping, Sweden: Swedish National Road and Transport Research Institute.

Falkmer, T., \& Gregersen, N. P. (2003). The TRAINER project - The evaluation of a new simulator-based driver training methodology. . In: Dorn, L. (red.) Driver Behaviour and Training., Proceedings of the First International Conference on Driver Behaviour and Training, Stratford-upon-Avon, U.K., pp. 317-330.

Farmer, E., van Rooij, J., Riemersma, J., Jorna, P., \& Moraal, J. (1999). Handbook of SimulatorBased Training. Farnham, Surrey, U.K.: Ashgate Publishing, Ltd.

Fidler, W., \& Lambert, T. W. (2001). A prescription for health: a primary care based intervention to maintain the non-smoking status of young people. Tobacco Control, 10, 23-26.

Fischhoff, B., Parker, A. M., Bruine de Bruin, W. n., Downs, J., Palmgren, C., Dawes, R., et al. (2000). Teen expectations for significant life events. Public Opinion Quarterly, 64(2), 189-205. 
Fisher, D. L., Laurie, N. E., Glaser, R., Connerney, K., Pollatsek, A., Duffy, S. A., et al. (2002). The use of an advanced driving simulator to evaluate the effects of training and experience on drivers' behavior in risky traffic scenarios. Human Factors, 44, pp. 287302. Human Factors, 44, 287-302.

Fisher, D. L., Pollatsek, A., \& Pradhan, A. (2006). Can novice drivers be trained to scan for information that will reduce their likelihood of a crash? Injury Prevention, Volume 12 (Supplement 1, i25-i29).

Fisher, D. L., Pradhan, A. K., Pollatsek, A., \& Knodeler, M. A. J. (2007). Empirical evalution of hazard anticipation behaviors in the and on a driving simulator using an eye tracker. Proceedings of the 86th Transportation Research Board Annual Meeting (CD-ROM). Washington, DC: Transportation Research Board.

Friend, K., \& Levy, D. T. (2002). Reduction in smoking prevalence and cigarette consumption associated with mass media campaigns. Health Education Research, 17(1), 85-98.

Gingiss, P., Boerm, M., \& Roberts-Gray, C. (2006). Follow-up comparisons of intervention and comparison schools in a state tobacco prevention and control initiative. Journal of School Health, 76(3), 98-103.

Gortmaker, S. L., Peterson, K., Wiecha, J., Sobol, A. M., Dixit, S., Fox, M. K., et al. (1999). Reducing Obesity via a School-Based Interdisciplinary Intervention Among Youth Archives of Pediatrics and Adolescent Medicine, 153, 409-418.

Hansen, W. B., Johnson, C., Flay, B., Graham, J., \& Sobel, J. (1988). Affective and Social Influences approaches to the prevention of multiple substance use among seventh grade students: Results from Project Smart. Preventive Medicine, 17, 135-144.

Harthun, M. L., Drapeau, A. E., Dustman, P. A., \& Marsiglia, F. F. (2002). Implementing a prevention curriculum: An effective researcher-teacher partnership. Education and Urban Society, 34(3), 353-363.

Hatakka, M., Keskinen, E., Hernetkoski, K., Gregersen, N.P., \& Glad, A. (2003). Goals and contents of driver education. In L. Dorn (Ed.), Driver Behaviour and Training Proceedings of the First International Conference on Driver Behaviour and Training, (pp. 309-315). Stratford-upon-Avon, U.K.: Ashgate.

Hedlund, J., Shults, R. A., \& Compton, R. (2006). Graduated driver licensing and teenage driver research in 2006. Journal of Safety Research, 37(2), 107-121.

Henderson, M., Wight, D., Raab, G. M., Abraham, C., Parkes, A., Scott, S., et al. (2007). Impact of a theoretically based sex education programme (SHARE) delivered by teachers on NHS registered conceptions and terminations: Final results of cluster randomised trial. BMJ: British Medical Journal, 334(7585). 
Hovell, M. F., Adams, J. A., \& Adams, M. A. (2001). The feasibility and efficacy of tobacco use prevention in orthodontics. Journal of Dental Education, 65, 348-353.

Hovell, M. F., Slymen, D. J., Jones, J. A., Hofstetter, C. R., Burkham-Kreitner, S., \& Conway, T. (1996). An adolescent tobacco-use prevention trial in orthodontic offices. American Journal of Public Health, 86, 191-215.

Insurance Institute for Highway Safety. (2008). Beginning Teenage Drivers. (Brochure). Arlington, VA. Retrieved January 2, 2008 from www.iihs.org/brochures/pdf/beginning_drivers.pdf

Kentala, J., Utriainen, P., Pahkala, K., \& Mattila, K. (1999). Can brief intervention through community dental care have an effect on adolescent smoking? Preventive Medicine, 29, 107-111.

Klauer, S. G., Dingus, T. A., Neale, V. L., Sudweeks, J. D., \& Ramsey, D. J. (2006, April). The Impact of Driver Inattention On Near-Crash/Crash Risk: An Analysis Using the 100-Car Naturalistic Driving Study Data. (Report No. DOT HS 810 594.) Washington, DC: National Highway Traffic Safety Administration. Available at www.nhtsa.gov/DOT/NHTSA/NRD/Multimedia/PDFs/Crash\%20Avoidance/2006/Driver Inattention.pdf.

Korteling, J. E., Helsdingen, A., and Baeyer, A. v. (2000). Handbook of Low-Cost Simulators. (PowerPoint Technical Report WP5.g, ELSTAR, EUCLID RTP 11.8). Available at http://www.army.forces.gc.ca/tswg/meetings/2000-

01_Netherlands_DenHaag/Presentations/Ser\%2026\%20Seminar\%20Netherlands\%20ELSTAR\% 20다 $\% 20 \operatorname{Cost} \% 20$ Simulation.pdf.

Krowchuk, H. V. (2005). Effectiveness of Adolescent Smoking Prevention Strategies. American Journal of Maternal Child Nursing, 30(6), 366-371.

Lonero, L., Clinton, K. M., Laurie, I., Black, D., Brock, J., \& Wilde, G. (1995). Novice driver education model curriculum outline. Washington, DC: AAA Foundation for Traffic Safety.

Magarey, A. M., Daniels, L. A., Boulton, T. J., \& Cockington, R. A. (2003). Predicting obesity in early adulthood from childhood and parental obesity. International Journal of Obesity \& Related Metabolic Disorders, 27(4), 505.

Mayhew, D. R., \& Simpson, H. M. (1995). The role of driving experience: Implications for the training and licensing of new drivers. Toronto, Ontario: Insurance Bureau of Canada.

Mayhew, D. R., \& Simpson, H. M. (1996). Effectiveness and role of driver education and training in a graduated licensing system. Ottawa, Ontario: Traffic Injury Research Foundation.

Mayhew, D. R., \& Simpson, H. M. (2002). The Safety Value of Driver Education and Training. Injury Prevention, 8 (Supplement II), ii3-ii8. 
Mayhew, D. R., Simpson, H. M., \& Pak, A. (2003). Changes in collision rates among novice drivers during the first months of driving. Accident Analysis and Prevention,, 35, 683691.

McGehee, D. V., Raby, M., Carney, C., Lee, J. D., \& Reyes, M. L. (2007). Extending parental mentoring using an event-triggered video intervention in rural teen drivers. Journal of Safety Research, 38(2), 215-227.

McKnight, A. J. (1985). Driver education - When? In: D.R. Mayhew, H.M. Simpson and A.C. Donelson, Editors, Young driver accidents: In search of solutions. Proceedings of an international symposium, Traffic Injury Research Foundation, Ottawa, Ontario (1985), pp. 109-115.

McKnight, A. J., \& McKnight, S. A. (2003). Young novice drivers: Careless or clueless. Accident Analysis and Prevention, 35, 921-925.

Mourant, R. R., \& Rockwell, T. R. (1972). Strategies of visual search by novice drivers and experienced drivers. Human Factors, 14, 325-335.

NHTSA. (2009). Countermeasures That Work: A Highway Safety Countermeasure Guide for State Highway Safety Offices, Fourth Edition. Washington, DC: National Highway Traffic Safety Administration. Available at http://ntl.bts.gov/lib/30000/30500/30532/811081.pdf.

NHTSA. (1994, May 31). Research agenda for an improved novice driver education program. (Report to Congress, Report No. DOT HS 808 161). Washington, DC: National Highway Traffic Safety Administration. Available at www.nhtsa.gov/people/injury/research/pub/drive-ed.pdf.

Nichols, J. L. (2003). A review of the history and effectiveness of driver education and training as a traffic safety program. Washington, DC: National Transporation Safety Board.

Park, G. D., Cook, M. L., Allen, R. W., \& Fiorentino, D. (2006). Automated assessment and training of novice drivers. Advances in Transportation Studies an International Journal,(Special Issue), pp. 87-96, University of Roma Tre (Italy).

Pashler, H., Bain, P., Bottge, B., Graesser, A., Koedinger, K., McDaniel, M., et al. (2007, September). Organizing Instruction and Study to Improve Student Learning: IES Practice Guide. Washington, DC: National Center for Education Research, Department of Education. Available at www.columbia.edu/cu/psychology/metcalfe/PDFs/IES\%20Manual\%202007.pdf.

Pollatsek, A., Fisher, D. L., \& Pradhan, A. K. (2006). Identifying and remediating failures of selective attention in younger drivers. Current Directions in Psychological Science, 15, 255-259. 
Pollatsek, A., Narayanaan, V., Pradhan, A., \& Fisher, D. L. (2006). The use of eye movements to evaluate the effect of PC-based risk awareness training on an advanced driving simulator. Human Factors, 48, 447-464.

Pradhan, A. K., Hammel, K. R., DeRamus, R., Pollatsek, A., Noyce, D. A., \& Fisher, D. L. (2005). The use of eye movements to evaluate the effect of PC-based risk awareness training on an advanced driving simulator. Human Factors, 47, 840-852.

Regan, M. A., Triggs, T. J., \& Godley, S. T. (2000). Simulator-based evaluation of the DriveSmart novice driver.(CD-ROM). Paper presented at the Proceedings of the Road Safety Research, Policing and Education Conference. Brisbane, Australia.

Regan, M. A., Triggs, T. J., \& Wallace, P. R. (1999). A CD-ROM product for enhancing perceptual and cognitive skills in novice car drivers. Proceedings of the 1st Interational Conference on Novice Driver Issues.

Ringwalt, C. L., Greene, J. M., Ennett, S. T., Iachan, R., Clayton, R. R., \& Leukefeld, C. G. (1994). Past and future directions of the D.A.R.E. program: An evaluation review (Draft Final Report). Research Triangle Park, NC: Research Triangle Institute.

Roberts, I., Kwan, I., \& Reviewers, C. I. G. D. E. (2002). School-based driver education for the prevention of traffic crashes. The Cochrane Library, Issue 1, Oxford, England.

Robinson, T. N. (1999). Reducing children's television viewing to prevent obesity: A randomized controlled trial. JAMA: Journal of the American Medical Association, 282(16), 1561-1567.

Sagberg, F., \& Bjørnskau, T. (2006). Accident Analysis \& Prevention. Hazard perception and driving experience among novice drivers., 3, 407-414.

Simons-Morton, B. G., Hartos, J. L., Leaf, W. A., \& Preusser, D. F. (2006). The effects of the checkpoints program on parent-imposed driving limits and crash outcomes among Connecticut novice teen drivers at 6-months post-licensure. Journal of Safety Research, 37(1), 9-15.

Sims, J. H., Meurer, J. R., Sims, M., \& Layde, R. (2004). Factors associated with physician interventions to address adolescent smoking. HSR: Health Services Research, 39, $571-$ 585.

Skara, S., \& Sussman, S. (2003). A review of 25 long-term adolescent tobacco and other drug use prevention program evaluations. Preventive Medicine, 37(5), 451-474.

Smith, T. J., Smith, K. U., \& Salvendy, G. (1987). Feedback-control mechanisms of human behavior. In Handbook of human factors. (pp. 251-293). Oxford, England: John Wiley \& Sons. 
Snowden, A., \& Stead, L. (2003). Community interventions for preventing smoking in young people. Cochrane Database of Systematic Reviews (1), Art. No. CD001291. DOI: 001210.001002/14651858.CD14001291.

Stevens, M. M., Olson, A. L., Gaffney, C. A., Tosteson, T. D., Mott, L. A., \& Starr, P. (2002). A pediatric, practice-based, randomized trial of drinking and smoking prevention and bicycle helmet, gun, and seatbelt safety promotion. Pediatrics, 109, 490-497.

Stice, E., Shaw, H., \& Marti, N. (2006). A meta-analytic review of obesity prevention programs for children and adolescents: The skinny on interventions that work. Psychological Bulletin, 132(5), 667-691.

Stock, J. R., Weaver, J. K., Ray, H. W., Brink, J. R., \& Sadof, M. G. (1983). Evaluation of safe performance secondary school driver education curriculum demonstration project. Washington, D.C: National Highway Traffic and Safety Administration.

Thomas, R., \& Perera, R. (2002). School-based programmes for preventing smoking. Cochrane Database of Systematic Reviews (4), Art. No.: CD001293. DOI: 001210.001002/14651858.CD14001293.pub14651852.

TRAINER. (2002). Deliverable 5.1: TRAINER assessment criteria and methodology. URL: http://ec.europa.eu/transport/roadsafety/publications/projectfiles/trainer_en.htm Accessed February 1, 2008

Tobler, N. S. (1986). Meta-analysis of 143 adolescent drug prevention programs: Quantitative outcome results of program participants compared to a control or comparison group. Journal of Drug Issues, 16, 537-567.

Underwood, G., Chapman, P., Brocklehurst, N., Underwood, J., \& Crundall, D. (2003). Visual attention while driving: Sequences of eye fixations made by experienced and novice drivers. Ergonomics, 46(6), 629-646.

Vernick, J. D., Li, G., Ogaitis, S., MacKenzie, E. J., Baker, S. P., \& Gielen, A. C. (1999). Effects of high school driver education on motor vehicle crashes, violations, and licensure. American Journal of Preventive Medicine, 1S, 16.

Vlakveld, W. (2006). Will simulator training in basic driver education to help enhance road safety? Proceedings of the HUMAN Centred Design for Information Socoety Technologies, Task Force G: Workshop, organized by UPM, European Guidelines for the Application of New Technologies for Driver Training and Education.

Vlakveld, W. P., \& Twisk, D. A. M. (2005). Young, novice motorists, their crash rates, and measures to reduce them: A literature study. Leidschendam, the Netherlands: SWOV.

Wight, D., \& Dixon, H. (2004). SHARE - Sexual Health And RElationships: Safe, Happy And REsponsible. Education and Health, 22(1), 3-7. 
Wikman, A., Nieminen, T., \& Summala, H. (1998). Driving experience and time-sharing during in-car tasks on roads of different width. Ergonomics, 41(3), 358-372.

Williams, A. F. (2003). Teenage drivers: patterns of risk. Journal of Safety Research, 34(3), 515.

Williams, A. F., Preusser, D. F., Ferguson, S. A., \& Ulmer, R. G. (1997). Analysis of the fatal crash involvements of 15-year-old drivers. Journal of Safety Research, 28(1), 49-54.

Willis, D. K. (1998). The impetus for the development of a new risk management training program for teen drivers. In Proceedings of the Human Factors and Ergonomics Society 42nd Annual Meeting (pp. 1394-1395). Santa Monica, CA: Human Factors and Ergonomics Society.

Woolley, J. (2000). In car driver training at high schools: a literature review. Walkerville, South Australia: Safety Strategy, Transport SA. 
Appendix 
Table 1. The role of driver education in the GDL process for first-time teen drivers

\begin{tabular}{|c|c|c|c|c|c|c|c|c|c|c|c|}
\hline & $\begin{array}{l}\text { Driver } \\
\text { education } \\
\text { required if } \\
\text { under age } \\
18 ?\end{array}$ & $\begin{array}{l}\text { Other } \\
\text { training } \\
\text { accepted or } \\
\text { required? }\end{array}$ & $\begin{array}{c}\text { Driver } \\
\text { education } \\
\text { lead to early } \\
\text { unrestricted } \\
\text { license? }\end{array}$ & $\begin{array}{c}\text { Age of first } \\
\text { unrestricted } \\
\text { license with } \\
\text { driver } \\
\text { education }\end{array}$ & $\begin{array}{l}\text { Age of first } \\
\text { unrestricted } \\
\text { license } \\
\text { without } \\
\text { driver } \\
\text { education }\end{array}$ & $\begin{array}{l}\text { Other benefit } \\
\text { if take driver } \\
\text { education }\end{array}$ & $\begin{array}{l}\text { Permit } \\
\text { min. age }\end{array}$ & $\begin{array}{l}\text { Practice } \\
\text { driving hours } \\
\text { requirement }\end{array}$ & $\begin{array}{c}\text { Intermediate } \\
\text { license min. } \\
\text { age }\end{array}$ & $\begin{array}{l}\text { Min. age } \\
\text { nighttime } \\
\text { restriction } \\
\text { removed }\end{array}$ & $\begin{array}{c}\text { Min. age } \\
\text { passenger } \\
\text { restriction } \\
\text { removed }\end{array}$ \\
\hline Alabama & No & No & No & 17 & 17 & $\begin{array}{l}\text { BTW practice } \\
\text { waived }\end{array}$ & 15 & 30 & 16 & 17 & 17 \\
\hline Alaska & No & No & No & $\begin{array}{c}16 \text { years } 6 \\
\text { months }\end{array}$ & $\begin{array}{c}16 \text { years } 6 \\
\text { months }\end{array}$ & None & 14 & $\begin{array}{l}40 \text { with } 10 \text { in } \\
\text { challenging } \\
\text { environment }\end{array}$ & 16 & $\begin{array}{c}16 \text { years } 6 \\
\text { months }\end{array}$ & $\begin{array}{c}16 \text { years } 6 \\
\text { months }\end{array}$ \\
\hline Arizona & No & No & No & 16 & 16 & $\begin{array}{l}\text { BTW practice } \\
\text { waived; BTW } \\
\text { portion of } \\
\text { driver test } \\
\text { waived }\end{array}$ & $\begin{array}{c}15 \text { years } 7 \\
\text { months }\end{array}$ & $\begin{array}{c}25 \text { with } 5 \text { at } \\
\text { night }\end{array}$ & 16 & $\begin{array}{c}\text { No } \\
\text { restriction }\end{array}$ & $\begin{array}{l}\text { No } \\
\text { restriction }\end{array}$ \\
\hline Arkansas & No & No & No & $\begin{array}{l}18 \text { years; } 16 \text { if } \\
\text { married, have } \\
\text { high school } \\
\text { diploma or } \\
\text { GED; military }\end{array}$ & $\begin{array}{l}18 \text { years; } 16 \\
\text { if married, } \\
\text { have high } \\
\text { school } \\
\text { diploma or } \\
\text { GED; } \\
\text { military }\end{array}$ & None & 14 & None & 16 & $\begin{array}{l}\text { No } \\
\text { restriction }\end{array}$ & $\begin{array}{l}\text { No } \\
\text { restriction }\end{array}$ \\
\hline California & Yes & No & No & 18 & 18 & None & $\begin{array}{c}15 \text { years } 6 \\
\text { months }\end{array}$ & $\begin{array}{c}50 \text { with } 10 \text { at } \\
\text { night }\end{array}$ & 16 & 17 & 17 \\
\hline Colorado & No & $\begin{array}{c}\text { 4-hour } \\
\text { driver } \\
\text { awareness } \\
\text { program }\end{array}$ & Yes & 17 & 18 & None & 15 & $\begin{array}{c}50 \text { with } 10 \text { at } \\
\text { night }\end{array}$ & 16 & 17 & 17 \\
\hline Connecticut & Yes & $\begin{array}{c}\text { 8-hour } \\
\text { course on } \\
\text { safe driving } \\
\end{array}$ & No & 18 & 18 & None & 16 & $\begin{array}{c}50 \text { with } 10 \text { at } \\
\text { night }\end{array}$ & $\begin{array}{l}16 \text { years } 4 \\
\text { months }\end{array}$ & 18 & 18 \\
\hline Delaware & Yes & No & Yes & 17 & 18 & None & 16 & $\begin{array}{c}50 \text { with } 10 \text { at } \\
\text { night }\end{array}$ & NA & 17 & 17 \\
\hline $\begin{array}{l}\text { District of } \\
\text { Columbia }\end{array}$ & No & No & No & 18 & 18 & None & 16 & 40 & $\begin{array}{c}16 \text { years } 6 \\
\text { months }\end{array}$ & 18 & 18 \\
\hline
\end{tabular}




\begin{tabular}{|c|c|c|c|c|c|c|c|c|c|c|c|}
\hline & $\begin{array}{c}\text { Driver } \\
\text { education } \\
\text { required if } \\
\text { under age } \\
18 ?\end{array}$ & $\begin{array}{l}\text { Other } \\
\text { training } \\
\text { accepted or } \\
\text { required? }\end{array}$ & $\begin{array}{c}\text { Driver } \\
\text { education } \\
\text { lead to early } \\
\text { unrestricted } \\
\text { license? }\end{array}$ & $\begin{array}{c}\text { Age of first } \\
\text { unrestricted } \\
\text { license with } \\
\text { driver } \\
\text { education }\end{array}$ & $\begin{array}{l}\text { Age of first } \\
\text { unrestricted } \\
\text { license } \\
\text { without } \\
\text { driver } \\
\text { education }\end{array}$ & $\begin{array}{l}\text { Other benefit } \\
\text { if take driver } \\
\text { education }\end{array}$ & $\begin{array}{l}\text { Permit } \\
\text { min. age }\end{array}$ & $\begin{array}{l}\text { Practice } \\
\text { driving hours } \\
\text { requirement }\end{array}$ & $\begin{array}{l}\text { Intermediate } \\
\text { license min. } \\
\text { age }\end{array}$ & $\begin{array}{l}\text { Min. age } \\
\text { nighttime } \\
\text { restriction } \\
\text { removed }\end{array}$ & $\begin{array}{c}\text { Min. age } \\
\text { passenger } \\
\text { restriction } \\
\text { removed }\end{array}$ \\
\hline Florida & No & $\begin{array}{l}\text { 4-hour } \\
\text { traffic law } \\
\text { and } \\
\text { substance } \\
\text { abuse } \\
\text { education } \\
\text { course }\end{array}$ & No & 18 & 18 & $\begin{array}{l}\text { Road test may } \\
\text { be waived if } \\
\text { took full } \\
\text { driver } \\
\text { education } \\
\text { course }\end{array}$ & 15 & $\begin{array}{c}50 \text { with } 10 \text { at } \\
\text { night }\end{array}$ & 16 & 18 & $\begin{array}{c}\text { No } \\
\text { restriction }\end{array}$ \\
\hline Georgia & No & $\begin{array}{l}\text { Georgia } \\
\text { Drug and } \\
\text { Alcohol } \\
\text { Awareness } \\
\text { Program }\end{array}$ & No & 18 & 18 & $\begin{array}{c}\text { Provisional } \\
\text { license at age } \\
16 \text { instead of } \\
17\end{array}$ & 15 & $\begin{array}{c}40 \text { with } 6 \text { at } \\
\text { night }\end{array}$ & 16 & 18 & 18 \\
\hline Hawaii & Yes & No & Yes & 17 & 18 & None & $\begin{array}{c}15 \text { years } 6 \\
\text { months }\end{array}$ & $\begin{array}{c}50 \text { with } 10 \text { at } \\
\text { night }\end{array}$ & 16 & 17 & 17 \\
\hline Idaho & No & No & Yes & 16 & 17 & None & $\begin{array}{c}14 \text { years } 6 \\
\text { months }\end{array}$ & $\begin{array}{c}50 \text { with } 10 \text { at } \\
\text { night }\end{array}$ & 15 & 16 & $\begin{array}{c}15 \text { years } 6 \\
\text { months }\end{array}$ \\
\hline Illinois & Yes & No & No & 18 & 18 & None & 15 & $\begin{array}{c}50 \text { with } 10 \text { at } \\
\text { night }\end{array}$ & 16 & 18 & 18 \\
\hline Indiana & No & No & No & 18 & 18 & $\begin{array}{l}\text { Permit at age } \\
15 \text { instead of } \\
16 \text {; Road test } \\
\text { waived; } \\
\text { Probationary } \\
\text { license at age } \\
16 \text { and } 30 \\
\text { days instead } \\
\text { of age } 16 \text { and } \\
180 \text { days }\end{array}$ & 15 & None & $\begin{array}{c}16 \text { years } 30 \\
\text { days }\end{array}$ & 18 & $\begin{array}{c}16 \text { years } 4 \\
\text { months }\end{array}$ \\
\hline
\end{tabular}




\begin{tabular}{|c|c|c|c|c|c|c|c|c|c|c|c|}
\hline & $\begin{array}{l}\text { Driver } \\
\text { education } \\
\text { required if } \\
\text { under age } \\
18 ?\end{array}$ & $\begin{array}{l}\text { Other } \\
\text { training } \\
\text { accepted or } \\
\text { required? }\end{array}$ & $\begin{array}{c}\text { Driver } \\
\text { education } \\
\text { lead to early } \\
\text { unrestricted } \\
\text { license? }\end{array}$ & $\begin{array}{c}\text { Age of first } \\
\text { unrestricted } \\
\text { license with } \\
\text { driver } \\
\text { education }\end{array}$ & $\begin{array}{l}\text { Age of first } \\
\text { unrestricted } \\
\text { license } \\
\text { without } \\
\text { driver } \\
\text { education }\end{array}$ & $\begin{array}{c}\text { Other benefit } \\
\text { if take driver } \\
\text { education }\end{array}$ & $\begin{array}{l}\text { Permit } \\
\text { min. age }\end{array}$ & $\begin{array}{l}\text { Practice } \\
\text { driving hours } \\
\text { requirement }\end{array}$ & $\begin{array}{c}\text { Intermediate } \\
\text { license min. } \\
\text { age }\end{array}$ & $\begin{array}{l}\text { Min. age } \\
\text { nighttime } \\
\text { restriction } \\
\text { removed }\end{array}$ & $\begin{array}{l}\text { Min. age } \\
\text { passenger } \\
\text { restriction } \\
\text { removed }\end{array}$ \\
\hline Iowa & Yes & No & Yes & 17 & 18 & None & 14 & $\begin{array}{l}20 \text { with } 2 \text { at } \\
\text { night with } \\
\text { permit; } 10 \\
\text { with } 2 \text { at night } \\
\text { with } \\
\text { intermediate } \\
\text { license }\end{array}$ & 16 & 17 & 17 \\
\hline Kansas & No & No & No & 16 & 16 & $\begin{array}{c}\text { Restricted } \\
\text { license at age } \\
15 \text { instead of } \\
16 \text {; Driving } \\
\text { test waived }\end{array}$ & 14 & $\begin{array}{c}50 \text { with } 10 \text { at } \\
\text { night }\end{array}$ & 15 & NA & 16 \\
\hline Kentucky & No & $\begin{array}{l}\text { 4-hour } \\
\text { graduated } \\
\text { licensing } \\
\text { course }\end{array}$ & Yes & 17 & 18 & None & 16 & $\begin{array}{c}60 \text { with } 10 \text { at } \\
\text { night }\end{array}$ & $\begin{array}{c}16 \text { years } 6 \\
\text { months }\end{array}$ & 17 & 17 \\
\hline Louisiana & No & $\begin{array}{l}\text { 6-hour pre- } \\
\text { licensing } \\
\text { course if } \\
\text { over age } 17\end{array}$ & Yes & 17 & $\begin{array}{l}\text { All first-time } \\
\text { drivers must } \\
\text { complete } \\
\text { driver } \\
\text { education or } \\
\text { pre-licensing } \\
\text { course }\end{array}$ & None & 15 & None & 16 & 17 & 17 \\
\hline Maine & Yes & No & Yes & $\begin{array}{c}16 \text { years } 180 \\
\text { days }\end{array}$ & 18 & None & 15 & $\begin{array}{l}35 \text { with } 5 \text { at } \\
\text { night }\end{array}$ & 16 & $\begin{array}{l}16 \text { years } \\
180 \text { days }\end{array}$ & $\begin{array}{c}16 \text { years } 180 \\
\text { days }\end{array}$ \\
\hline Maryland & Yes & No & Yes & $\begin{array}{c}17 \text { years } 9 \\
\text { months }\end{array}$ & $\begin{array}{l}\text { All first-time } \\
\text { drivers must } \\
\text { complete } \\
\text { driver } \\
\text { education } \\
\text { and GDL } \\
\text { process }\end{array}$ & None & $\begin{array}{c}15 \text { years } 9 \\
\text { months }\end{array}$ & $\begin{array}{c}60 \text { with } 10 \text { at } \\
\text { night }\end{array}$ & $\begin{array}{c}16 \text { years } 3 \\
\text { months }\end{array}$ & $\begin{array}{c}17 \text { years } 9 \\
\text { months }\end{array}$ & $\begin{array}{c}16 \text { years } 8 \\
\text { months }\end{array}$ \\
\hline Massachusetts & Yes & No & No & 18 & 18 & None & 16 & 40 & $\begin{array}{l}16 \text { years } 6 \\
\text { months }\end{array}$ & 18 & 17 \\
\hline
\end{tabular}




\begin{tabular}{|c|c|c|c|c|c|c|c|c|c|c|c|}
\hline & $\begin{array}{l}\text { Driver } \\
\text { education } \\
\text { required if } \\
\text { under age } \\
18 ?\end{array}$ & $\begin{array}{l}\text { Other } \\
\text { training } \\
\text { accepted or } \\
\text { required? }\end{array}$ & $\begin{array}{c}\text { Driver } \\
\text { education } \\
\text { lead to early } \\
\text { unrestricted } \\
\text { license? }\end{array}$ & $\begin{array}{c}\text { Age of first } \\
\text { unrestricted } \\
\text { license with } \\
\text { driver } \\
\text { education }\end{array}$ & $\begin{array}{l}\text { Age of first } \\
\text { unrestricted } \\
\text { license } \\
\text { without } \\
\text { driver } \\
\text { education }\end{array}$ & $\begin{array}{l}\text { Other benefit } \\
\text { if take driver } \\
\text { education }\end{array}$ & $\begin{array}{l}\text { Permit } \\
\text { min. age }\end{array}$ & $\begin{array}{c}\text { Practice } \\
\text { driving hours } \\
\text { requirement }\end{array}$ & $\begin{array}{c}\text { Intermediate } \\
\text { license min. } \\
\text { age }\end{array}$ & $\begin{array}{l}\text { Min. age } \\
\text { nighttime } \\
\text { restriction } \\
\text { removed }\end{array}$ & $\begin{array}{l}\text { Min. age } \\
\text { passenger } \\
\text { restriction } \\
\text { removed }\end{array}$ \\
\hline Michigan & Yes & No & Yes & 17 & 18 & None & $\begin{array}{c}14 \text { years } 9 \\
\text { months }\end{array}$ & $\begin{array}{c}50 \text { with } 10 \text { at } \\
\text { night }\end{array}$ & 16 & 17 & NA \\
\hline Minnesota & Yes & No & Yes & 17 & 18 & None & 15 & $\begin{array}{l}30 \text { with } 10 \text { at } \\
\text { night with } \\
\text { permit; } 10 \\
\text { with } \\
\text { provisional } \\
\text { license }\end{array}$ & 16 & NA & NA \\
\hline Mississippi & No & No & No & 16 & 16 & $\begin{array}{c}\text { Learner } \\
\text { permit at age } \\
14 \text { instead of } \\
15\end{array}$ & 14 & None & $\begin{array}{c}15 \text { years } 6 \\
\text { months }\end{array}$ & 16 & NA \\
\hline Missouri & No & No & No & 18 & 18 & None & 15 & $\begin{array}{c}40 \text { with } 10 \text { at } \\
\text { night }\end{array}$ & 16 & 18 & 18 \\
\hline Montana & No & No & Yes & 16 & $17-1 / 2$ & None & $\begin{array}{c}14 \text { years } 6 \\
\text { months }\end{array}$ & $\begin{array}{c}50 \text { with } 10 \text { at } \\
\text { night }\end{array}$ & 15 & 16 & 16 \\
\hline Nebraska & No & No & No & 17 & 17 & $\begin{array}{l}\text { Practice } \\
\text { driving } \\
\text { waived; } \\
\text { written and } \\
\text { road tests } \\
\text { waived }\end{array}$ & 14 & $\begin{array}{c}50 \text { with } 10 \text { at } \\
\text { night }\end{array}$ & 16 & 17 & $\begin{array}{c}16 \text { years } 6 \\
\text { months }\end{array}$ \\
\hline Nevada & $\begin{array}{c}\text { Yes } \\
\text { (Unless no } \\
\text { course } \\
\text { within } 30 \\
\text { miles and } \\
\text { have no } \\
\text { Internet } \\
\text { access) }\end{array}$ & No & No & 18 & 18 & $\begin{array}{l}\text { Only have to } \\
\text { complete } 50 \\
\text { hours of } \\
\text { practice } \\
\text { driving } \\
\text { instead of } 100 \\
\text { hours. }\end{array}$ & $\begin{array}{c}15 \text { years } 6 \\
\text { months }\end{array}$ & $\begin{array}{c}50 \text { with } 10 \text { at } \\
\text { night; } 100 \\
\text { with } 10 \text { at } \\
\text { night if no } \\
\text { driver } \\
\text { education }\end{array}$ & 16 & 18 & $\begin{array}{c}16 \text { years } 6 \\
\text { months }\end{array}$ \\
\hline New Hampshire & Yes & No & No & 18 & 18 & None & $\begin{array}{c}15 \text { years } 6 \\
\text { months }\end{array}$ & 20 & 16 & 18 & $\begin{array}{c}16 \text { years } 6 \\
\text { months }\end{array}$ \\
\hline New Jersey & No & No & Yes & 18 & 18.5 & None & 16 & None & 17 & 18 & 18 \\
\hline
\end{tabular}




\begin{tabular}{|c|c|c|c|c|c|c|c|c|c|c|c|}
\hline & $\begin{array}{c}\text { Driver } \\
\text { education } \\
\text { required if } \\
\text { under age } \\
18 ?\end{array}$ & $\begin{array}{l}\text { Other } \\
\text { training } \\
\text { accepted or } \\
\text { required? }\end{array}$ & $\begin{array}{c}\text { Driver } \\
\text { education } \\
\text { lead to early } \\
\text { unrestricted } \\
\text { license? }\end{array}$ & $\begin{array}{c}\text { Age of first } \\
\text { unrestricted } \\
\text { license with } \\
\text { driver } \\
\text { education }\end{array}$ & $\begin{array}{l}\text { Age of first } \\
\text { unrestricted } \\
\text { license } \\
\text { without } \\
\text { driver } \\
\text { education }\end{array}$ & $\begin{array}{l}\text { Other benefit } \\
\text { if take driver } \\
\text { education }\end{array}$ & $\begin{array}{l}\text { Permit } \\
\text { min. age }\end{array}$ & $\begin{array}{c}\text { Practice } \\
\text { driving hours } \\
\text { requirement }\end{array}$ & $\begin{array}{l}\text { Intermediate } \\
\text { license min. } \\
\text { age }\end{array}$ & $\begin{array}{l}\text { Min. age } \\
\text { nighttime } \\
\text { restriction } \\
\text { removed }\end{array}$ & $\begin{array}{c}\text { Min. age } \\
\text { passenger } \\
\text { restriction } \\
\text { removed }\end{array}$ \\
\hline New Mexico & Yes & No & Yes & $\begin{array}{c}16 \text { years and } 6 \\
\text { months }\end{array}$ & 18 & None & 15 & $\begin{array}{c}50 \text { with } 10 \text { at } \\
\text { night }\end{array}$ & $\begin{array}{c}15 \text { years } 6 \\
\text { months }\end{array}$ & $\begin{array}{l}16 \text { years } 6 \\
\text { months }\end{array}$ & $\begin{array}{c}16 \text { years } 6 \\
\text { months }\end{array}$ \\
\hline New York & No & $\begin{array}{l}\text { Pre- } \\
\text { licensing } \\
\text { course }\end{array}$ & Yes & 17 & 18 & $\begin{array}{l}\text { If age } 17 \text {, can } \\
\text { waive practice } \\
\text { driving } \\
\text { requirement }\end{array}$ & 16 & 20 & $\begin{array}{c}16 \text { years } 6 \\
\text { months }\end{array}$ & 17 & 17 \\
\hline North Carolina & Yes & No & No & 18 & 18 & None & 15 & None & $\begin{array}{l}16 \text { years for } \\
\text { Limited } \\
\text { Provisional } \\
\text { License; } 16 \\
\text { years } 6 \\
\text { months for } \\
\text { Full } \\
\text { Provisional } \\
\text { License }\end{array}$ & $\begin{array}{l}16 \text { years } 6 \\
\text { months }\end{array}$ & 18 \\
\hline North Dakota & No & No & No & 16 & 16 & $\begin{array}{l}\text { Required for } \\
\text { minor's } \\
\text { (restricted) } \\
\text { driver license }\end{array}$ & 14 & None & $\begin{array}{c}14 \text { years } 6 \\
\text { months }\end{array}$ & NA & 16 \\
\hline Ohio & Yes & No & No & 18 & 18 & None & $\begin{array}{c}15 \text { years } 6 \\
\text { months }\end{array}$ & $\begin{array}{c}50 \text { with } 10 \text { at } \\
\text { night }\end{array}$ & 16 & 18 & 17 \\
\hline Oklahoma & No & No & Yes & $\begin{array}{c}16 \text { years and } 6 \\
\text { months }\end{array}$ & $\begin{array}{c}17 \text { years } 6 \\
\text { months }\end{array}$ & None & $\begin{array}{c}15 \text { years } 6 \\
\text { months }\end{array}$ & $\begin{array}{c}40 \text { with } 10 \text { at } \\
\text { night }\end{array}$ & 16 & $\begin{array}{c}16 \text { years } 6 \\
\text { months }\end{array}$ & $\begin{array}{c}16 \text { years } 6 \\
\text { months }\end{array}$ \\
\hline Oregon & No & No & No & 17 & 17 & $\begin{array}{l}\text { Practice hours } \\
\text { reduced to } 50 \\
\text { hours from } \\
100 \text { hours }\end{array}$ & 15 & $\begin{array}{c}50 \text { with driver } \\
\text { education; } 100 \\
\text { without driver } \\
\text { education }\end{array}$ & 16 & 17 & 17 \\
\hline Pennsylvania & No & No & Yes & $\begin{array}{c}17 \text { years and } 6 \\
\text { months }\end{array}$ & 18 & None & 16 & 50 & $\begin{array}{c}16 \text { years } 6 \\
\text { months }\end{array}$ & $\begin{array}{c}17 \text { years } 6 \\
\text { months }\end{array}$ & $\begin{array}{c}17 \text { years } 6 \\
\text { months }\end{array}$ \\
\hline Rhode Island & Yes & No & Yes & $\begin{array}{l}17 \text { years and } 6 \\
\text { months }\end{array}$ & 18 & None & 16 & $\begin{array}{c}50 \text { with } 10 \text { at } \\
\text { night }\end{array}$ & $\begin{array}{c}16 \text { years } 6 \\
\text { months }\end{array}$ & $\begin{array}{l}17 \text { years } 6 \\
\text { months }\end{array}$ & $\begin{array}{c}17 \text { years } 6 \\
\text { months }\end{array}$ \\
\hline
\end{tabular}




\begin{tabular}{|c|c|c|c|c|c|c|c|c|c|c|c|}
\hline & $\begin{array}{l}\text { Driver } \\
\text { education } \\
\text { required if } \\
\text { under age } \\
18 ?\end{array}$ & $\begin{array}{l}\text { Other } \\
\text { training } \\
\text { accepted or } \\
\text { required? }\end{array}$ & $\begin{array}{c}\text { Driver } \\
\text { education } \\
\text { lead to early } \\
\text { unrestricted } \\
\text { license? }\end{array}$ & $\begin{array}{c}\text { Age of first } \\
\text { unrestricted } \\
\text { license with } \\
\text { driver } \\
\text { education }\end{array}$ & $\begin{array}{l}\text { Age of first } \\
\text { unrestricted } \\
\text { license } \\
\text { without } \\
\text { driver } \\
\text { education }\end{array}$ & $\begin{array}{l}\text { Other benefit } \\
\text { if take driver } \\
\text { education }\end{array}$ & $\begin{array}{l}\text { Permit } \\
\text { min. age }\end{array}$ & $\begin{array}{c}\text { Practice } \\
\text { driving hours } \\
\text { requirement }\end{array}$ & $\begin{array}{c}\text { Intermediate } \\
\text { license min. } \\
\text { age }\end{array}$ & $\begin{array}{l}\text { Min. age } \\
\text { nighttime } \\
\text { restriction } \\
\text { removed }\end{array}$ & $\begin{array}{l}\text { Min. age } \\
\text { passenger } \\
\text { restriction } \\
\text { removed }\end{array}$ \\
\hline South Carolina & No & No & Yes & 16 & 17 & $\begin{array}{l}\text { Vision and } \\
\text { road skills } \\
\text { tests waived } \\
\text { for } \\
\text { unrestricted } \\
\text { license }\end{array}$ & 15 & $\begin{array}{c}40 \text { with } 10 \text { at } \\
\text { night }\end{array}$ & 15 & 16 & 16 \\
\hline South Dakota & No & No & No & 16 & 16 & $\begin{array}{c}\text { Permit } \\
\text { holding period } \\
\text { reduced from } \\
180 \text { days to } 90 \\
\text { days }\end{array}$ & 14 & None & $\begin{array}{c}14 \text { years } 3 \\
\text { months }\end{array}$ & 16 & NA \\
\hline Tennessee & No & No & No & 17 & 17 & None & 15 & $\begin{array}{c}50 \text { with } 10 \text { at } \\
\text { night }\end{array}$ & 16 & 17 & 17 \\
\hline Texas & Yes & No & Yes & $\begin{array}{l}16 \text { years and } 6 \\
\text { months }\end{array}$ & 18 & None & 15 & None & 16 & $\begin{array}{c}16 \text { years } 6 \\
\text { months }\end{array}$ & $\begin{array}{c}16 \text { years } 6 \\
\text { months }\end{array}$ \\
\hline Utah & Yes & No & Yes & 17 & $\begin{array}{l}\text { All first-time } \\
\text { drivers must } \\
\text { complete } \\
\text { driver } \\
\text { education }\end{array}$ & None & 15 & $\begin{array}{c}40 \text { with } 10 \text { at } \\
\text { night }\end{array}$ & 16 & 17 & $\begin{array}{c}16 \text { years } 6 \\
\text { months }\end{array}$ \\
\hline Vermont & Yes & No & Yes & $\begin{array}{c}16 \text { years } 6 \\
\text { months }\end{array}$ & 18 & None & 15 & $\begin{array}{l}40 \text { with } 10 \text { at } \\
\text { night }\end{array}$ & 16 & $\begin{array}{l}\text { No } \\
\text { restrictions }\end{array}$ & $\begin{array}{c}16 \text { years } 6 \\
\text { months }\end{array}$ \\
\hline Virginia & Yes & No & Yes & 18 & 19 & $\begin{array}{l}\text { Road test } \\
\text { waived }\end{array}$ & $\begin{array}{c}15 \text { years } 6 \\
\text { months }\end{array}$ & $\begin{array}{l}40 \text { with } 10 \text { at } \\
\text { night }\end{array}$ & $\begin{array}{c}16 \text { years } 3 \\
\text { months }\end{array}$ & 18 & 18 \\
\hline Washington & Yes & No & Yes & 17 & 18 & $\begin{array}{l}\text { Knowledge } \\
\text { test waived }\end{array}$ & 15 & $\begin{array}{c}50 \text { with } 10 \text { at } \\
\text { night }\end{array}$ & 16 & 17 & 17 \\
\hline West Virginia & No & No & No & 17 & 17 & $\begin{array}{c}\text { Practice } \\
\text { driving } \\
\text { waived }\end{array}$ & 15 & $\begin{array}{l}30 \text { if did not } \\
\text { take driver } \\
\text { education }\end{array}$ & 16 & 17 & 17 \\
\hline Wisconsin & Yes & No & No & 18 & 18 & None & $\begin{array}{c}15 \text { years } 6 \\
\text { months }\end{array}$ & $\begin{array}{c}30 \text { with } 10 \text { at } \\
\text { night }\end{array}$ & 16 & $\begin{array}{c}16 \text { years } 9 \\
\text { months }\end{array}$ & $\begin{array}{c}16 \text { years } 9 \\
\text { months }\end{array}$ \\
\hline Wyoming & No & No & Yes & $\begin{array}{c}16 \text { years and } 6 \\
\text { months }\end{array}$ & 17 & $\begin{array}{c}\text { Road test } \\
\text { waived }\end{array}$ & 15 & $\begin{array}{c}50 \text { with } 10 \text { at } \\
\text { night }\end{array}$ & 16 & $\begin{array}{c}16 \text { years } 6 \\
\text { months }\end{array}$ & $\begin{array}{c}16 \text { years } 6 \\
\text { months }\end{array}$ \\
\hline
\end{tabular}


Table 2. Driver education program requirements and data by State

\begin{tabular}{|c|c|c|c|c|c|c|c|c|c|c|c|c|}
\hline & \multicolumn{6}{|c|}{ Program Requirements } & \multicolumn{6}{|c|}{ Driver Education Statistics } \\
\hline & $\begin{array}{l}\text { Classroom } \\
\text { hours }\end{array}$ & BTW hours & $\begin{array}{c}\text { In-car } \\
\text { observation } \\
\text { hours }\end{array}$ & $\begin{array}{l}\text { Curriculum } \\
\text { Guide }\end{array}$ & Oversight & $\begin{array}{c}\text { Teacher } \\
\text { certification }\end{array}$ & $\begin{array}{l}\text { Teens } \\
\text { licensed in } \\
2006 \text { who } \\
\text { took driver } \\
\text { education }\end{array}$ & $\begin{array}{c}\text { High } \\
\text { School } \\
\text { Programs }\end{array}$ & $\begin{array}{c}\text { Commercial } \\
\text { Programs }\end{array}$ & $\begin{array}{c}\text { Internet } \\
\text { Programs }\end{array}$ & $\begin{array}{l}\text { Parent- } \\
\text { taught } \\
\text { Programs }\end{array}$ & $\begin{array}{c}\text { Other } \\
\text { Programs }\end{array}$ \\
\hline Alabama & 30 & 6 & 12 & $\begin{array}{c}\text { Alabama } \\
\text { Driver and } \\
\text { Traffic Safety } \\
\text { Education } \\
\text { Guide }\end{array}$ & $\begin{array}{l}\text { Department of } \\
\text { Education }\end{array}$ & Yes & $*$ & 300 & 3 & None & None & None \\
\hline Alaska & 8 & 8 & None & None & $\begin{array}{c}\text { Division of } \\
\text { Motor Vehicles } \\
\text { Department of } \\
\text { Administration }\end{array}$ & Yes & $*$ & None & 13 & None & None & None \\
\hline Arizona & $\begin{array}{l}30 \text { for high } \\
\text { school; no } \\
\text { requirements } \\
\text { for } \\
\text { commercial }\end{array}$ & $\begin{array}{l}6 \text { for high } \\
\text { school; } \\
\text { none for } \\
\text { commercial }\end{array}$ & None & Core topics & $\begin{array}{l}\text { Department of } \\
\text { Education for } \\
\text { high school; } \\
\text { MVD for } \\
\text { commercial }\end{array}$ & Yes & $\begin{array}{l}\text { HS: } 5,183 \\
\text { Comm: } \\
22,676\end{array}$ & 76 & 66 & None & None & None \\
\hline Arkansas & 30 & $\begin{array}{c}6 \text { with an } \\
\text { additional } 6 \\
\text { with a } \\
\text { parent ( } 2 \text { at } \\
\text { night) }\end{array}$ & None & $\begin{array}{l}3 \text { textbooks to } \\
\text { choose from; } \\
\text { Core topics }\end{array}$ & $\begin{array}{l}\text { Department of } \\
\text { Education for } \\
\text { high school; } \\
\text { State Board of } \\
\text { Private Career } \\
\text { Education for } \\
\text { commercial; } \\
\text { Home School } \\
\text { Office for } \\
\text { parent-taught }\end{array}$ & Yes & $*$ & 180 & 4 & None & $*$ & None \\
\hline California & 30 & 6 & $\begin{array}{c}6 \text { for } \\
\text { commercial } \\
\text { only }\end{array}$ & $\begin{array}{l}\text { California } \\
\text { Driver } \\
\text { Handbook; } \\
\text { Teen/Parent } \\
\text { Handbook }\end{array}$ & $\begin{array}{l}\text { Department of } \\
\text { Education for } \\
\text { high school; } \\
\text { DMV for } \\
\text { commercial } \\
\text { and Internet }\end{array}$ & Yes & $*$ & 1159 & 591 & $*$ & $*$ & None \\
\hline
\end{tabular}




\begin{tabular}{|c|c|c|c|c|c|c|c|c|c|c|c|c|}
\hline & \multicolumn{6}{|c|}{ Program Requirements } & \multicolumn{6}{|c|}{ Driver Education Statistics } \\
\hline & $\begin{array}{l}\text { Classroom } \\
\text { hours }\end{array}$ & BTW hours & $\begin{array}{c}\text { In-car } \\
\text { observation } \\
\text { hours }\end{array}$ & $\begin{array}{l}\text { Curriculum } \\
\text { Guide }\end{array}$ & Oversight & $\begin{array}{l}\text { Teacher } \\
\text { certification }\end{array}$ & $\begin{array}{l}\text { Teens } \\
\text { licensed in } \\
2006 \text { who } \\
\text { took driver } \\
\text { education }\end{array}$ & $\begin{array}{c}\text { High } \\
\text { School } \\
\text { Programs }\end{array}$ & $\begin{array}{c}\text { Commercial } \\
\text { Programs }\end{array}$ & $\begin{array}{l}\text { Internet } \\
\text { Programs }\end{array}$ & $\begin{array}{c}\text { Parent- } \\
\text { taught } \\
\text { Programs }\end{array}$ & $\begin{array}{l}\text { Other } \\
\text { Programs }\end{array}$ \\
\hline Colorado & 30 & 6 & None & Core topics & $\begin{array}{l}\text { Department of } \\
\text { Revenue } \\
\text { Driver License } \\
\text { Department }\end{array}$ & No & $*$ & 8 & 110 & 7 & $*$ & 114 \\
\hline Connecticut & $\begin{array}{l}30 \text { for high } \\
\text { school and } \\
\text { commercial; } \\
22 \text { parent- } \\
\text { taught }\end{array}$ & 20 & None & $*$ & $*$ & $*$ & $*$ & * & $*$ & $*$ & $*$ & $*$ \\
\hline Delaware & 30 & $\begin{array}{l}14 \text { BTW } \\
\text { and } \\
\text { observation } \\
\text { combined }\end{array}$ & $\begin{array}{c}14 \text { BTW } \\
\text { and } \\
\text { observation } \\
\text { combined }\end{array}$ & $\begin{array}{c}\text { DMV } \\
\text { Handbook }\end{array}$ & $\begin{array}{l}\text { Department of } \\
\text { Education }\end{array}$ & Yes & $*$ & 39 & $\begin{array}{l}\text { None for } 18 \\
\text { and under }\end{array}$ & None & None & None \\
\hline $\begin{array}{l}\text { District of } \\
\text { Columbia }\end{array}$ & $*$ & $*$ & $*$ & $*$ & $*$ & $*$ & $*$ & $*$ & $*$ & $*$ & $*$ & $*$ \\
\hline Florida & 4 & $*$ & $*$ & $*$ & $*$ & $*$ & $*$ & $*$ & $*$ & $*$ & $*$ & $*$ \\
\hline Georgia & 30 & 6 & $*$ & $\begin{array}{c}\text { ADTSEA } \\
\text { curriculum } \\
\text { guide }\end{array}$ & $\begin{array}{c}\text { Division of } \\
\text { Driver Services }\end{array}$ & Yes & $*$ & 127 & 128 & $*$ & $*$ & $*$ \\
\hline Hawaii & $*$ & $*$ & $*$ & $*$ & $\begin{array}{c}\text { Director of } \\
\text { Transportation }\end{array}$ & $*$ & * & * & * & * & * & * \\
\hline Idaho & 30 & 6 & 6 & $\begin{array}{c}\text { Content } \\
\text { Standards }\end{array}$ & $\begin{array}{c}\text { Department of } \\
\text { Education }\end{array}$ & Yes & $*$ & 105 & 42 & $*$ & None & None \\
\hline Illinois & 30 & 6 & None & $\begin{array}{l}\text { Rules of the } \\
\text { Road }\end{array}$ & $\begin{array}{l}\text { State Board of } \\
\text { Education for } \\
\text { high school; } \\
\text { Driver Services } \\
\text { Department of } \\
\text { Secretary of } \\
\text { State for } \\
\text { commercial }\end{array}$ & Yes & $\begin{array}{l}\text { HS: } \\
\text { 122,151 } \\
\text { Comm: } \\
\text { unknown }\end{array}$ & 558 & 73 & None & None & None \\
\hline
\end{tabular}




\begin{tabular}{|c|c|c|c|c|c|c|c|c|c|c|c|c|}
\hline & \multicolumn{6}{|c|}{ Program Requirements } & \multicolumn{6}{|c|}{ Driver Education Statistics } \\
\hline & $\begin{array}{l}\text { Classroom } \\
\text { hours }\end{array}$ & BTW hours & $\begin{array}{c}\text { In-car } \\
\text { observation } \\
\text { hours }\end{array}$ & $\begin{array}{l}\text { Curriculum } \\
\text { Guide }\end{array}$ & Oversight & $\begin{array}{c}\text { Teacher } \\
\text { certification }\end{array}$ & $\begin{array}{l}\text { Teens } \\
\text { licensed in } \\
2006 \text { who } \\
\text { took driver } \\
\text { education }\end{array}$ & $\begin{array}{c}\text { High } \\
\text { School } \\
\text { Programs }\end{array}$ & $\begin{array}{c}\text { Commercial } \\
\text { Programs }\end{array}$ & $\begin{array}{l}\text { Internet } \\
\text { Programs }\end{array}$ & $\begin{array}{c}\text { Parent- } \\
\text { taught } \\
\text { Programs }\end{array}$ & $\begin{array}{c}\text { Other } \\
\text { Programs }\end{array}$ \\
\hline Indiana & 30 & 6 & None & No & $\begin{array}{l}\text { Department Of } \\
\text { Education for } \\
\text { high school } \\
\text { and parent- } \\
\text { taught; Bureau } \\
\text { of Motor } \\
\text { Vehicles for } \\
\text { commercial }\end{array}$ & Yes & $*$ & 168 & 108 & * & $*$ & None \\
\hline Iowa & 30 & 6 & 6 & Core topics & $\begin{array}{l}\text { Department of } \\
\text { Education for } \\
\text { high school; } \\
\text { Iowa } \\
\text { Department of } \\
\text { Transportation } \\
\text { for commercial }\end{array}$ & Yes & $\begin{array}{l}\text { HS: } 28,500 \\
\text { Comm: } \\
9,500\end{array}$ & 340 & 34 & None & None & None \\
\hline Kansas & $\begin{array}{c}\text { None for } \\
\text { high school; } \\
8 \text { for } \\
\text { commercial }\end{array}$ & $\begin{array}{l}\text { None for } \\
\text { high } \\
\text { school; } 6 \\
\text { for } \\
\text { commercial }\end{array}$ & None & None & $\begin{array}{c}\text { Department of } \\
\text { Education }\end{array}$ & Yes & $\begin{array}{l}\text { HS: } 16,960 \\
\text { Comm: } \\
6,408\end{array}$ & 276 & 27 & $\begin{array}{l}\text { Embedded } \\
\text { in high } \\
\text { school } \\
\text { programs }\end{array}$ & None & $\begin{array}{c}9 \\
\text { motorcycle } \\
\text { training }\end{array}$ \\
\hline Kentucky & 5 & None & None & None & State Police & Yes & $*$ & $55-70$ & $*$ & None & None & None \\
\hline Louisiana & $\begin{array}{l}30 \text { if under } \\
17 ; 6 \text { for pre- } \\
\text { licensing } \\
\text { course if } \\
\text { over } 17\end{array}$ & $\begin{array}{c}6 \text { if under } \\
17\end{array}$ & None & $\begin{array}{c}\text { Driver } \\
\text { Education, } \\
\text { Traffic Safety, } \\
\text { and } \\
\text { Administrative } \\
\text { Guide for } \\
\text { Louisiana } \\
\text { Schools }\end{array}$ & $\begin{array}{l}\text { Department of } \\
\text { Education for } \\
\text { high school; } \\
\text { State Police for } \\
\text { commercial }\end{array}$ & Yes & $*$ & $*$ & 126 & None & None & None \\
\hline Maine & 30 & 10 & None & $\begin{array}{c}\text { Responsible } \\
\text { Driving } \\
\text { Textbook }\end{array}$ & $\begin{array}{c}\text { Bureau of } \\
\text { Motor Vehicles } \\
\text { and Secretary } \\
\text { of State }\end{array}$ & Yes & $*$ & 17 & 191 & None & None & None \\
\hline Maryland & 30 & 6 & None & $*$ & $\begin{array}{l}\text { Motor Vehicle } \\
\text { Administration }\end{array}$ & $*$ & $*$ & $*$ & * & None & None & None \\
\hline
\end{tabular}




\begin{tabular}{|c|c|c|c|c|c|c|c|c|c|c|c|c|}
\hline & \multicolumn{6}{|c|}{ Program Requirements } & \multicolumn{6}{|c|}{ Driver Education Statistics } \\
\hline & $\begin{array}{c}\text { Classroom } \\
\text { hours }\end{array}$ & BTW hours & $\begin{array}{c}\text { In-car } \\
\text { observation } \\
\text { hours }\end{array}$ & $\begin{array}{l}\text { Curriculum } \\
\text { Guide }\end{array}$ & Oversight & $\begin{array}{l}\text { Teacher } \\
\text { certification }\end{array}$ & $\begin{array}{c}\text { Teens } \\
\text { licensed in } \\
2006 \text { who } \\
\text { took driver } \\
\text { education }\end{array}$ & $\begin{array}{c}\text { High } \\
\text { School } \\
\text { Programs }\end{array}$ & $\begin{array}{c}\text { Commercial } \\
\text { Programs }\end{array}$ & $\begin{array}{l}\text { Internet } \\
\text { Programs }\end{array}$ & $\begin{array}{c}\text { Parent- } \\
\text { taught } \\
\text { Programs }\end{array}$ & $\begin{array}{l}\text { Other } \\
\text { Programs }\end{array}$ \\
\hline Massachusetts & 30 & 12 & 6 & $\begin{array}{c}\text { Massachusetts } \\
\text { RMV } \\
\text { Standardized } \\
\text { Curriculum }\end{array}$ & $\begin{array}{c}\text { Registry of } \\
\text { Motor Vehicles }\end{array}$ & * & $*$ & * & * & * & * & * \\
\hline Michigan & $\begin{array}{l}24 \text { Segment } \\
1 ; 6 \text { Segment } \\
\quad 2\end{array}$ & $\begin{array}{c}6 \text { Segment } \\
1\end{array}$ & None & $\begin{array}{l}\text { Michigan } \\
\text { Department of } \\
\text { State Driver } \\
\text { Education } \\
\text { Curriculum } \\
\text { Guide }\end{array}$ & $\begin{array}{l}\text { Secretary of } \\
\text { State: Driver } \\
\text { Programs } \\
\text { Division }\end{array}$ & Yes & $*$ & 234 & 217 & None & None & None \\
\hline Minnesota & 30 & 6 & None & Core topics & $\begin{array}{c}\text { Division of } \\
\text { Vehicle Safety }\end{array}$ & Yes & $*$ & 275 & 115 & None & 12 & None \\
\hline Mississippi & $*$ & * & * & * & $*$ & * & * & $*$ & * & * & * & $*$ \\
\hline Missouri & $*$ & $*$ & $*$ & $*$ & $*$ & Yes & $*$ & $*$ & $*$ & $*$ & $*$ & $*$ \\
\hline Montana & 42 & 6 & 12 & $\begin{array}{l}\text { Montana Teen } \\
\text { Driver } \\
\text { Education and } \\
\text { Training } \\
\text { Curriculum } \\
\text { Standards and } \\
\text { Benchmarks }\end{array}$ & $\begin{array}{l}\text { Office of } \\
\text { Public } \\
\text { Instruction }\end{array}$ & Yes & $\begin{array}{c}\text { Total: } \\
10,310 \\
(9,437 \\
\text { completed, } \\
\text { but not } \\
\text { necessarily } \\
\text { licensed) }\end{array}$ & 141 & None & None & None & None \\
\hline Nebraska & 20 & 5 & None & Core topics & DMV & Yes & $*$ & 128 & 23 & 2 & $*$ & None \\
\hline Nevada & 30 & None & None & Yes & $\begin{array}{l}\text { Department of } \\
\text { Education for } \\
\text { high school; } \\
\text { DMV for } \\
\text { commercial } \\
\text { and Internet }\end{array}$ & Yes & $*$ & 18 & 24 & 7 & None & None \\
\hline
\end{tabular}




\begin{tabular}{|c|c|c|c|c|c|c|c|c|c|c|c|c|}
\hline & \multicolumn{6}{|c|}{ Program Requirements } & \multicolumn{6}{|c|}{ Driver Education Statistics } \\
\hline & $\begin{array}{c}\text { Classroom } \\
\text { hours }\end{array}$ & BTW hours & $\begin{array}{c}\text { In-car } \\
\text { observation } \\
\text { hours }\end{array}$ & $\begin{array}{l}\text { Curriculum } \\
\text { Guide }\end{array}$ & Oversight & $\begin{array}{c}\text { Teacher } \\
\text { certification }\end{array}$ & $\begin{array}{l}\text { Teens } \\
\text { licensed in } \\
2006 \text { who } \\
\text { took driver } \\
\text { education }\end{array}$ & $\begin{array}{c}\text { High } \\
\text { School } \\
\text { Programs }\end{array}$ & $\begin{array}{c}\text { Commercial } \\
\text { Programs }\end{array}$ & $\begin{array}{l}\text { Internet } \\
\text { Programs }\end{array}$ & $\begin{array}{c}\text { Parent- } \\
\text { taught } \\
\text { Programs }\end{array}$ & $\begin{array}{c}\text { Other } \\
\text { Programs }\end{array}$ \\
\hline $\begin{array}{c}\text { New } \\
\text { Hampshire }\end{array}$ & 30 & 10 & 6 & $\begin{array}{c}\text { New } \\
\text { Hampshire } \\
\text { Driver } \\
\text { Education } \\
\text { Guide }\end{array}$ & $\begin{array}{c}\text { Jointly by } \\
\text { DMV, } \\
\text { Highway } \\
\text { Patrol and } \\
\text { Department of } \\
\text { Education }\end{array}$ & Yes & * & 40 & 103 & None & None & None \\
\hline New Jersey & 30 & 6 & None & None & $\begin{array}{l}\text { Motor Vehicle } \\
\text { Commission }\end{array}$ & Yes & * & 560 & 230 & None & None & None \\
\hline New Mexico & $\begin{array}{c}56 \text { high } \\
\text { school; } 33 \\
\text { commercial }\end{array}$ & $\begin{array}{l}\text { None for } \\
\text { high } \\
\text { school; } 7 \\
\text { for } \\
\text { commercial }\end{array}$ & None & $*$ & $\begin{array}{c}\text { Traffic Safety } \\
\text { Bureau }\end{array}$ & Yes & $\begin{array}{c}\text { Estimates } \\
\text { HS: } 10,000 \\
\text { Comm: } \\
7,000\end{array}$ & 120 & 36 & None & None & None \\
\hline New York & $*$ & $*$ & $*$ & $*$ & DMV & $*$ & $*$ & $*$ & $*$ & $*$ & $*$ & $*$ \\
\hline $\begin{array}{c}\text { North } \\
\text { Carolina }\end{array}$ & 30 & 6 & 12 & None & $\begin{array}{l}\text { State } \\
\text { Superintendent } \\
\text { of Public } \\
\text { Instruction for } \\
\text { high school; } \\
\text { DMV for } \\
\text { commercial; } \\
\text { Division of } \\
\text { Non-public } \\
\text { Education for } \\
\text { parent-taught }\end{array}$ & Yes & * & * & * & None & $*$ & None \\
\hline North Dakota & $\begin{array}{l}30 \text { for high } \\
\text { school; none } \\
\text { for } \\
\text { commercial }\end{array}$ & 6 & None & None & $\begin{array}{c}\text { Department of } \\
\text { Public } \\
\text { Instruction for } \\
\text { High School; } \\
\text { Highway } \\
\text { Patrol for } \\
\text { commercial } \\
\end{array}$ & Yes & $*$ & $*$ & 15 & $*$ & None & None \\
\hline Ohio & 24 & 8 & None & $*$ & $\begin{array}{l}\text { Department of } \\
\text { Public Safety }\end{array}$ & $*$ & $*$ & $*$ & $*$ & $*$ & $*$ & $*$ \\
\hline Oklahoma & 30 & $\begin{array}{l}6 \text { (55 if } \\
\text { parent- } \\
\text { taught) }\end{array}$ & None & $*$ & $\begin{array}{l}\text { Department of } \\
\text { Public Safety }\end{array}$ & $*$ & $*$ & $*$ & $*$ & $*$ & $*$ & $*$ \\
\hline
\end{tabular}




\begin{tabular}{|c|c|c|c|c|c|c|c|c|c|c|c|c|}
\hline & \multicolumn{6}{|c|}{ Program Requirements } & \multicolumn{6}{|c|}{ Driver Education Statistics } \\
\hline & $\begin{array}{l}\text { Classroom } \\
\text { hours }\end{array}$ & BTW hours & $\begin{array}{c}\text { In-car } \\
\text { observation } \\
\text { hours }\end{array}$ & $\begin{array}{l}\text { Curriculum } \\
\text { Guide }\end{array}$ & Oversight & $\begin{array}{l}\text { Teacher } \\
\text { certification }\end{array}$ & $\begin{array}{c}\text { Teens } \\
\text { licensed in } \\
2006 \text { who } \\
\text { took driver } \\
\text { education }\end{array}$ & $\begin{array}{c}\text { High } \\
\text { School } \\
\text { Programs }\end{array}$ & $\begin{array}{c}\text { Commercial } \\
\text { Programs }\end{array}$ & $\begin{array}{l}\text { Internet } \\
\text { Programs }\end{array}$ & $\begin{array}{c}\text { Parent- } \\
\text { taught } \\
\text { Programs }\end{array}$ & $\begin{array}{c}\text { Other } \\
\text { Programs }\end{array}$ \\
\hline Oregon & 30 & 6 & None & $\begin{array}{c}\text { Oregon Driver } \\
\text { Risk } \\
\text { Prevention } \\
\text { Curriculum }\end{array}$ & $\begin{array}{l}\text { Department of } \\
\text { Transportation: } \\
\text { Transportation } \\
\text { Safety Division }\end{array}$ & Yes & $\begin{array}{l}\text { HS: } 10,000 \\
\text { Comm: } \\
\text { unknown }\end{array}$ & 85 & 25 & None & * & 7 \\
\hline Pennsylvania & 30 & 6 & None & $\mathrm{C}$ & $\begin{array}{l}\text { Department of } \\
\text { Education }\end{array}$ & Yes & * & 288 & 167 & 4 & None & None \\
\hline Rhode Island & 33 & $\begin{array}{l}\text { None for } \\
\text { CCRI } \\
\text { course; } 6 \\
\text { for } \\
\text { commercial }\end{array}$ & None & None & $\begin{array}{c}\text { Department of } \\
\text { Education for } \\
\text { high } \\
\text { school/college; } \\
\text { Department of } \\
\text { Motor Vehicles } \\
\text { for commercial }\end{array}$ & Yes & * & 1 & 28 & None & None & None \\
\hline South Carolina & $\begin{array}{l}30 \text { for high } \\
\text { school; } 8 \\
\text { commercial }\end{array}$ & 6 & $\begin{array}{l}6 \text { for high } \\
\text { school only }\end{array}$ & $\begin{array}{l}\text { State-adopted } \\
\text { materials to } \\
\text { choose from }\end{array}$ & $\begin{array}{l}\text { Department of } \\
\text { Education for } \\
\text { high school; } \\
\text { DMV Driver } \\
\text { Improvement } \\
\text { Division for } \\
\text { commercial }\end{array}$ & Yes & $*$ & * & 130 & None & None & None \\
\hline South Dakota & 30 & 6 & None & None & $\begin{array}{l}\text { Department of } \\
\text { Education }\end{array}$ & Yes & $\begin{array}{c}\text { Total: } \\
7,849 \\
\text { (includes } \\
\text { motorcycle } \\
\text { safety } \\
\text { course) }\end{array}$ & 142 & None & None & None & None \\
\hline Tennessee & $*$ & $*$ & $*$ & $*$ & * & $*$ & $*$ & $*$ & $*$ & $*$ & $*$ & $*$ \\
\hline
\end{tabular}




\begin{tabular}{|c|c|c|c|c|c|c|c|c|c|c|c|c|}
\hline & \multicolumn{6}{|c|}{ Program Requirements } & \multicolumn{6}{|c|}{ Driver Education Statistics } \\
\hline & $\begin{array}{c}\text { Classroom } \\
\text { hours }\end{array}$ & BTW hours & $\begin{array}{c}\text { In-car } \\
\text { observation } \\
\text { hours }\end{array}$ & $\begin{array}{l}\text { Curriculum } \\
\text { Guide }\end{array}$ & Oversight & $\begin{array}{c}\text { Teacher } \\
\text { certification }\end{array}$ & $\begin{array}{l}\text { Teens } \\
\text { licensed in } \\
2006 \text { who } \\
\text { took driver } \\
\text { education }\end{array}$ & $\begin{array}{c}\text { High } \\
\text { School } \\
\text { Programs }\end{array}$ & $\begin{array}{c}\text { Commercial } \\
\text { Programs }\end{array}$ & $\begin{array}{l}\text { Internet } \\
\text { Programs }\end{array}$ & $\begin{array}{c}\text { Parent- } \\
\text { taught } \\
\text { Programs }\end{array}$ & $\begin{array}{c}\text { Other } \\
\text { Programs }\end{array}$ \\
\hline Texas & 32 & 7 & 7 & $\begin{array}{c}\text { Texas } \\
\text { Education } \\
\text { Agency's } \\
\text { Program of } \\
\text { Organized } \\
\text { Instruction for } \\
\text { Driver } \\
\text { Education and } \\
\text { Traffic Safety }\end{array}$ & $\begin{array}{c}\text { Texas } \\
\text { Education } \\
\text { Agency }\end{array}$ & Yes & $\begin{array}{l}\text { HS: } 29,894 \\
\text { Comm: } \\
\text { 118,978 } \\
\text { Parent: } \\
92,000\end{array}$ & 335 & 290 & $*$ & $\begin{array}{c}\text { Approx. } \\
92,000 \\
\text { teens }\end{array}$ & None \\
\hline Utah & $\begin{array}{l}30 \text { for high } \\
\text { school; } 18 \\
\text { commercial }\end{array}$ & 6 & $\begin{array}{l}6 \text { for high } \\
\text { school; } 10 \\
\text { for } \\
\text { commercial }\end{array}$ & Core topics & $\begin{array}{l}\text { Department Of } \\
\text { Education for } \\
\text { high school; } \\
\text { Driver License } \\
\text { Division of } \\
\text { Department of } \\
\text { Public Safety }\end{array}$ & Yes & $\begin{array}{l}\text { Total: } \\
34,269\end{array}$ & 141 & 35 & $*$ & None & None \\
\hline Vermont & 30 & 6 & 6 & $\begin{array}{c}\text { Vermont } \\
\text { Driver Risk } \\
\text { Prevention } \\
\text { Curriculum }\end{array}$ & $\begin{array}{l}\text { Department of } \\
\text { Education for } \\
\text { high school; } \\
\text { DMV for } \\
\text { commercial }\end{array}$ & Yes & $\begin{array}{c}\text { HS: } 5,096 \\
\text { Comm: } \\
1,416\end{array}$ & 72 & 26 & None & None & None \\
\hline Virginia & 36 & 7 & 7 & $\begin{array}{l}\text { Curriculum } \\
\text { Guide for } \\
\text { Driver } \\
\text { Education in } \\
\text { Virginia }\end{array}$ & $\begin{array}{l}\text { Department of } \\
\text { Education for } \\
\text { high school; } \\
\text { Dept. of Motor } \\
\text { Vehicles } \\
\text { Driver Services } \\
\text { Administration } \\
\text { for } \\
\text { commercial; } \\
\text { Local school } \\
\text { superintendent } \\
\text { for parent- } \\
\text { taught }\end{array}$ & Yes & $\begin{array}{l}\text { HS: } 44,142 \\
\text { Comm: } \\
27,625 \\
\text { Parent: } 522 \\
\text { Other: } 629\end{array}$ & 600 & 207 & None & 300 & None \\
\hline
\end{tabular}




\begin{tabular}{|c|c|c|c|c|c|c|c|c|c|c|c|c|}
\hline & \multicolumn{6}{|c|}{ Program Requirements } & \multicolumn{6}{|c|}{ Driver Education Statistics } \\
\hline & $\begin{array}{c}\text { Classroom } \\
\text { hours }\end{array}$ & BTW hours & $\begin{array}{c}\text { In-car } \\
\text { observation } \\
\text { hours }\end{array}$ & $\begin{array}{l}\text { Curriculum } \\
\text { Guide }\end{array}$ & Oversight & $\begin{array}{c}\text { Teacher } \\
\text { certification }\end{array}$ & $\begin{array}{c}\text { Teens } \\
\text { licensed in } \\
2006 \text { who } \\
\text { took driver } \\
\text { education }\end{array}$ & $\begin{array}{c}\text { High } \\
\text { School } \\
\text { Programs }\end{array}$ & $\begin{array}{c}\text { Commercial } \\
\text { Programs }\end{array}$ & $\begin{array}{l}\text { Internet } \\
\text { Programs }\end{array}$ & $\begin{array}{c}\text { Parent- } \\
\text { taught } \\
\text { Programs }\end{array}$ & $\begin{array}{c}\text { Other } \\
\text { Programs }\end{array}$ \\
\hline Washington & 30 & 6 & $\begin{array}{l}4 \text { for high } \\
\text { school; } 1 \\
\text { for } \\
\text { commercial }\end{array}$ & $\begin{array}{l}\text { Washington } \\
\text { Driver Risk } \\
\text { Prevention } \\
\text { Student } \\
\text { Curriculum }\end{array}$ & $\begin{array}{l}\text { Office of the } \\
\text { Superintendent } \\
\text { of Public } \\
\text { Instruction for } \\
\text { high school; } \\
\text { Department of } \\
\text { Licensing for } \\
\text { commercial }\end{array}$ & Yes & $\begin{array}{c}\text { Estimated } \\
\text { HS: } 20,000 \\
\text { Comm: } \\
33,691\end{array}$ & 96 & 283 & None & None & None \\
\hline West Virginia & 50 & 8 & 10 & Core topics & $\begin{array}{c}\text { Department of } \\
\text { Education }\end{array}$ & Yes & $*$ & 265 & 35 & None & None & None \\
\hline Wisconsin & 30 & 6 & 6 & $\begin{array}{l}\text { Standards to } \\
\text { be followed }\end{array}$ & $\begin{array}{c}\text { Department of } \\
\text { Public } \\
\text { Instruction for } \\
\text { high school; } \\
\text { Motor Vehicles } \\
\text { Driver } \\
\text { Training } \\
\text { School } \\
\text { Division for } \\
\text { commercial } \\
\end{array}$ & Yes & $*$ & 55 & 141 & 2 & None & None \\
\hline Wyoming & 30 & 6 & 6 & Core topics & $\begin{array}{c}\text { Department of } \\
\text { Education }\end{array}$ & Yes & $*$ & 55 & None & None & None & $\begin{array}{c}4 \\
\text { categories } \\
\text { of } \\
\text { programs, } \\
\text { unknown } \\
\text { number } \\
\text { operating }\end{array}$ \\
\hline
\end{tabular}



DOT HS 811543

April 2012 